\title{
An in vitro and in vivo study towards the effect of Chlamydia pneumoniae infection on brain cells
}

Citation for published version (APA):

Boelen, E. (2007). An in vitro and in vivo study towards the effect of Chlamydia pneumoniae infection on brain cells. [Doctoral Thesis, Maastricht University]. Universiteit Maastricht. https://doi.org/10.26481/dis.20070705eb

Document status and date:

Published: 01/01/2007

DOI:

10.26481/dis.20070705eb

Document Version:

Publisher's PDF, also known as Version of record

\section{Please check the document version of this publication:}

- A submitted manuscript is the version of the article upon submission and before peer-review. There can be important differences between the submitted version and the official published version of record.

People interested in the research are advised to contact the author for the final version of the publication, or visit the DOI to the publisher's website.

- The final author version and the galley proof are versions of the publication after peer review.

- The final published version features the final layout of the paper including the volume, issue and page numbers.

Link to publication

\footnotetext{
General rights rights.

- You may freely distribute the URL identifying the publication in the public portal. please follow below link for the End User Agreement:

www.umlib.nl/taverne-license

Take down policy

If you believe that this document breaches copyright please contact us at:

repository@maastrichtuniversity.nl

providing details and we will investigate your claim.
}

Copyright and moral rights for the publications made accessible in the public portal are retained by the authors and/or other copyright owners and it is a condition of accessing publications that users recognise and abide by the legal requirements associated with these

- Users may download and print one copy of any publication from the public portal for the purpose of private study or research.

- You may not further distribute the material or use it for any profit-making activity or commercial gain

If the publication is distributed under the terms of Article $25 \mathrm{fa}$ of the Dutch Copyright Act, indicated by the "Taverne" license above, 
An in vitro and in vivo study towards the effect of Chlamydia pneumoniae infection on brain cells 
(c) Ellen Boelen, Hoeselt 2007

ISBN 978-90-9021811-3

Production: Datawyse, Maastricht, The Netherlands 


\title{
An in vitro and in vivo study towards the effect of Chlamydia pneumoniae infection on brain cells
}

\section{PROEFSCHRIFT}

Ter verkrijging van de graad van doctor aan de Universiteit Maastricht op gezag van de Rector Magnificus Prof. mr. G.P.M.F. Mols, volgens het besluit van het College van Decanen in het openbaar te verdedigen op donderdag 5 juli 2007 om 16.00 uur

door

\author{
Ellen Boelen
}

geboren te Genk op 26 juli 1980 


\section{Promotores}

Prof. dr. C.A. Bruggeman

Prof. dr. H.W.M. Steinbusch

\section{Copromotores}

Dr. F.R.M. Stassen

Dr. A.J.A.M. van der Ven, Radboud Universiteit Nijmegen

\section{Beoordelingscommissie}

Prof. dr. W.A. Buurman (voorzitter)

Dr. M.H. de Baets

Prof. dr. P. Eikelenboom (Universitair Medisch Centrum, Amsterdam)

Prof. dr. J.D. Laman (Erasmus Medisch Centrum, Rotterdam)

Prof. dr. M. Limburg

Financial support by Maastricht University, the Institute of Brain and Behaviour, the Internationale Stichting Alzheimer Onderzoek and BD Biosciences for the printing of this thesis is gratefully acknowledged. 
Voor mijn ouders 



\section{CONTENTS}

$\begin{array}{ll}\text { List of abbreviations } & 9\end{array}$

Chapter 1 General Introduction \& Outline of the Thesis 11

Chapter 2 Chlamydia pneumoniae infection of brain cells: an in vitro 41 study

Chapter 3 Inflammatory responses following Chlamydia pneumoniae 61 infection of glial cells

Chapter 4 Possible pathways involved in the control of intracellular 81 Chlamydia pneumoniae infection by microglial cells

Chapter 5 Impact of Chlamydia pneumoniae infection on astrocytic glutamate uptake - consequences for neurodegeneration

Chapter 6 Detection of amyloid beta aggregates in the brain of 119 BALB/c mice after Chlamydia pneumoniae infection

Chapter 7 General Discussion \& Summary

Samenvatting

Dankwoord

Curriculum vitae

List of publications 



\section{List of abbreviations}

\begin{tabular}{|c|c|}
\hline$A \beta$ & amyloid beta \\
\hline$A D$ & Alzheimer's disease \\
\hline BV-2/MMC & murine microglial cell line \\
\hline CNS & central nervous system \\
\hline Cpn & Chlamydia pneumoniae \\
\hline CSF & cerebrospinal fluid \\
\hline C8D1A/MAC & murine astrocyte cell line \\
\hline DMEM & Dulbecco's modified Eagle's medium \\
\hline EAAT & excitatory amino acid transporter \\
\hline EB & elementary body \\
\hline EMEM & Eagle's minimal essential medium \\
\hline GFAP & glial fibrillar acidic protein \\
\hline Hep2 & human epithelial cells \\
\hline HIV & human immunodeficiency virus \\
\hline $\mathrm{HO}$ & Hoechst 33258 \\
\hline HSV-1 & herpes simplex type 1 virus \\
\hline IFU/ml & inclusion forming units per millilitre \\
\hline IL & interleukin \\
\hline INF & interferon \\
\hline LPS & lipopolysaccharide \\
\hline MCP & monocyte chemoattractant protein \\
\hline MOI & multiplicity of infection \\
\hline NB41A3 & murine neuronal cell line \\
\hline PBS & phosphate-buffered saline \\
\hline $\mathrm{PI}$ & propidium iodide \\
\hline p.i. & post infection \\
\hline PBMC & peripheral blood monocyte-derived macrophages \\
\hline RB & reticulate body \\
\hline SPG & sucrose-phosphate-glucose solution \\
\hline TGF & transforming growth factor \\
\hline TLRs & toll-like receptors \\
\hline TNF & tumour necrosis factor \\
\hline
\end{tabular}



General Introduction \& Outline of the Thesis 


\section{Preface}

Over the past few decades there's a significant increase in both morbidity as well as mortality due to neurodegenerative disorders such as Alzheimer's disease $(A D)$ or Parkinson's disease. This increase is predominantly due to an improved life expectancy, in particular in the Western society. Thus, it is crucial to gain knowledge concerning the underlying events resulting in disease pathology. In this respect, the role of cerebral inflammation is becoming increasingly appreciated. In particular, viral infections like human immunodeficiency virus (HIV), herpes simplex virus (HSV) or cytomegalovirus (CMV) have been shown to stimulate these inflammatory responses, and may as such contribute to the process of neurodegeneration. Recent data suggest that Chlamydia pneumoniae (Cpn), a widespread respiratory obligate intracellular bacterium, should be added to the list of pathogens potentially involved in the pathogenesis of some of these diseases. In particular, the prominent presence of $\mathrm{Cpn}$ in brains from $\mathrm{AD}$ patients, in contrast to the relative absence in control brains, has emerged a potential role for $\mathrm{Cpn}$ in AD. However, it remains to be established whether this micro-organism really contributes to neurodegenerative disorders or is merely an innocent bystander. Therefore, in this thesis, it was our goal to unravel the potential role of Cpn in AD. In the present chapter, current knowledge concerning neurodegenerative disorders and the suggested role for pathogens in this pathology will be reviewed. Then, in the remainder of the thesis both in vitro as well as in vivo experiments will be described in which we tried to further unravel the potential role of $\mathrm{Cpn}$ in neurodegeneration and $A D$ in particular. 


\section{Neurodegenerative disorders}

Neurodegenerative disorders, characterized by the progressive degeneration of neurons in the brain, are an increasing health problem in our society. These syndromes can be subdivided into three groups, mood-related syndromes, disorders resulting in movement disabilities and cognitive-related conditions, triggering memory problems. Some pathological hallmarks are shared by the latter two entities. First, there is the obvious loss of neurons and secondly, most of these disorders display the deposition and accumulation of filamentous protein aggregates in the central nervous system (CNS), like amyloid- $\beta 42$ in Alzheimer's disease $(A D)$ and $\alpha$-synuclein in Parkinson's disease $(P D)^{1,2}$. In addition, onset can occur during middle age, termed as the genetic associated familial form or at a later time point, named sporadic AD.

\subsection{Neurodegenerative movement disorders}

Neurodegenerative movement disorders are usually the result of progressive loss of motor neurons. The most common representative of these syndromes is PD. After AD, this disorder is the second most common neurodegenerative disease. Currently, approximately 5,000 people in the USA are diagnosed with PD each year (World Health Organisation). Its prevalence among persons between 65 and 69 years of age was 0.5 to $1 \%$ while this number increased to $1-3 \%$ above the age of 80 and older $^{3}$. Clinical symptoms of this disease are resting tremor, bradykinesia, rigidity and postural instability, features generally termed as parkinsonism ${ }^{1}$. Pathologically, this disorder is characterized by the loss of dopaminergic neurons, predominantly in the substantia nigra and associated with Lewy bodies (proteinaceous cytoplasmic inclusions) and Lewy neuritis (proteinaceous inclusions within neuritis).

Parkinson's disease can be subdivided into two distinct forms, familial and sporadic PD. Several genes and loci were described to possibly be involved in causing the familial cases of this disease. On the other hand, in sporadic PD, aetiology is still unclear although various non-genetic environmental risk factors have been described as potential risk factors. Among those, exclusively aging and smoking were considered consistent. Conversely, involvement of pesticides, herbicides, heavy metals, coffee, alcohol, dietary factors, oestrogens and inflammation is still questionable ${ }^{3}$. So, because of increasing morbidity and mortality rates, research exploring risk factors for the sporadic type of $P D$ are expanding. 


\subsection{Neurodegenerative cognitive-related disorders}

Cognitive decline is the most important feature of dementia, which is closely related to ageing and further characterized by destruction of brain cells and has a major impact on the quality of daily life ${ }^{5}$. Furthermore, as dementia is closely related to aging, the increased longevity of the population makes it a major health problem, in particular in the Western society ${ }^{6}$. Two distinct forms of dementia have been described so far, i) a reversible curable type and, ii) an irreversible form, such as $A D$.

\section{Alzheimer's disease}

The most common cause of dementia (60-70\%) and the leading neurodegenerative disorder is $A D$. Patients suffering from this progressive and usually fatal disease experience memory impairment, decline in learning capacity and deficits in reasoning, comprehension, calculation, communication and judgment. Behavioural disturbances will progress from mood changes and apathy at the onset of the disease to psychosis and agitation at later stages ${ }^{7}$. $A D$ can be clinically diagnosed by well-established criteria of the National Institute of Neurological and Communicative Disorders and Stroke-AD and Related Disorders Association ${ }^{8}$. It can be categorized as definitive, (confirmed by post-mortem histology), probably, (clinical syndromes without illness confirmation), or possible, (atypical clinical features without alternative diagnosis $)^{9,10}$. AD can also manifest in two distinct forms; the familial and more frequent sporadic type.

Recent estimations indicated that there are currently around 130,000 people affected with Alzheimer's disease in The Netherlands (and approximately 20 million worldwide). While $1 \%$ of the people at the age of 60 suffer from this disorder, about $30 \%$ of all individuals older than 85 may have $A D$. After the age of 65 , the probability of having the disease doubles every five years ${ }^{10}$. Because of the increasing amount of elderly in our society, this number will raise enormously in the future. The incidence rate of $A D$ per year is approximately $1 \%$ in people aged $65-70$ and increases to approximately $6-8 \%$ in people older than $85^{1}$. The occurrence of $A D$ is slightly higher in women but could possibly be described to a higher life expectancy, rather than to sex-related differences ${ }^{11}$. Moreover, the costs per AD patient are extraordinary and were estimated at approximately 10,000 euros per year in The Netherlands ${ }^{12}$. In conclusion, this is a devastating neurological disorder in high need for treatment. 
The neuropathology in both the familial and sporadic form of $A D$ is characterized by i) diffuse or neuritic plaques, consisting mainly of amyloid beta protein $(A \beta)$ (Figure 1), ii) neurofibrillary tangles with modified tau protein as its key component (Figure 2) and, iii) by the loss of neurons and synapses. Additionally, brain atrophy was detected in post-mortem AD brains ${ }^{13}$. Next, we will briefly describe these three main features in AD pathology.

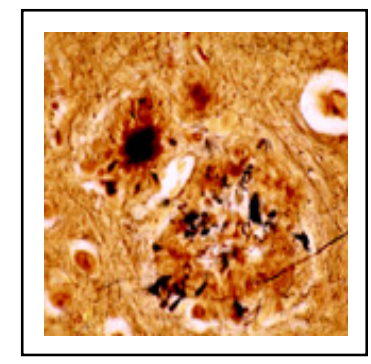

Figure 1. Neuritic plaque in $A D$

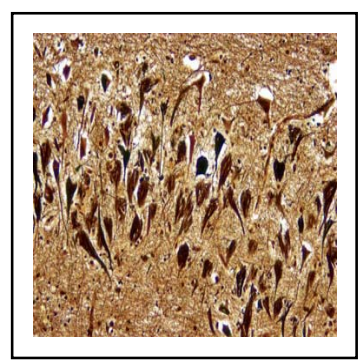

Figure 2. Neurofibrillary tangles in $A D$

\section{i) Neuritic and diffuse plaques}

Neuritic or senile plaques are complicated lesions consisting primarily of $A \beta$ peptides $^{13}$. The $A \beta$ peptides, usually $A \beta 40$ and $A \beta 42$, derived from cleavage of the amyloid precursor protein (APP) ${ }^{14}$, are present as fibrils of filamentous, starshaped aggregates with a thioflavin-S (or Congo red) positive dense core ${ }^{15}$. These structures are commonly surrounded by reactive glia, i.e. astrocytes and microglial cells with abundant filaments. The latter are usually located within and adjacent to the core of the plaque, whereas astrocytes often ring the outside of the plaque ${ }^{16}$. These symptoms are described first in the entorhinal cortex and hippocampus, and will eventually also appear in the neocortex ${ }^{17}$. Diffuse, non-fibrillar plaques also consist of $A \beta$ aggregations, predominantly $A \beta 42$, however without a fibrillar core and little or no detectable neuritic dystrophy. These plaques are considered as the immature lesions in $A D$ pathology and appear also in healthy aged humans ${ }^{14}$.

\section{ii) Neurofibrillary tangles}

Neurofibrillary tangles (NFT) are found inside $A D$ neurons as large nonmembrane-bound bundles of abnormal fibres, composed of a hyperphosphorylated form of the microtubular protein tau ${ }^{14}$. Functional properties of this microtubule-associated protein consist of supporting the cytoskeleton and contributing to axonal transport ${ }^{18}$. As a result of hyperphosphorylation, tau will ultimately dissociate from microtubules and 
aggregate into insoluble paired helical filaments ${ }^{14}$. NFT are predominantly located intraneuronally but were also demonstrated in the extracellular space, most likely originated from dead neurons ${ }^{18}$. Currently, growing evidence suggests that the presence of these tangles is a secondary consequence of $A \beta$ depositioning ${ }^{19}$.

\section{iii) Loss of neurons and synapses}

Neuronal and synaptic loss are regarded as key features in the course of $A D$. Cognitive impairments in $A D$ patients are considered as a direct result of neuronal loss and disruption of inter-neuronal connections. However, the time course and nature of neuronal cell death in $A D$ is still controversial. Although several studies associate neurodegeneration in $A D$ with apoptosis ${ }^{20-22}$, others refute this hypothesis. Although initial phases of apoptosis, like DNA fragmentation, have been demonstrated ${ }^{21}$, processes such as chromatin condensation, apoptotic bodies and blebbing, determining the final stages of apoptosis, seem to be absent in $A D^{23-25}$. The situation in which the initiation of apoptosis does not advance to caspase-dependent cell death, was already termed as "abortive apoptosis", possibly resulting in prolonged neuronal survival $^{25}$. Therefore, it remains unclear whether neuronal loss has to be attributed to apoptosis or other forms of cell death.

Like several other adult onset neurodegenerative diseases, $A D$ is a multifactorial illness with both genetic and non-genetic causes. Recent genetic studies have identified four genes associated with inherited risk for AD. These genes account for about half of the total genetic risk for Alzheimer's disease. For the early-onset, autosomal familial form of $A D$, mutations in three genes have been described; the amyloid precursor protein (APP) gene on chromosome 21 and the preselinin-1 (PS-1) and -2 (PS-2) genes on chromosome 14 and 1 respectively. However, although important, these mutations are rather infrequent causes of the disease ${ }^{1}$. On the contrary, carrying the $\varepsilon 4$ allel of apolipoprotein-E (ApoE), has been abundantly shown as a major risk factor, predominantly for sporadic $A D^{26-28}$. Moreover, several familial forms of $A D$ could not be associated with the described genes which strongly suggests that additional genetic risk factors will be discovered in the near future.

Besides genetic risk factors there is overwhelming evidence for non-genetic factors that contribute to this disorder. These risk factors are predominantly associated with sporadic $A D$, the most common type of the disease. 
Generally, aging is still considered as the major risk factor for developing $A D$. The number of affected people increases with age; after 65 years and older, the amount of $A D$ patients more or less doubles with each additional 10 years of $\mathrm{age}^{29}$. Also, education has been suggested to be a protective factor as people with low education are at higher risk for getting the disease ${ }^{30}$. Moreover, it has also been shown that people undergoing frequent physical and mental activities during late life seem to be protected from the disease ${ }^{31}$. The residence area during childhood could also have an effect as people that were raised in nurturing and protective households have a lower risk for developing $A D^{32}$. Similarly, moderate alcohol consumption has been shown to be beneficial in preventing $A D$, while smoking increases the risk two- or fourfold, especially in people carrying the ApoE- $\varepsilon 4$ alle ${ }^{33}$. Furthermore, a history of a traumatic brain injury ${ }^{34}$, hyperlipidemia, hypertension, diabetes and related vascular factors has been demonstrated to increase the risk for $A D^{35}$.

The application of antioxidants ${ }^{36}$, oestrogen by postmenopausal women ${ }^{37}$ and lipid-lowering agents like statins ${ }^{38,39}$ have also been considered beneficial and lowered the possibility for developing AD. Finally, the use of anti-inflammatory agents has been found to reduce the amount of $A D$ cases. Some of these compounds have been shown to decrease the amount of $A \beta 1-42^{40,41}$ or alter the gamma-secretase activity ${ }^{41}$, necessary for $A \beta$ peptides release.

Summarizing, tremendous advancement has been made in understanding the genetic basis of $A D$, with identification of causative genes for early-onset familial $A D$, and the role of the polymorphism of the ApoE gene in the late-onset form of the disease. Also multiple non-genetic risk factors have been identified.

Besides the identification of these risk factors, it has become increasingly clear that neuroinflammatory processes are important biochemical driving forces in the aetiology of $A D^{42}$. This inflammatory process is driven by activated microglia, astrocytes and the induction of proinflammatory molecules and related signalling pathways, leading to both synaptic and neuronal damage as well as further inflammatory cell activation. In the next few paragraphs, we will elaborate on this topic in more detail.

\section{Inflammation in Alzheimer's disease}

In the initial studies, revealing inflammation as an important feature in the $A D$ pathogenesis, profound inflammatory disturbances in limbic and associated cortices were reported ${ }^{14}$. Currently, there is compelling evidence that cerebral amyloid beta deposition in the brain, one of the hallmarks in $A D$, is associated with a local inflammatory response, which is initiated by microglial activation and the recruitment of astrocytes. Activated microglia, the resident immune cells of the brain, are often found in the vicinity of maturing amyloid plaques and are 


\section{CHAPTER 1}

candidates for early cellular responses in the $A \beta$-mediated pathogenic pathway. These activated microglia are thought to be a major source of various proinflammatory cytokines with subsequent reactive astrocytosis ${ }^{14}$, finally resulting in neuronal degeneration and cell death. Likewise, it has already been suggested in some models that $A \beta$ neurotoxicity is modulated through a variety of secondary mechanism including inflammation ${ }^{10}$ (Figure 3 ).

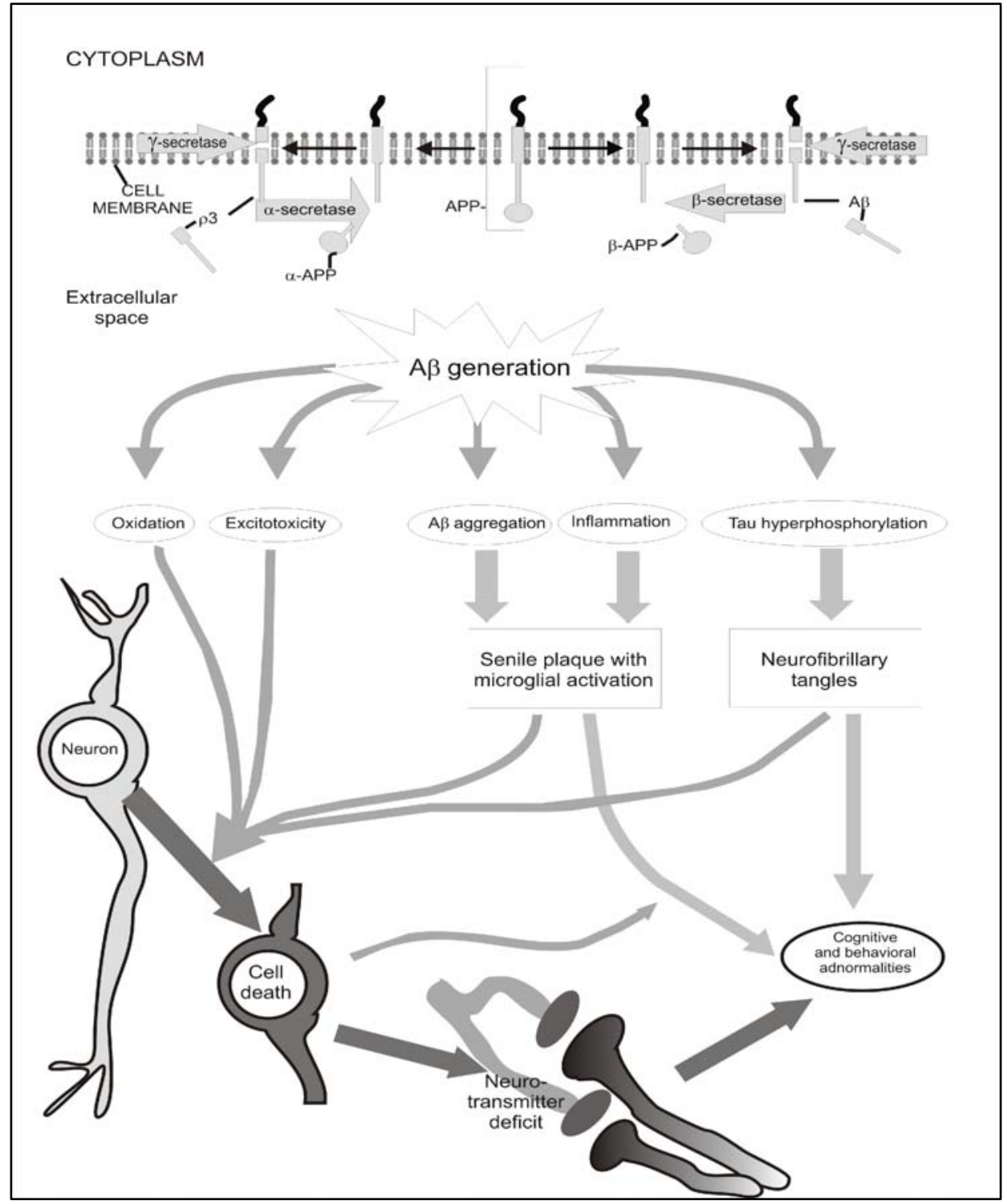

Figure 3. Putative amyloid cascade, initiating at the generation of beta-amyloid peptide from APP and evolving through secondary steps like inflammation to cell death. 
Indices for activation of various inflammatory pathways, like complement activation, the presence of acute phase proteins, release of cytokines/chemokines and others, have been revealed in the AD brain and are thought to interact which each other ${ }^{42}$. Probably the most important of these involves the production of several cytokines and chemokines. For instance, interleukin (IL)-1 $\beta$, IL-6, tumour necrosis factor (TNF)- $\alpha$, IL-8, transforming growth factor (TGF)- $\beta$ and several chemokines, like the monocyte chemoattractant protein (MCP-1), have been shown to be up-regulated in $A D$ patients compared to healthy controls ${ }^{42}$. Moreover, it has been suggested that patients, which are classified as "pro-inflammatory phenotypes" may be at higher risk for $A D$ as these patients produce larger amounts of pro-inflammatory cytokines compared to anti-inflammatory compounds ${ }^{43}$. Next, some of the most important cytokines/chemokines associated with AD will be discussed briefly.

\section{i) IL-1 $\beta$}

In brain regions affected by $A D$, this pro-inflammatory cytokine is prominently present $^{44,45}$. As enhanced production can already be detected early in plaque evolution, it has been suggested that IL-1 $\beta$ plays a key role in $A D$ pathogenesis ${ }^{44}$. Bi-directional relationships between this cytokine and APP were revealed. On one hand, it has been shown that IL-1 $\beta$ promotes the synthesis and further processing of APP ${ }^{46-48}$, while on the other hand, soluble APP seems to be able to activate microglia, resulting in the production of IL- $1 \beta^{49}$. Thereupon, the latter could activate astrocytes with subsequent release of $\mathrm{S} 100 \beta$, a neurite growth-promoting cytokine $^{50}$. As such, IL-1 $\beta$ has been linked to amyloid transition from the diffuse to the dense core stage ${ }^{51}$.

\section{ii) IL-6}

This pleiotropic cytokine is well known to mediate a large variety of immune responses and inflammation, thereby affecting cell growth and differentiation in the central nervous system ${ }^{52}$. Although IL- 6 is already produced to some extent in the normal adult CNS, this production is strongly upregulated under pathological conditions ${ }^{53}$. Then the cytokine is predominantly released by microglia, astroglia, neurons and endothelial cells ${ }^{54-56}$. In $A D$ patients, augmented IL-6 levels have been reported in the brain itself, but also in the blood and cerebrospinal fluid (CSF $)^{57-59}$. Although there is some evidence supporting an anti-inflammatory role ${ }^{60,61}$, this cytokine is generally described as being destructive and pro-inflammatory. It is commonly accepted that this cytokine has a prominent role in the AD pathology ${ }^{62-65}$. 
iii) TNF- $\alpha$

Though this cytokine has been described as protective under certain circumstances $^{66,67}$, it is commonly known for its destructive functions. Mice overexpressing this molecule display severe inflammation and neurodegeneration $^{68,69}$. Moreover, TNF- $\alpha$ has been demonstrated to stimulate nuclear factor-kappaB (NF-kB), finally resulting in the increased expression of several pro-inflammatory compounds ${ }^{70}$. Likewise, in many CNS disorders, such as multiple sclerosis (MS) and PD, this cytokine acts as a pro-inflammatory and cytotoxic compound ${ }^{71,72}$. Similarly, it has been shown to be up-regulated in $A D$ serum, CSF, cortex and glial cultures after $A \beta$ exposure ${ }^{73,74}$, suggesting a conspicuous role for this cytokine in AD.

\section{iv) TGF- $\beta$}

All three isoforms of this growth factor (TGF- $\beta 1,2$ and 3 ) have been demonstrated in the CNS, in particular within neurons, astrocytes and microglia, and associations between all three and numerous $A D$ processes have been described $^{75-79}$.

TGF- $\beta 1$ could be detected in plaques, serum and CSF of AD patients ${ }^{80-82}$ and levels correlated with the degree of amyloid deposition. Although it was described as an anti-inflammatory cytokine, it could act pro-inflammatory in some pathological conditions. In various reports, it has been suggested that TGF- $\beta 1$ (and TGF- $\beta 2$ and 3 ) has an effect on the accumulation, redistribution and clearance of $A \beta$ in the brain ${ }^{83-86}$. Furthermore, evidence suggests that TGF$\beta 1$ augments APP production in cultured astrocytes and microglia after application of this compound ${ }^{87,88}$. In contrast, TGF- $\beta$ has also been shown to offer protection against $A \beta$ toxicity, however only after short-term $A \beta$ exposure $^{89}$.

\section{v) Chemokines}

Chemokines can be divided into four distinct families, $\alpha$ (CXC), $\beta(C C), \gamma\left(C_{3} C\right)$ and $\delta(C)^{90}$. The two major families are the CXC and $C C$ family and consist, among others, of IL-8 and MCP-1, respectively. With respect to $A D$, it has been demonstrated that some of these chemokines are up-regulated in affected brains and evidence suggests that they contribute to plaque-associated inflammation and neurodegeneration ${ }^{91}$. For instance, MCP-1 was shown in mature senile plaques and activated microglia ${ }^{92}$. Also, $A \beta$ seems able to increase the production of, for instance, IL- 8 and MCP- $1^{42}$. Finally, it can be hypothesized that enhanced chemokine production might play a distinct role in 
the recruitment of astrocytes and microglia to senile plaques, thereby promoting the progression of the disease.

Overall, various cytokines have been associated with $A D$ and it has been suggested that they are capable to drive the development of several hallmarks in $A D$ pathology. Alternatively, some models suggest that CNS inflammation might be a secondary mechanism in $A D$ resulting from $A \beta$ accumulation. Therefore, one could question which other mechanisms potentially control these inflammatory reactions. As such, infections have been implied as aetiological factors in neurodegenerative disorders.

\section{Neurodegenerative disorders and infections}

Recently, infections have been suggested as a potential cause of neuroinflammation and thus, as a contributing factor in neurodegenerative diseases. Although, in younger persons, some pathogens can be transferred from peripheral nerves into the CNS, it is well established that with aging, the vulnerability of the central nervous system for infections increases. Under these circumstances, the blood-brain barrier and cellular immune systems are compromised. So infectious agents can reside in the CNS without being detected. Furthermore, as a result of the increase in oxidative stress and impaired energy production, neurons become extra vulnerable. Additionally, survival and plasticity promotion of neurons could be damaged during aging ${ }^{93}$. Besides, also pathogens that do not reach the CNS were suggested to aggravate the inflammatory processes or disease progression in brains, already affected with existing inflammation, by further activation of primed microglial cells $^{94}$. Moreover, in a pilot study, it was shown that in AD patients cognitive functions could be further impaired after a systemic infection ${ }^{95}$.

So, based on these observations, it has been suggested that infections might play a role in the initiation and/or aggravation of neurodegenerative disorders. This hypothesis will be addressed in the next paragraph.

\subsection{Viral infections}

\section{Human immunodeficiency virus (HIV)}

Presently, dementia is a common phenomenon in acquired immune deficiency syndrome (AIDS) caused by the human immunodeficiency virus (HIV-1). Degeneration of synapses and neurons was detected in the hippocampus, related cortical and limbic structures and basal ganglia ${ }^{96,97}$. The virus probably persists or replicates in microglia with consequent release of viral proteins 
gp120 and gp41, thereby damaging neurons and increasing oxidative stress ${ }^{98-}$ ${ }^{100}$. Moreover, augmented levels of inflammatory molecules, like TNF- $\alpha$, IL-1, IL2 and IL-6, have been shown in HIV-1 infected patients ${ }^{101}$. Likewise, it has been demonstrated that HIV-1 activates microglia thereby triggering local inflammation through the release of cytokines and neurotoxins. This will ultimately result in neuronal cell death and dysfunction in adjacent cells not infected by the virus ${ }^{102,103}$.

Next to this HIV dementia, HIV infected patients were also described to develop a rapid progressive amyotrophic lateral sclerosis (ALS), a neurodegenerative disorder resulting in progressive paralysis and death ${ }^{104}$.

\section{Herpes viruses}

The herpes simplex virus type 1 (HSV-1) could also be detected in the brain of many elderly, and was postulated as a risk factor for $A D$, especially in patients harbouring the ApoE- $\varepsilon 4$ allel ${ }^{105-107}$. HSV-1, which is frequently present in a latent state in peripheral neurons ${ }^{108}$, was associated with chronic inflammation and oxidative damage ${ }^{109}$. Moreover, HSV-1 is recurrently found in high proportions in those brain regions most effected by $A D$ pathology ${ }^{110}$. Furthermore, in $A D$ brains, it has also been suggested that human herpes virus 6 (HHV-6) could enhance the damage resulting from HSV-1 infection ${ }^{108,111}$.

Several observations indicated that human cytomegalovirus (HCMV) has a tropism for the central nervous system; specifically for neurons and glial cells ${ }^{112}$. It was postulated that CMV can enter the brain either via the vascular system or via the olfactory mucosa to the olfactory bulb. Additionally, CMV infected lymphocytes or neuronal axons could possibly provide viral entry to the brain ${ }^{113}$. The production of inflammatory compounds, like IL- 6 and TNF- $\alpha$, was determined after in vitro CMV infection of microglial cells ${ }^{114}$. CMV infection in the CNS manifests in ventriculoencephalitis, characterized by necrotic lesions in the periventricular areas and micronodular encephalitis consisting of microglial nodules ${ }^{112}$. CMV was also found in a higher proportion in vascular dementia patients compared with healthy controls ${ }^{115}$.

\subsection{Bacterial infections}

Besides the aforementioned variety of viruses, some bacteria have been likewise associated with neurodegenerative diseases. For example, a potential link between Helicobacter pylori and PD has been reported as $H$. pylori seropositivity was substantially higher in PD patients compared to control subjects $^{116}$. Moreover, this bacteria was also found associated with $A D$ by 
Kountouras and co-workers ${ }^{117}$. The detection of spirochetes in blood and cerebrospinal fluid of $A D$ patients also resulted in the speculation that these pathogens might be related to the disease ${ }^{118}$, although its role in AD pathology is not yet determined. Similarly, Treponema was shown in a significant higher amount in $A D$ patients compared to non- $A D$ controls ${ }^{119}$. Conversely, other studies failed in detecting the presence of the bacterium in $A D^{120,121}$.

Peptidoglycan (PG), a major component of the cell wall of Gram-positive bacteria was detected in the CNS of MS patients ${ }^{122}$. Moreover, it was shown that PG, isolated from Staphylococcus aureus could induce the development of experimental autoimmune encephalomyelitis, a model for MS, in mice ${ }^{123}$.

Finally, an increasing body of evidence suggested a link between Chlamydia pneumoniae and a variety of neurodegenerative disorders, predominantly AD.

\section{Chlamydia pneumoniae}

\subsection{Microbiology}

Chlamydia pneumoniae (Cpn) was first isolated in 1965 from the conjunctiva of a Taiwanese child, but only in 1989, it was officially established as a third species of Chlamydia ${ }^{124,125}$, a family consisting of small, obligate intracellular pathogens. Conversely, they were classified as bacteria because their cell wall consists of inner and outer membranes, replication occurs via binary fission, nucleic acids and ribosomes could be detected and proteins could be synthesized $^{126}$. Four species of Chlamydiae are recognized; Chlamydia psitacci, Chlamydia pecorum, Chlamydia trachomatis and Chlamydia pneumoniae. The first two are predominantly known for infections in animals, while the latter are human pathogens.

\subsection{Epidemiology}

It is generally accepted that Cpn, responsible for the majority of human chlamydial infections, is one of the most prevalent infectious agents in the Western society. Serological data describe a peak among teenagers as in approximately $50 \%$ of the 20ers detectable Cpn antibodies could be identified $^{127}$. Thereafter, levels start to increase and the antibody prevalence, higher in adult men compared to women, corresponded to $40-50 \%$ in the Northern hemisphere and $60-70 \%$ in the tropical countries ${ }^{125}$. These figures indicate that a majority of people are infected and re-infected during life ${ }^{128}$. Infection can take place during the whole year and the pathogen is transmitted from man to man, probably via respiratory droplets with an incubation period of 
several weeks ${ }^{127}$. Moreover, it has been demonstrated that at room temperature and high relative humidity, Cpn can survive in aerosol for a relative short period, possibly revealing a direct person-to-person transmission route in a crowded humid environment ${ }^{129}$.

\subsection{Replication}

Cpn is able to infect a diversity of eukaryotic cell types, like macrophages, endothelial and smooth muscle cells ${ }^{130}$, in which it undergoes a unique biphasic life cycle consisting of two distinct forms: the small infectious elementary body and the larger metabolically active reticulate body. The life cycle initiates as soon as the pear-shaped infectious elementary body enters the host cell within a vacuole by endocytosis. The chlamydial major outer membrane protein (MOMP) has been suggested to play a role in this by decreasing the electrostatic repulsion between host cell and elementary bodies $(E B)^{131}$. Next, transformation takes place to the non-infectious reticulate body (RB). These particles will replicate by binary fission with subsequent formation of an inclusion body. Afterwards, reorganization occurs to infectious elementary bodies. These newly formed organisms will be released after more or less 72 hours as the host cell lyses. The cycle restarts as soon as infectious chlamydia particles reach a neighbouring cell ${ }^{127,132,133}$ (Figure 4).

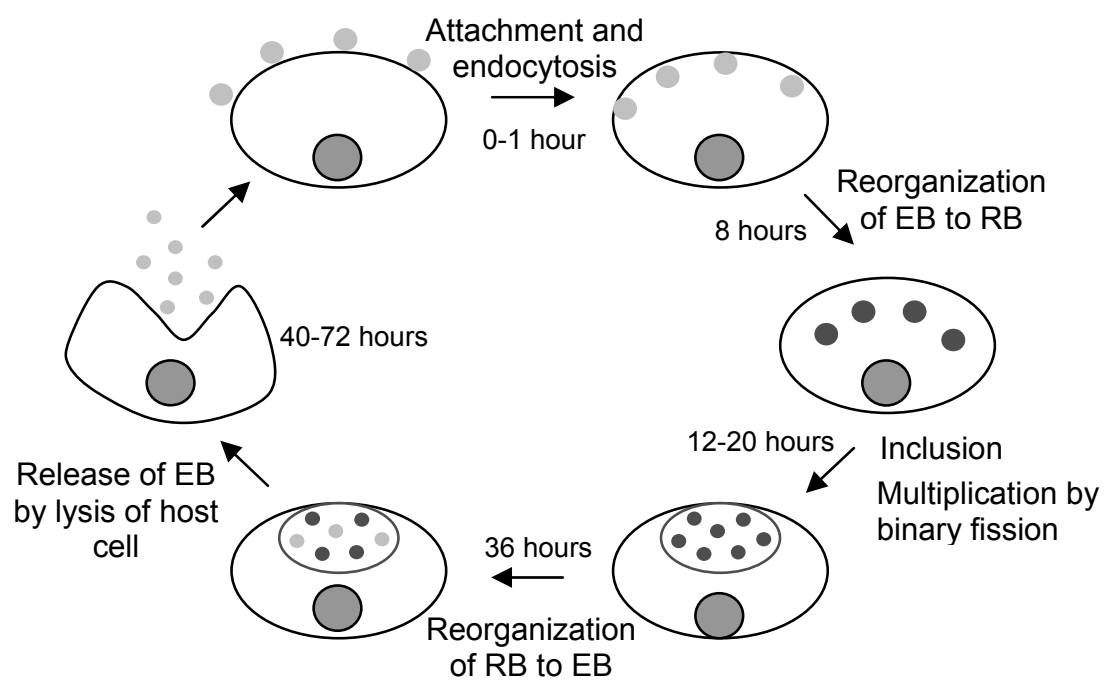

Figure 4. Life cycle of Chlamydia pneumonia

Chlamydia persistence, a state in which the organism is present in the host cell but growth or replication is impaired, has also been described, until reactivation takes place ${ }^{132,134,135}$. In particular, monocytes/macrophages may act as potent 
sources of latent $\mathrm{Cpn}$. This persistent state is possibly due to the anti-apoptotic properties of Cpn. It has been shown that $\mathrm{Cpn}$ is able to inhibit apoptotic processes of its host cell, as described in human epithelial, monocyte and peripheral blood mononuclear cells ${ }^{136,137}$. These mechanisms could possible explain why $\mathrm{Cpn}$ infections can be linked, next to acute disorders, to chronic diseases.

\subsection{Chlamydia pneumoniae and disease}

Most people undergo a Cpn infection asymptomatic or suffer from mild illness. However, in various cases, severe diseases could be linked to acute and/or chronic Cpn infections.

In children, Cpn infection is mostly associated with mild upper respiratory infection with prolonged cough ${ }^{138}$. After the age of five, upper respiratory tract infections are more common, though with variable results, including rhinitis, sinusitis and otitis media ${ }^{138,139}$. Pneumonia, however, is the best known consequence of Cpn infection ${ }^{127,140,141,142}$. In young adults, symptoms are often persistent, dry cough and low fever. Re-infections can occur and are mostly mild, however, in the elderly, severe pneumonia was demonstrated ${ }^{143}$.

\subsection{Chronic Chlamydia pneumoniae infections}

Several reports linked chronic bronchitis with the presence of $\mathrm{Cpn}^{141,144,145}$. Involvement of Cpn was also illustrated in various chronic conditions of the upper respiratory tract, like chronic otitis media and chronic persistent pharyngitis ${ }^{146,147}$. More recently, asthma was associated with $\mathrm{Cpn}^{148,149}$. In children, a positive correlation was detected between the severity of this disease and the presence of Cpn antibodies ${ }^{150}$.

Not only respiratory diseases were associated with acute Cpn infection, but also some cardiovascular disorders. Cpn was described as possibly involved in carditis, vasculiditis, subacute myocarditis, myocardial infarction and reactive arthritis $^{151-157}$. Most evidence is available regarding a role of $\mathrm{Cpn}$ in atherosclerosis, a chronic inflammatory vascular disorder. Although conflicting results exist ${ }^{158}$, the majority of sero-epidemiological evidence revealed an association between $\mathrm{Cpn}$ and atherosclerosis ${ }^{159,160}$. Moreover, human atherosclerotic material was found positive for $\mathrm{Cpn}$ by various techniques ${ }^{161-163}$. Additionally, in vitro and animal studies have been performed to elucidate a role for $\mathrm{Cpn}$ in this inflammatory disorder ${ }^{164-167}$ with only minor negative results ${ }^{168,169}$. A profound inflammatory response including IL-1 $\beta, \mathrm{IL}-6, \mathrm{TNF}-\alpha, \mathrm{INF}-\gamma$ and MCP-1 $\alpha$ secretion, was detected after Cpn infection in macrophages ${ }^{170-173}$, 
monocytes ${ }^{174}$, endothelial cells ${ }^{175}$ and smooth muscle cells ${ }^{176}$ but also in a mouse model ${ }^{177}$. Recently, an increasing body of evidence suggests a potential link between $\mathrm{Cpn}$ and inflammatory mechanisms in the CNS, possibly resulting in various severe disorders ${ }^{178,179}$.

\section{Chlamydia pneumoniae and neurodegenerative disorders}

Elevated Cpn antibody titers in some acute neurological syndromes, like encephalomyelitis ${ }^{180-182}$, acute stroke ${ }^{183}$, cerebella syndrome ${ }^{181}$ and meningoradiculitis $^{184}$ suggest an association between Cpn infection and CNS injury. Unfortunately, in the majority of these case reports, direct evidence for infection of the CNS with Cpn is lacking.

In patients suffering from HIV-associated dementia complex (HADC), the presence of $\mathrm{Cpn}$ was investigated by applying polymerase chain reaction (PCR) and Enzyme-Linked ImmunoSorbent Assay (ELISA) techniques. Among 17.3\% of all HADC cases, Cpn DNA was identified and among these patients high levels of $\mathrm{Cpn}$ antibodies in the CSF were demonstrated ${ }^{185}$. The presence of $\mathrm{Cpn}$ DNA was also examined in vascular dementia ( $\mathrm{VaD})$ patients, previously screened for CMV infection. Unfortunately, no positive PCR signal for Cpn was shown, neither in the CMV positive patient material, nor in the material negative for CMV infection ${ }^{186}$. On the contrary, in a more recent study, in which serum Cpn antibodies were investigated in $\mathrm{VaD}$ patients, Cpn was identified as a possible risk factor ${ }^{187}$.

In MS, a severe chronic inflammatory disease of the CNS, Cpn was recently postulated as a possible provocative agent ${ }^{178}$. Inspired by a single case report ${ }^{188}$, various groups examined the possible association between Cpn and MS. Although initial results indeed revealed a strong association between Cpn and $\mathrm{MS}^{189,190}$, later studies failed to confirm these early positive results ${ }^{191-196}$. Further studies are needed to clarify these controversies.

\subsection{Chlamydia pneumoniae and Alzheimer's Disease}

First evidence for an association between Cpn and AD appeared in 1998 as Balin and co-workers demonstrated the presence of Cpn DNA in post-mortem brain material of 17 out of 19 late-onset AD patients while Cpn DNA was found in only 1 out of 19 controls (non-AD) ${ }^{197}$. In these Cpn PCR positive brains, electron microscopy revealed chlamydial bodies in regions most affected by $A D$, such as the hippocampus. Here, the pathogen could be demonstrated within 
pericytes, microglia and astroglia after immunohistochemical analysis. So, based on these results it was suggested that $\mathrm{Cpn}$ could possibly be a risk factor for AD. Soon after, Gieffers and colleagues performed similar experiments, unfortunately without detection of Cpn DNA and antigens in their paraffin embedded tissue samples ${ }^{198}$. Likewise, absence of $\mathrm{Cpn}$ in $\mathrm{AD}$ patient material was also reported by others ${ }^{199-201}$. However, these discrepancies could possibly be explained by different protocols for PCR, immunohistochemistry and tissue sampling. Another possible explanation for these discrepancies might be related to genetic differences. Previously, it has been suggested that ApoE $\varepsilon 4$ carriership may increase a patients sensitivity for $\mathrm{Cpn}$ infection ${ }^{202}$. This association, as well as the knowledge that the ApoE $\varepsilon 4$ carriership is also a major risk factor for $A D$, inspired Gerard et al. to study whether $C p n$ is present in $A D$ patients carrying this allele. Interestingly, Cpn DNA was detected in a significant higher amount in brain material of ApoE \&4-carrying AD patients versus patients without this alle ${ }^{203}$, suggesting a possible intimate relationship between genotype and environment in a patients susceptibility to develop AD.

Additional evidence for a role of $\mathrm{Cpn}$ in $\mathrm{AD}$ comes from animal experiments as AD-like pathology was demonstrated in the brain of BALB/c mice after Cpn infection $^{204}$. Three-month-old mice were inoculated intranasally with $\mathrm{Cpn}$, isolated out of an $A D$ brain, and analysed for the presence of $C p n$ and $A D$ pathology at 1 and 3 months post infection. Cpn could still be detected in the olfactory bulbs at 3 months after inoculation, using light and electron microscopy. Significant more $A \beta$ depositions were demonstrated in the infected mouse brains up to 3 months p.i., with increasing pathology as the infection progressed. Based on these results it was concluded that in naïve BALB/c mice, AD-like pathology can be induced by $\mathrm{Cpn}$ infection. However, doubts exist concerning the amyloid-like plaques, developing post $\mathrm{Cpn}$ infection, as being only uncorroborated elevations in amyloid and a confirmation of these results is required ${ }^{205}$.

In conclusion, although discrepancies and uncertainties remain, the impact of infections on neurodegenerative disorders should not be ignored, but more detailed studies are mandatory to unravel the exact relationship between pathogens, like Cpn, and the pathogenesis of these diseases. 


\section{Hypothesis and Outline of the Thesis}

Genetic factors play a significant role in the development of early-onset Alzheimer's disease. The majority of cases, however, are late-onset (also known as sporadic), occurring in patients aged 65 and older. Even though a number of genetic risk factors have been identified over the past decades, potential risk modifiers for the sporadic form of AD are far less characterized although both environmental, as well as life style factors have been associated with disease initiation and/or progression. More recently, and based on their associations with other neurological diseases, infections have been proposed as an etiological factor in the pathogenesis of AD. Several research groups have suggested a potential association between infections and late-onset AD. In particular, herpes simplex virus type I has been implicated, as it is neurotrophic and ubiquitous within the human population. Likewise, recent evidence suggests a role for the obligate intracellular Gram-negative bacterium Chlamydia pneumoniae (Cpn) in $A D$ and chronic cerebral inflammation, which ultimately may result in neuronal death and cognitive decline. Nevertheless, apart from the knowledge that Cpn is able to travel towards the brain thereby causing a local inflammatory reaction, currently little is known on the mechanisms by which Cpn might contribute to neurodegeneration and $A D$. Therefore, the main objective of this thesis was to study potential pathogenic effects of Cpn on cerebral integrity which may, in the end, result in neuronal loss and dysfunction. To realize this goal, both in vitro models as well as an experimental animal model were used.

First, we assessed the susceptibility of specific brain cells to Cpn infection in vitro. Previously, it has been shown that not all cells of different origin are equally susceptible for Cpn. Though, to our knowledge, evidence concerning the susceptibility of brain cells for Cpn is lacking. Therefore, three well characterized isolated mouse brain cell lines; a microglial, an astrocyte and a neuroblast cell line were screened for Cpn infection. Moreover, the viability and replication of the pathogen in these brain cells was investigated. Finally, as Cpn may contribute to neurodegeneration, we examined the effect of Cpn infection on these cells in terms of cell death (Chapter 2).

Besides its potential direct pathogenic effects on brain cells, Cpn might also cause neurodegeneration by alternative pathways. For example, infection of glial cells may result in the production and release of a large variety proinflammatory cytokines/chemokines. Subsequently, these molecules may contribute significantly to neuronal cell death. As such, apart from its direct effects on neuronal cells, Cpn might contribute to neurodegeneration in an 
alternative, indirect pathway. Therefore, the release of various cytokines/chemokines by $\mathrm{Cpn}$ infected glial cells was investigated. Similarly, it was determined which of these cytokines may finally instigate neuronal cell death (Chapter 3).

Earlier data demonstrated that cells of the myeloid lineage, like monocytes, are protected against chlamydial growth predominantly due to the production of INF- $\gamma$. As microglial cells, which are considered to arise form circulation blood monocytes late in gestation and postnatally, also showed an aberrant course of Cpn infection, we tried to unravel whether microglial cells use similar pathways to control Cpn infection. Therefore, impact of several molecules - INF- $\gamma$, IL-6 and TNF- $\alpha$ - on the susceptibility to $\mathrm{Cpn}$, the replication of Cpn and production of viable progeny were analysed in our microglial cell line (Chapter 4).

Next, we hypothesized that impairment of glutamate transport in astrocytes due to the profound release of pro-inflammatory cytokines by neighbouring microglial cells may contribute to neuronal death in the long run. Therefore, astrocytes were treated with conditioned medium obtained from $\mathrm{Cpn}$ infected microglial cells. Consequences on glutamate transport and subsequent neuronal cell death were investigated (Chapter 5).

Finally, as Cpn infection is increasingly associated with Alzheimer's disease (AD), we investigated whether Cpn infection results in the extracellular aggregation of amyloid beta, one of the hallmarks of $A D$, in normal BALB/C mice. In addition, we compared the findings in the brains of Cpn infected normal mice with the signs and symptoms found in brains obtained from APP751 $1^{\mathrm{SL}} / \mathrm{PS}^{\mathrm{M} 146 \mathrm{~L}}$ mice, a well-known transgenic mouse model, which is characterized by the development of severe AD (Chapter 6 ).

In the last chapter (Chapter 7), the outcome of all studies will be discussed and put into a wider perspective. 


\section{References}

1. Mayeux, R., Epidemiology of neurodegeneration. Annu Rev Neurosci, 2003. 26: p. 81-104.

2. Skovronsky, D.M., V.M.-L. Lee, and J.Q. Trojanowski, Neurodegenerative diseases: New concepts of Pathogenesis and Their Therapeutic Implications. Annu.Rev.Pathol.Mech.Dis., 2006. 1: p. 151-170.

3. de Lau, L.M. and M.M. Breteler, Epidemiology of Parkinson's disease. Lancet Neurol, 2006. 5(6): p. 525-35.

4. Nussbaum, R.L. and C.E. Ellis, Alzheimer's disease and Parkinson's disease. N Engl J Med, 2003. 348(14): p. 1356-64.

5. Roman, G.C., Defining dementia: clinical criteria for the diagnosis of vascular dementia. Acta Neurol Scand Suppl, 2002. 178: p. 6-9.

6. Brayne, C., et al., Dementia before death in ageing societies--the promise of prevention and the reality. PLoS Med, 2006. 3(10): p. e397.

7. Mega, M.S., et al., The spectrum of behavioral changes in Alzheimer's disease. Neurology, 1996. 46(1): p. 130-5.

8. McKhann, G., et al., Clinical diagnosis of Alzheimer's disease: report of the NINCDS-ADRDA Work Group under the auspices of Department of Health and Human Services Task Force on Alzheimer's Disease. Neurology, 1984. 34(7): p. 939-44.

9. Morris, J.C., Dementia update 2003. Alzheimer Dis Assoc Disord, 2003. 17(4): p. 245-58.

10. Cummings, J.L., Alzheimer's disease. N Engl J Med, 2004. 351(1): p. 56-67.

11. Hebert, L.E., et al., Is the risk of developing Alzheimer's disease greater for women than for men? Am J Epidemiol, 2001. 153(2): p. 132-6.

12. McDonnell, J., et al., The cost of treatment of Alzheimer's disease in The Netherlands: a regression-based simulation model. Pharmacoeconomics, 2001. 19(4): p. 379-90.

13. Dickson, D.W., Neuropathology of Alzheimer's disease and other dementias. Clin Geriatr Med, 2001. 17(2): p. 209-28.

14. Selkoe, D.J., Alzheimer's disease: genes, proteins, and therapy. Physiol Rev, 2001. 81(2): p. 741-66.

15. Dickson, D.W., The pathogenesis of senile plaques. J Neuropathol Exp Neurol, 1997. 56(4): p. 321-39.

16. Dickson, D.W., et al., Glycation and microglial reaction in lesions of Alzheimer's disease. Neurobiol Aging, 1996. 17(5): p. 733-43.

17. Braak, H. and E. Braak, Staging of Alzheimer's disease-related neurofibrillary changes. Neurobiol Aging, 1995. 16(3): p. 271-8; discussion 278-84.

18. Mandelkow, E., et al., On the structure of microtubules, tau, and paired helical filaments. Neurobiol Aging, 1995. 16(3): p. 347-54.

19. Hardy, J. and D.J. Selkoe, The amyloid hypothesis of Alzheimer's disease: progress and problems on the road to therapeutics. Science, 2002. 297(5580): p. 353-6.

20. Deng, G., C.J. Pike, and C.W. Cotman, Alzheimer-associated presenilin-2 confers increased sensitivity to apoptosis in PC12 cells. FEBS Lett, 1996. 397(1): p. 50-4.

21. Cotman, C.W., Apoptosis decision cascades and neuronal degeneration in Alzheimer's disease. Neurobiol Aging, 1998. 19(1 Suppl): p. S29-32.

22. Yankner, B.A., New clues to Alzheimer's disease: unraveling the roles of amyloid and tau. Nat Med, 1996. 2(8): p. 850-2.

23. Perry, G., et al., Apoptosis and Alzheimer's disease. Science, 1998. 282(5392): p. 1268-9.

24. Perry, G., A. Nunomura, and M.A. Smith, A suicide note from Alzheimer disease neurons? Nat Med, 1998. 4(8): p. 897-8. 
25. Raina, A.K., et al., Abortive apoptosis in Alzheimer's disease. Acta Neuropathol (Berl), 2001. 101(4): p. 305-10.

26. Strittmatter, W.J. and A.D. Roses, Apolipoprotein E and Alzheimer disease. Proc Natl Acad Sci U S A, 1995. 92(11): p. 4725-7.

27. Saunders, A.M., et al., Association of apolipoprotein E allele epsilon 4 with late-onset familial and sporadic Alzheimer's disease. Neurology, 1993. 43(8): p. 1467-72.

28. Corder, E.H., et al., Gene dose of apolipoprotein E type 4 allele and the risk of Alzheimer's disease in late onset families. Science, 1993. 261(5123): p. 921-3.

29. Jorm, A.F., A.E. Korten, and A.S. Henderson, The prevalence of dementia: a quantitative integration of the literature. Acta Psychiatr Scand, 1987. 76(5): p. 465-79.

30. Stern, Y., et al., Influence of education and occupation on the incidence of Alzheimer's disease. Jama, 1994. 271(13): p. 1004-10.

31. Scarmeas, N., et al., Influence of leisure activity on the incidence of Alzheimer's disease. Neurology, 2001. 57(12): p. 2236-42.

32. Moceri, V.M., et al., Early-life risk factors and the development of Alzheimer's disease. Neurology, 2000. 54(2): p. 415-20.

33. Ruitenberg, A., et al., Alcohol consumption and risk of dementia: the Rotterdam Study. Lancet, 2002. 359(9303): p. 281-6.

34. Plassman, B.L., et al., Documented head injury in early adulthood and risk of Alzheimer's disease and other dementias. Neurology, 2000. 55(8): p. 1158-66.

35. Breteler, M.M., Vascular risk factors for Alzheimer's disease: an epidemiologic perspective. Neurobiol Aging, 2000. 21(2): p. 153-60.

36. Engelhart, M.J., et al., Diet and risk of dementia: Does fat matter?: The Rotterdam Study. Neurology, 2002. 59(12): p. 1915-21.

37. Waring, S.C., et al., Postmenopausal estrogen replacement therapy and risk of AD: a population-based study. Neurology, 1999. 52(5): p. 965-70.

38. Crisby, M., L.A. Carlson, and B. Winblad, Statins in the prevention and treatment of Alzheimer disease. Alzheimer Dis Assoc Disord, 2002. 16(3): p. 131-6.

39. Rockwood, K., J.E. Graham, and S. Fay, Goal setting and attainment in Alzheimer's disease patients treated with donepezil. J Neurol Neurosurg Psychiatry, 2002. 73(5): p. 500-7.

40. Blasko, I., et al., Ibuprofen decreases cytokine-induced amyloid beta production in neuronal cells. Neurobiol Dis, 2001. 8(6): p. 1094-101.

41. Weggen, S., et al., A subset of NSAIDs lower amyloidogenic Abeta42 independently of cyclooxygenase activity. Nature, 2001. 414(6860): p. 212-6.

42. Akiyama, H., et al., Inflammation and Alzheimer's disease. Neurobiol Aging, 2000. 21(3): p. 383-421.

43. Remarque, E.J., et al., Patients with Alzheimer's disease display a pro-inflammatory phenotype. Exp Gerontol, 2001. 36(1): p. 171-6.

44. Griffin, W.S., et al., Interleukin-1 expression in different plaque types in Alzheimer's disease: significance in plaque evolution. J Neuropathol Exp Neurol, 1995. 54(2): p. 276-81.

45. Griffin, W.S., et al., Glial-neuronal interactions in Alzheimer's disease: the potential role of a 'cytokine cycle' in disease progression. Brain Pathol, 1998. 8(1): p. 65-72.

46. Goldgaber, D., et al., Interleukin 1 regulates synthesis of amyloid beta-protein precursor mRNA in human endothelial cells. Proc Natl Acad Sci U S A, 1989. 86(19): p. 7606-10.

47. Mackenzie, I.R., Anti-inflammatory drugs and Alzheimer-type pathology in aging. Neurology, 2000. 54(3): p. 732-4.

48. Buxbaum, J.D., et al., Cholinergic agonists and interleukin 1 regulate processing and secretion of the Alzheimer beta/A4 amyloid protein precursor. Proc Natl Acad Sci U S A, 1992. 89(21): p. 10075-8.

49. Barger, S.W. and A.D. Harmon, Microglial activation by Alzheimer amyloid precursor protein and modulation by apolipoprotein E. Nature, 1997. 388(6645): p. 878-81. 


\section{CHAPTER 1}

50. Sheng, J.G., et al., Human brain S100 beta and S100 beta mRNA expression increases with age: pathogenic implications for Alzheimer's disease. Neurobiol Aging, 1996. 17(3): p. 359-63.

51. Sheng, J.G., R.E. Mrak, and W.S. Griffin, Microglial interleukin-1 alpha expression in brain regions in Alzheimer's disease: correlation with neuritic plaque distribution. Neuropathol Appl Neurobiol, 1995. 21(4): p. 290-301.

52. Heinrich, P.C., et al., Interleukin-6 and related cytokines: effect on the acute phase reaction. $\mathbf{Z}$ Ernahrungswiss, 1998. 37 Suppl 1: p. 43-9.

53. Vallieres, L. and S. Rivest, Regulation of the genes encoding interleukin-6, its receptor, and gp130 in the rat brain in response to the immune activator lipopolysaccharide and the proinflammatory cytokine interleukin-1beta. J Neurochem, 1997. 69(4): p. 1668-83.

54. Frei, K., et al., On the cellular source and function of interleukin 6 produced in the central nervous system in viral diseases. Eur J Immunol, 1989. 19(4): p. 689-94.

55. Marz, P., et al., Sympathetic neurons can produce and respond to interleukin 6. Proc Natl Acad Sci U S A, 1998. 95(6): p. 3251-6.

56. Van Wagoner, N.J., et al., Interleukin-6 (IL-6) production by astrocytes: autocrine regulation by IL-6 and the soluble IL-6 receptor. J Neurosci, 1999. 19(13): p. 5236-44.

57. Kalman, J., et al., Serum interleukin-6 levels correlate with the severity of dementia in Down syndrome and in Alzheimer's disease. Acta Neurol Scand, 1997. 96(4): p. 236-40.

58. Singh, V.K. and P. Guthikonda, Circulating cytokines in Alzheimer's disease. J Psychiatr Res, 1997. 31(6): p. 657-60.

59. Terreni, L. and M.G. De Simoni, Role of the brain in interleukin-6 modulation. Neuroimmunomodulation, 1998. 5(3-4): p. 214-9.

60. Mastorakos, G., G.P. Chrousos, and J.S. Weber, Recombinant interleukin-6 activates the hypothalamic-pituitary-adrenal axis in humans. J Clin Endocrinol Metab, 1993. 77(6): p. 16904.

61. Crowl, R.M., et al., Induction of phospholipase A2 gene expression in human hepatoma cells by mediators of the acute phase response. J Biol Chem, 1991. 266(4): p. 2647-51.

62. Ringheim, G.E., et al., Enhancement of beta-amyloid precursor protein transcription and expression by the soluble interleukin- 6 receptor/interleukin- 6 complex. Brain Res Mol Brain Res, 1998. 55(1): p. 35-44.

63. Vandenabeele, P. and W. Fiers, Is amyloidogenesis during Alzheimer's disease due to an IL1-/IL-6-mediated 'acute phase response' in the brain? Immunol Today, 1991. 12(7): p. 217-9.

64. Chong, Y., Effect of a carboxy-terminal fragment of the Alzheimer's amyloid precursor protein on expression of proinflammatory cytokines in rat glial cells. Life Sci, 1997. 61(23): p. 232333.

65. Hull, M., et al., The participation of interleukin-6, a stress-inducible cytokine, in the pathogenesis of Alzheimer's disease. Behav Brain Res, 1996. 78(1): p. 37-41.

66. Barger, S.W., et al., Tumor necrosis factors alpha and beta protect neurons against amyloid beta-peptide toxicity: evidence for involvement of a kappa B-binding factor and attenuation of peroxide and Ca2+ accumulation. Proc Natl Acad Sci U S A, 1995. 92(20): p. 9328-32.

67. Mattson, M.P., et al., Cellular signaling roles of TGF beta, TNF alpha and beta APP in brain injury responses and Alzheimer's disease. Brain Res Brain Res Rev, 1997. 23(1-2): p. 47-61.

68. Akassoglou, K., et al., Astrocyte-specific but not neuron-specific transmembrane TNF triggers inflammation and degeneration in the central nervous system of transgenic mice. J Immunol, 1997. 158(1): p. 438-45.

69. Probert, L., et al., Spontaneous inflammatory demyelinating disease in transgenic mice showing central nervous system-specific expression of tumor necrosis factor alpha. Proc Natl Acad Sci U S A, 1995. 92(24): p. 11294-8.

70. Cardinaux, J.R., I. Allaman, and P.J. Magistretti, Pro-inflammatory cytokines induce the transcription factors C/EBPbeta and C/EBPdelta in astrocytes. Glia, 2000. 29(1): p. 91-7. 
71. D'Souza, S.D., et al., Multiple sclerosis: Fas signaling in oligodendrocyte cell death. J Exp Med, 1996. 184(6): p. 2361-70.

72. Mogi, M., et al., Tumor necrosis factor-alpha (TNF-alpha) increases both in the brain and in the cerebrospinal fluid from parkinsonian patients. Neurosci Lett, 1994. 165(1-2): p. 208-10.

73. Fillit, H., et al., Elevated circulating tumor necrosis factor levels in Alzheimer's disease. Neurosci Lett, 1991. 129(2): p. 318-20.

74. Good, P.F., et al., Evidence of neuronal oxidative damage in Alzheimer's disease. Am J Pathol, 1996. 149(1): p. 21-8.

75. Bottner, M., K. Unsicker, and C. Suter-Crazzolara, Expression of TGF-beta type II receptor mRNA in the CNS. Neuroreport, 1996. 7(18): p. 2903-7.

76. Krieglstein, K., et al., Neural functions of the transforming growth factors beta. Int J Dev Neurosci, 1995. 13(3-4): p. 301-15.

77. Lippa, C.F., et al., Lewy bodies contain altered alpha-synuclein in brains of many familial Alzheimer's disease patients with mutations in presenilin and amyloid precursor protein genes. Am J Pathol, 1998. 153(5): p. 1365-70.

78. Slotkin, T.A., et al., Expression of mRNAs coding for the transforming growth factor-beta receptors in brain regions of euthyroid and hypothyroid neonatal rats and in adult brain. Brain Res Dev Brain Res, 1997. 99(1): p. 61-5.

79. Unsicker, K., et al., Transforming growth factor beta isoforms in the adult rat central and peripheral nervous system. Neuroscience, 1991. 44(3): p. 613-25.

80. van der Wal, E.A., F. Gomez-Pinilla, and C.W. Cotman, Transforming growth factor-beta 1 is in plaques in Alzheimer and Down pathologies. Neuroreport, 1993. 4(1): p. 69-72.

81. Chao, C.C., et al., Serum cytokine levels in patients with Alzheimer's disease. Clin Diagn Lab Immunol, 1994. 1(4): p. 433-6.

82. Chao, C.C., et al., Transforming growth factor beta in Alzheimer's disease. Clin Diagn Lab Immunol, 1994. 1(1): p. 109-10.

83. Wyss-Coray, T., et al., Chronic overproduction of transforming growth factor-beta1 by astrocytes promotes Alzheimer's disease-like microvascular degeneration in transgenic mice. Am J Pathol, 2000. 156(1): p. 139-50.

84. Wyss-Coray, T., et al., Amyloidogenic role of cytokine TGF-beta1 in transgenic mice and in Alzheimer's disease. Nature, 1997. 389(6651): p. 603-6.

85. Frautschy, S.A., et al., Rodent models of Alzheimer's disease: rat A beta infusion approaches to amyloid deposits. Neurobiol Aging, 1996. 17(2): p. 311-21.

86. Harris-White, M.E., et al., Effects of transforming growth factor-beta (isoforms 1-3) on amyloid-beta deposition, inflammation, and cell targeting in organotypic hippocampal slice cultures. J Neurosci, 1998. 18(24): p. 10366-74.

87. Gray, C.W. and A.J. Patel, Regulation of beta-amyloid precursor protein isoform mRNAs by transforming growth factor-beta 1 and interleukin-1 beta in astrocytes. Brain Res Mol Brain Res, 1993. 19(3): p. 251-6.

88. Monning, U., et al., Transforming growth factor beta mediates increase of mature transmembrane amyloid precursor protein in microglial cells. FEBS Lett, 1994. 342(3): p. 26772.

89. Prehn, J.H., et al., Protective effect of transforming growth factor-beta 1 on beta-amyloid neurotoxicity in rat hippocampal neurons. Mol Pharmacol, 1996. 49(2): p. 319-28.

90. Prieschl, E.E., P.A. Kulmburg, and T. Baumruker, The nomenclature of chemokines. Int Arch Allergy Immunol, 1995. 107(4): p. 475-83.

91. Xia, M.Q. and B.T. Hyman, Chemokines/chemokine receptors in the central nervous system and Alzheimer's disease. J Neurovirol, 1999. 5(1): p. 32-41.

92. Ishizuka, K., et al., Identification of monocyte chemoattractant protein-1 in senile plaques and reactive microglia of Alzheimer's disease. Psychiatry Clin Neurosci, 1997. 51(3): p. 135-8. 


\section{CHAPTER 1}

93. Mattson, M.P., Infectious agents and age-related neurodegenerative disorders. Ageing Res Rev, 2004. 3(1): p. 105-20.

94. Perry, V.H., T.A. Newman, and C. Cunningham, The impact of systemic infection on the progression of neurodegenerative disease. Nat Rev Neurosci, 2003. 4(2): p. 103-12.

95. Holmes, C., et al., Systemic infection, interleukin 1beta, and cognitive decline in Alzheimer's disease. J Neurol Neurosurg Psychiatry, 2003. 74(6): p. 788-9.

96. Berger, J.R. and G. Arendt, HIV dementia: the role of the basal ganglia and dopaminergic systems. J Psychopharmacol, 2000. 14(3): p. 214-21.

97. Nath, A., et al., Neurotoxicity and dysfunction of dopaminergic systems associated with AIDS dementia. J Psychopharmacol, 2000. 14(3): p. 222-7.

98. Kruman, II, A. Nath, and M.P. Mattson, HIV-1 protein Tat induces apoptosis of hippocampal neurons by a mechanism involving caspase activation, calcium overload, and oxidative stress. Exp Neurol, 1998. 154(2): p. 276-88.

99. Kolson, D.L. and F. Gonzalez-Scarano, HIV and HIV dementia. J Clin Invest, 2000. 106(1): p. 11-3.

100. McArthur, J.C., et al., Human immunodeficiency virus-associated dementia: an evolving disease. J Neurovirol, 2003. 9(2): p. 205-21.

101. Wesselingh, S.L., et al., Intracerebral cytokine messenger RNA expression in acquired immunodeficiency syndrome dementia. Ann Neurol, 1993. 33(6): p. 576-82.

102. Epstein, L.G. and H.E. Gendelman, Human immunodeficiency virus type 1 infection of the nervous system: pathogenetic mechanisms. Ann Neurol, 1993. 33(5): p. 429-36.

103. Pulliam, L., et al., Human immunodeficiency virus-infected macrophages produce soluble factors that cause histological and neurochemical alterations in cultured human brains. J Clin Invest, 1991. 87(2): p. 503-12.

104. Portegies, P. and E.S. Cohen, [Possible etiological role retroviruses and enteroviruses in the development of amyotrophic lateral sclerosis]. Ned Tijdschr Geneeskd, 2002. 146(30): p. 1398-400.

105. Dobson, C.B. and R.F. Itzhaki, Herpes simplex virus type 1 and Alzheimer's disease. Neurobiol Aging, 1999. 20(4): p. 457-65.

106. Itzhaki, R.F., et al., Herpes simplex virus type 1 in brain and risk of Alzheimer's disease. Lancet, 1997. 349(9047): p. 241-4.

107. Burgos, J.S., et al., ApoE4 is more efficient than E3 in brain access by herpes simplex virus type 1. Neuroreport, 2003. 14(14): p. 1825-7.

108. Itzhaki, R.F., C.B. Dobson, and M.A. Wozniak, Herpes simplex virus type 1 and Alzheimer's disease. Ann Neurol, 2004. 55(2): p. 299-300; author reply 300-1.

109. Valyi-Nagy, T., et al., Herpes simplex virus type 1 latency in the murine nervous system is associated with oxidative damage to neurons. Virology, 2000. 278(2): p. 309-21.

110. Jamieson, G.A., et al., Herpes simplex virus type 1 DNA is present in specific regions of brain from aged people with and without senile dementia of the Alzheimer type. J Pathol, 1992. 167(4): p. 365-8.

111. Lin, W.R., et al., Herpesviruses in brain and Alzheimer's disease. J Pathol, 2002. 197(3): p. 395-402.

112. Cinque, P., R. Marenzi, and D. Ceresa, Cytomegalovirus infections of the nervous system. Intervirology, 1997. 40(2-3): p. 85-97.

113. van Den Pol, A.N., et al., Cytomegalovirus cell tropism, replication, and gene transfer in brain. J Neurosci, 1999. 19(24): p. 10948-65.

114. Pulliam, L., D. Moore, and D.C. West, Human cytomegalovirus induces IL-6 and TNF alpha from macrophages and microglial cells: possible role in neurotoxicity. J Neurovirol, 1995. 1(2): p. 219-27.

115. Lin, W.R., et al., Cytomegalovirus is present in a very high proportion of brains from vascular dementia patients. Neurobiol Dis, 2002. 9(1): p. 82-7. 
116. Charlett, A., et al., Parkinsonism: siblings share Helicobacter pylori seropositivity and facets of syndrome. Acta Neurol Scand, 1999. 99(1): p. 26-35.

117. Kountouras, J., et al., Relationship between Helicobacter pylori infection and Alzheimer disease. Neurology, 2006. 66(6): p. 938-40.

118. Miklossy, J., et al., Further ultrastructural evidence that spirochaetes may play a role in the aetiology of Alzheimer's disease. Neuroreport, 1994. 5(10): p. 1201-4.

119. Riviere, G.R., K.H. Riviere, and K.S. Smith, Molecular and immunological evidence of oral Treponema in the human brain and their association with Alzheimer's disease. Oral Microbiol Immunol, 2002. 17(2): p. 113-8.

120. McLaughlin, R., et al., Alzheimer's disease may not be a spirochetosis. Neuroreport, 1999. 10(7): p. 1489-91.

121. Gutacker, M., et al., Arguments against the involvement of Borrelia burgdorferi sensu lato in Alzheimer's disease. Res Microbiol, 1998. 149(1): p. 31-7.

122. Schrijver, I.A., et al., Bacterial peptidoglycan and immune reactivity in the central nervous system in multiple sclerosis. Brain, 2001. 124(Pt 8): p. 1544-54.

123. Visser, L., et al., Proinflammatory bacterial peptidoglycan as a cofactor for the development of central nervous system autoimmune disease. J Immunol, 2005. 174(2): p. 808-16.

124. Kuo, C.C., et al., Identification of a new group of Chlamydia psittaci strains called TWAR. J Clin Microbiol, 1986. 24(6): p. 1034-7.

125. Grayston, J.T., et al., A new Chlamydia psittaci strain, TWAR, isolated in acute respiratory tract infections. N Engl J Med, 1986. 315(3): p. 161-8.

126. Cook, P.J. and D. Honeybourne, Chlamydia pneumoniae. J Antimicrob Chemother, 1994. 34(6): p. 859-73.

127. Kuo, C.C., et al., Chlamydia pneumoniae (TWAR). Clin Microbiol Rev, 1995. 8(4): p. 451-61.

128. Aldous, M.B., et al., Seroepidemiology of Chlamydia pneumoniae TWAR infection in Seattle families, 1966-1979. J Infect Dis, 1992. 166(3): p. 646-9.

129. Theunissen, H.J., et al., Influence of temperature and relative humidity on the survival of Chlamydia pneumoniae in aerosols. Appl Environ Microbiol, 1993. 59(8): p. 2589-93.

130. Gaydos, C.A., et al., Replication of Chlamydia pneumoniae in vitro in human macrophages, endothelial cells, and aortic artery smooth muscle cells. Infect Immun, 1996. 64(5): p. 161420.

131. Su, H., et al., Chlamydia trachomatis-host cell interactions: role of the chlamydial major outer membrane protein as an adhesin. Infect Immun, 1990. 58(4): p. 1017-25.

132. Beatty, W.L., R.P. Morrison, and G.I. Byrne, Persistent chlamydiae: from cell culture to a paradigm for chlamydial pathogenesis. Microbiol Rev, 1994. 58(4): p. 686-99.

133. Wolf, K., E. Fischer, and T. Hackstadt, Ultrastructural analysis of developmental events in Chlamydia pneumoniae-infected cells. Infect Immun, 2000. 68(4): p. 2379-85.

134. Gieffers, J., et al., Chlamydia pneumoniae infection in circulating human monocytes is refractory to antibiotic treatment. Circulation, 2001. 103(3): p. 351-6.

135. Haranaga, S., et al., Chlamydia pneumoniae infection of alveolar macrophages: a model. J Infect Dis, 2003. 187(7): p. 1107-15.

136. Airenne, S., et al., Chlamydia pneumoniae inhibits apoptosis in human epithelial and monocyte cell lines. Scand J Immunol, 2002. 55(4): p. 390-8.

137. Geng, Y., et al., Chlamydia pneumoniae inhibits apoptosis in human peripheral blood mononuclear cells through induction of IL-10. J Immunol, 2000. 164(10): p. 5522-9.

138. Normann, E., et al., Chlamydia pneumoniae in children with acute respiratory tract infections. Acta Paediatr, 1998. 87(1): p. 23-7.

139. Falck, G., J. Gnarpe, and H. Gnarpe, Prevalence of Chlamydia pneumoniae in healthy children and in children with respiratory tract infections. Pediatr Infect Dis J, 1997. 16(6): p. 549-54. 


\section{CHAPTER 1}

140. Grayston, J.T., et al., A new respiratory tract pathogen: Chlamydia pneumoniae strain TWAR. J Infect Dis, 1990. 161(4): p. 618-25.

141. Grayston, J.T., et al., Evidence that Chlamydia pneumoniae causes pneumonia and bronchitis. J Infect Dis, 1993. 168(5): p. 1231-5.

142. Kauppinen, M. and P. Saikku, Pneumonia due to Chlamydia pneumoniae: prevalence, clinical features, diagnosis, and treatment. Clin Infect Dis, 1995. 21 Suppl 3: p. S244-52.

143. Cosentini, R., et al., Severe community-acquired pneumonia: a possible role for Chlamydia pneumoniae. Respiration, 1996. 63(2): p. 61-5.

144. von Hertzen, L., et al., Measurement of sputum antibodies in the diagnosis of acute and chronic respiratory infections associated with Chlamydia pneumoniae. Clin Diagn Lab Immunol, 1995. 2(4): p. 454-7.

145. Verkooyen, R.P., et al., Diagnosis of Chlamydia pneumoniae infection in patients with chronic obstructive pulmonary disease by micro-immunofluorescence and ELISA. J Med Microbiol, 1997. 46(11): p. 959-64.

146. Storgaard, M., et al., Chlamydia pneumoniae in children with otitis media. Clin Infect Dis, 1997. 25(5): p. 1090-3.

147. Falck, G., et al., Chlamydia pneumoniae and chronic pharyngitis. Scand J Infect Dis, 1995. 27(2): p. 179-82.

148. Weinberger, M., Respiratory infections and asthma: current treatment strategies. Drug Discov Today, 2004. 9(19): p. 831-7.

149. Hahn, D.L., T. Anttila, and P. Saikku, Association of Chlamydia pneumoniae IgA antibodies with recently symptomatic asthma. Epidemiol Infect, 1996. 117(3): p. 513-7.

150. Cunningham, A.F., et al., Chronic Chlamydia pneumoniae infection and asthma exacerbations in children. Eur Respir J, 1998. 11(2): p. 345-9.

151. Saikku, P., et al., Serological evidence of an association of a novel Chlamydia, TWAR, with chronic coronary heart disease and acute myocardial infarction. Lancet, 1988. 2(8618): p. 983-6.

152. Tong, C.Y., et al., Chlamydia pneumoniae myocarditis. Lancet, 1995. 346(8976): p. 710-1.

153. Ljungstrom, L., et al., Reinfection with Chlamydia pneumoniae may induce isolated and systemic vasculitis in small and large vessels. Scand J Infect Dis Suppl, 1997. 104: p. 37-40.

154. Wesslen, L., et al., An increase in sudden unexpected cardiac deaths among young Swedish orienteers during 1979-1992. Eur Heart J, 1996. 17(6): p. 902-10.

155. Braun, J., et al., Chlamydia pneumoniae--a new causative agent of reactive arthritis and undifferentiated oligoarthritis. Ann Rheum Dis, 1994. 53(2): p. 100-5.

156. Mendall, M.A., et al., Chlamydia pneumoniae: risk factors for seropositivity and association with coronary heart disease. J Infect, 1995. 30(2): p. 121-8.

157. Thom, D.H., et al., Association of prior infection with Chlamydia pneumoniae and angiographically demonstrated coronary artery disease. Jama, 1992. 268(1): p. 68-72.

158. Danesh, J., et al., Chlamydia pneumoniae IgG titres and coronary heart disease: prospective study and meta-analysis. Bmj, 2000. 321(7255): p. 208-13.

159. Grayston, J.T., Does Chlamydia pneumoniae cause atherosclerosis? Arch Surg, 1999. 134(9): p. 930-4.

160. Kuo, C.C. and L.A. Campbell, Chlamydial infections of the cardiovascular system. Front Biosci, 2003. 8: p. e36-43.

161. Campbell, L.A., C.C. Kuo, and J.T. Grayston, Chlamydia pneumoniae and cardiovascular disease. Emerg Infect Dis, 1998. 4(4): p. 571-9.

162. Kuo, C.C., et al., Chlamydia pneumoniae (TWAR) in coronary arteries of young adults (15-34 years old). Proc Natl Acad Sci U S A, 1995. 92(15): p. 6911-4.

163. Ong, G., et al., Detection and widespread distribution of Chlamydia pneumoniae in the vascular system and its possible implications. J Clin Pathol, 1996. 49(2): p. 102-6. 
164. Kalayoglu, M.V. and G.I. Byrne, A Chlamydia pneumoniae component that induces macrophage foam cell formation is chlamydial lipopolysaccharide. Infect Immun, 1998. 66(11): p. 5067-72.

165. Ezzahiri, R., et al., Chlamydia pneumoniae infection induces an unstable atherosclerotic plaque phenotype in LDL-receptor, ApoE double knockout mice. Eur J Vasc Endovasc Surg, 2003. 26(1): p. 88-95.

166. de Kruif, M.D., et al., Chlamydia pneumoniae infections in mouse models: relevance for atherosclerosis research. Cardiovasc Res, 2005. 65(2): p. 317-27.

167. Moazed, T.C., et al., Chlamydia pneumoniae infection accelerates the progression of atherosclerosis in apolipoprotein E-deficient mice. J Infect Dis, 1999. 180(1): p. 238-41.

168. Caligiuri, G., et al., Chlamydia pneumoniae infection does not induce or modify atherosclerosis in mice. Circulation, 2001. 103(23): p. 2834-8.

169. Aalto-Setala, K., et al., Chlamydia pneumoniae does not increase atherosclerosis in the aortic root of apolipoprotein E-deficient mice. Arterioscler Thromb Vasc Biol, 2001. 21(4): p. 578-84.

170. Kaukoranta-Tolvanen , S.S., et al., Growth of Chlamydia pneumoniae in cultured human peripheral blood mononuclear cells and induction of a cytokine response. Microb Pathog, 1996. 21(3): p. 215-21.

171. Quinn, T.C. and C.A. Gaydos, In vitro infection and pathogenesis of Chlamydia pneumoniae in endovascular cells. Am Heart J, 1999. 138(5 Pt 2): p. S507-11.

172. Redecke, V., et al., Interaction of Chlamydia pneumoniae and human alveolar macrophages: infection and inflammatory response. Am J Respir Cell Mol Biol, 1998. 19(5): p. 721-7.

173. Netea, M.G., et al., Acellular components of Chlamydia pneumoniae stimulate cytokine production in human blood mononuclear cells. Eur J Immunol, 2000. 30(2): p. 541-9.

174. Heinemann, M., et al., Growth of Chlamydia pneumoniae induces cytokine production and expression of CD14 in a human monocytic cell line. Infect Immun, 1996. 64(11): p. 4872-5.

175. Summersgill, J.T., et al., Interactions of Chlamydia pneumoniae with human endothelial cells. $J$ Infect Dis, 2000. 181 Suppl 3: p. S479-82.

176. Miller, S.A., et al., Chlamydia pneumoniae activates nuclear factor kappaB and activator protein 1 in human vascular smooth muscle and induces cellular proliferation. J Surg Res, 2000. 90(1): p. 76-81.

177. Naiki, Y., et al., MyD88 is pivotal for the early inflammatory response and subsequent bacterial clearance and survival in a mouse model of Chlamydia pneumoniae pneumonia. $J$ Biol Chem, 2005. 280(32): p. 29242-9.

178. Stratton, C.W. and S. Sriram, Association of Chlamydia pneumoniae with central nervous system disease. Microbes Infect, 2003. 5(13): p. 1249-53.

179. Yucesan, C. and S. Sriram, Chlamydia pneumoniae infection of the central nervous system. Curr Opin Neurol, 2001. 14(3): p. 355-9.

180. Airas, L., et al., Encephalitis associated with Chlamydia pneumoniae. Neurology, 2001. 56(12): p. 1778-9.

181. Korman, T.M., J.D. Turnidge, and M.L. Grayson, Neurological complications of chlamydial infections: case report and review. Clin Infect Dis, 1997. 25(4): p. 847-51.

182. Guglielminotti, J., et al., Severe meningoencephalitis: an unusual manifestation of Chlamydia pneumoniae infection. Clin Infect Dis, 2000. 30(1): p. 209-10.

183. Cook, P.J., et al., Chlamydia pneumoniae antibody titers are significantly associated with acute stroke and transient cerebral ischemia: the West Birmingham Stroke Project. Stroke, 1998. 29(2): p. 404-10.

184. Socan, M., B. Beovic, and D. Kese, Chlamydia pneumonia and meningoencephalitis. N Engl J Med, 1994. 331(6): p. 406.

185. Contini, C., et al., Molecular identification and antibody testing of Chlamydophila pneumoniae in a subgroup of patients with HIV-associated dementia complex. Preliminary results. J Neuroimmunol, 2003. 136(1-2): p. 172-7. 


\section{CHAPTER 1}

186. Wozniak, M.A., et al., Absence of Chlamydia pneumoniae in brain of vascular dementia patients. Neurobiol Aging, 2003. 24(6): p. 761-5.

187. Yamamoto, H., et al., High prevalence of Chlamydia pneumoniae antibodies and increased high-sensitive C-reactive protein in patients with vascular dementia. J Am Geriatr Soc, 2005. 53(4): p. 583-9.

188. Sriram, S., W. Mitchell, and C. Stratton, Multiple sclerosis associated with Chlamydia pneumoniae infection of the CNS. Neurology, 1998. 50(2): p. 571-2.

189. Sriram, S., et al., Chlamydia pneumoniae infection of the central nervous system in multiple sclerosis. Ann Neurol, 1999. 46(1): p. 6-14.

190. Layh-Schmitt, G., et al., Evidence for infection with Chlamydia pneumoniae in a subgroup of patients with multiple sclerosis. Ann Neurol, 2000. 47(5): p. 652-5.

191. Boman, J., et al., Failure to detect Chlamydia pneumoniae in the central nervous system of patients with MS. Neurology, 2000. 54(1): p. 265.

192. Hammerschlag, M.R., et al., Is Chlamydia pneumoniae present in brain lesions of patients with multiple sclerosis? J Clin Microbiol, 2000. 38(11): p. 4274-6.

193. Munger, K.L., et al., A prospective study of Chlamydia pneumoniae infection and risk of MS in two US cohorts. Neurology, 2004. 62(10): p. 1799-803.

194. Chapman, M.D., et al., Lack of Serum Oligoclonal Antibody Responses to Chlamydophila pneumoniae in Multiple Sclerosis. Eur Neurol, 2005. 53(2): p. 81-83.

195. Pucci, E., et al., Lack of Chlamydia infection of the central nervous system in multiple sclerosis. Ann Neurol, 2000. 48(3): p. 399-400.

196. Ke, Z., et al., Lack of detectable Chlamydia pneumoniae in brain lesions of patients with multiple sclerosis. Ann Neurol, 2000. 48(3): p. 400.

197. Balin, B.J., et al., Identification and localization of Chlamydia pneumoniae in the Alzheimer's brain. Med Microbiol Immunol (Berl), 1998. 187(1): p. 23-42.

198. Gieffers, J., et al., Failure to detect Chlamydia pneumoniae in brain sections of Alzheimer's disease patients. J Clin Microbiol, 2000. 38(2): p. 881-2.

199. Nochlin, D., et al., Failure to detect Chlamydia pneumoniae in brain tissues of Alzheimer's disease. Neurology, 1999. 53(8): p. 1888.

200. Ring, R.H. and J.M. Lyons, Failure to detect Chlamydia pneumoniae in the late-onset Alzheimer's brain. J Clin Microbiol, 2000. 38(7): p. 2591-4.

201. Taylor, G.S., et al., Failure to correlate C. pneumoniae with late onset Alzheimer's disease. Neurology, 2002. 59(1): p. 142-3.

202. Gerard, H.C., et al., Frequency of apolipoprotein $E$ (APOE) allele types in patients with Chlamydia-associated arthritis and other arthritides. Microb Pathog, 1999. 26(1): p. 35-43.

203. Gerard, H.C., et al., The load of Chlamydia pneumoniae in the Alzheimer's brain varies with APOE genotype. Microb Pathog, 2005. 39(1-2): p. 19-26.

204. Little, C.S., et al., Chlamydia pneumoniae induces Alzheimer-like amyloid plaques in brains of BALB/c mice. Neurobiol Aging, 2004. 25(4): p. 419-29.

205. Robertson, M., Is Chlamydia associated with Alzheimer's? Drug Discov Today, 2004. 9(11): $p$. 469. 




\section{Chapt er}

\section{Chlamydia pneumoniae infection of brain cells: an in vitro study}

Ellen Boelen, Harry WM Steinbusch, André JAM van der Ven, Gert Grauls, Cathrien A Bruggeman, Frank RM Stassen 


\section{Abstract}

Inspired by the suggested associations between neurological diseases and infections, we determined the susceptibility of brain cells to Chlamydia pneumoniae (Cpn). Murine astrocyte (C8D1A), neuronal (NB41A3) and microglial (BV-2) cell lines were inoculated with Cpn. Infection was established by immunofluorescence and real-time PCR at various time points. Productive infection was assessed by transferring medium of infected cells to a detection layer. Finally, apoptosis and necrosis post infection was determined. Our data demonstrate that the neuronal cell line is highly sensitive to Cpn, produces viable progeny and is prone to die after infection by necrosis. Cpn tropism was similar in an astrocyte cell line, apart from the higher production of extracellular Cpn and less pronounced necrosis. In contrast, the microglial cell line is highly resistant to $\mathrm{Cpn}$ as the immunohistochemical signs almost completely disappeared after 24 hours. Nevertheless, significant Cpn DNA amounts could be detected, suggesting $\mathrm{Cpn}$ persistence. Low viable progeny and hardly any necrotic microglial cells were observed. Further research is warranted to determine whether these cell types show the same sensitivity to Cpn in an in vivo setting. 


\section{Introduction}

Previous data provided a strong link between infectious agents, like human immunodeficiency virus (HIV), herpes simplex virus (HSV) or cytomegalovirus $(\mathrm{CMV})$ and diseases of the central nervous system $(\mathrm{CNS})^{1-5}$. More recent data then suggested that Chlamydia pneumoniae ( $\mathrm{Cpn}$ ) should be added to the candidate list of microbes responsible for several of these diseases ${ }^{6}$. Cpn, an obligate intracellular bacterium, is a widespread respiratory pathogen able to infect a diversity of eukaryotic cell types ${ }^{7}$. Cpn infections mainly result in acute respiratory tract infections, including pneumonia, sinusitis, bronchitis and pharyngitis ${ }^{8,9}$. Furthermore, $\mathrm{Cpn}$ has been associated with various chronic diseases like asthma ${ }^{10}$, atherosclerosis ${ }^{11,12}$ and rheumatoid arthritis. Interestingly, previous studies suggested a potential link between $\mathrm{Cpn}$ and several disorders of the CNS as well ${ }^{13}$.

One of the neurological diseases associated with $\mathrm{Cpn}$ is Alzheimer's disease (AD). When post-mortem brain samples were analysed, Cpn was found in 17 out of 19 late-onset AD patients using PCR, immunohistochemistry and electron microscopy, while Cpn could be detected in only 1 out of 19 controls $^{14}$. Similarly, Cpn could be detected in other areas of neuropathology in the brain ${ }^{15}$. Additional evidence for a role of $\mathrm{Cpn}$ in neurological disorders comes from animal experiments as BALB/c mice develop AD-like pathology after infection with $\mathrm{Cpn}^{16}$. However, others failed to identify an association between $\mathrm{Cpn}$ and $A D^{17-21}$ and discrepancies exist regarding the presence of $C p n$ inside the brain in neurological diseases. Nonetheless, it is well recognised that $\mathrm{Cpn}$ can traffic towards the brain and cause a local inflammatory reaction ${ }^{6}$. Whether this is induced by direct infection of brain cells or rather by an indirect response is still ambiguous. Therefore, it is important to investigate the susceptibility of specific brain cells to Cpn infection. For this purpose, three brain cell lines were selected: neurons (NB41A3), microglial cells (BV-2) and astrocytes (C8D1A). Neurons are particularly involved in intracellular communication, while neuronal death is often connected with a variety of brain disorders like $A D$ and Parkinson's disease. Next, astrocytes play a role in maintaining an appropriate chemical content of the extracellular space for neuronal signalling. Finally, microglial cells have been termed the tissue macrophages of the central nervous system; they proliferate following brain injury and presumably help repair neural damage ${ }^{22}$.

In this study, it was our aim to examine the susceptibility of these murine brain cells to Cpn infection by immunohistochemical techniques and real-time polymerase chain reaction (real-time PCR). Furthermore, a productive infection 
was assessed by using a susceptible cell line (epithelial cell line, Hep2). Finally, we determined the occurrence of cell death and its nature - apoptotic vs. necrotic - in these cell lines following Cpn infection.

\section{Material and methods}

\subsection{Chlamydia pneumoniae (Cpn)}

The Cpn strain, TWAR 2043, was obtained from the American Type Culture Collection (ATCC VR-1355) and continuously propagated on Hep2 cells as described previously ${ }^{23}$. Bacterial titres, expressed as the number of inclusion forming units per millilitre (IFU/ml), were determined by titration in Hep2 cells as described by Ezzahiri ${ }^{11}$ and stained with a Chlamydia LPS-specific antibody succeeded by a FITC-conjugated secondary antibody (RR402, DAKO, Glostrup, Denmark).

\subsection{Cell cultures}

Murine microglial cells (MMC - BV-2) ${ }^{24}$ were kindly provided by the laboratory of dr. M. Leinonen (Oulu, Finland) and grown in Dulbecco's Modified Eagle's medium (DMEM) (GIBCO, Gran Island, NY, USA) supplemented with $10 \%$ foetal bovine serum, $5 \mathrm{M}$ Hepes and $2 \mathrm{mM}$ L-glutamine.

Murine Astrocyte type I cells (C8D1A; ATCC CRL-2541) (Rockville, MD, USA) were maintained in DMEM (GIBCO, Gran Island, NY, USA). Culture medium was supplemented with $4 \mathrm{mM} \mathrm{L-glutamine}$ and $10 \%$ horse serum.

Murine Neuroblasts (NB41A3; ATCC CCL-147) were cultured in Kaighn's modification of Ham's F12 medium (GIBCO, Gran Island, NY, USA) supplemented with $15 \%$ horse serum and $2.5 \%$ foetal bovine serum.

Human Epithelial cells (Hep2; ATCC CCL-23) were maintained in Eagle's Minimal Essential Medium (EMEM) (Bambrex BioScience, Verviers, Belgium) supplemented with $2 \mathrm{mM}$ L-glutamine, $10 \%$ foetal calf serum and $0.1 \mathrm{mM}$ nonessential amino acids.

For infection, Cpn was diluted in the original culture medium but serum concentrations were reduced by $50 \%$ and the media were supplemented with cycloheximide, an inhibitor of eukaryotic protein synthesis which has been described as enhancing infectivity ${ }^{25}$. Diverse concentrations of cycloheximide were used in the different cell cultures (MMC, $0.03 \mu \mathrm{g} / \mathrm{ml}$; C8D1A, $0.5 \mu \mathrm{g} / \mathrm{ml}$; NB41A3, $0.5 \mu \mathrm{g} / \mathrm{ml}$; Hep2, 0.5. $\mu \mathrm{g} / \mathrm{ml}$ ). Previous pilot experiments showed that 
with these concentrations, optimal infection efficiency and growth of chlamydia could be obtained.

All cells were cultured in $75-\mathrm{cm}^{2}$ flasks at $37^{\circ} \mathrm{C}$ with $5 \% \mathrm{CO}_{2}$ and saturated humidity.

\subsection{Infection protocol}

Cells were seeded in 24-well tissue culture plates (Corning Incorporated, NY, USA) to achieve a cell monolayer within $24 \mathrm{hr}$. MMC and epithelial cells were seeded at $10^{5}$ cells per well, while astrocytes and neuroblasts were seeded at a density of $5 \times 10^{5}$ cells/well. When confluency was reached, cells were infected by replacing the original culture medium by a culture medium containing $\mathrm{Cpn}$ at a multiplicity of infection (MOI) of 5 . Cells were then incubated for $1 \mathrm{hr}$ at $20^{\circ} \mathrm{C}$ and $4500 \mathrm{rpm}$. Subsequently, the inoculum was removed, the cells were washed three times, the appropriate infection medium without $\mathrm{Cpn}$ was reapplied and cells were cultivated for different time points at $37^{\circ} \mathrm{C}$. Controls (mock infected), consisting of cells incubated with sucrose-phosphate-glucose solution (SPG, solution for storage of $\mathrm{Cpn}$ ) were also included and processed in the same manner as Cpn infected cells.

\subsection{Presence of Cpn in brain cells}

\section{Immunofluorescence}

At various time intervals post infection (p.i.) (1 hour, 3, 6, 12, 24, 48, 72 and 168 hours $(=1$ week $)$ ), monolayers were rinsed with phosphate-buffered saline (PBS) and fixed with methanol. Subsequently, immunohistochemistry was performed at $37^{\circ} \mathrm{C}$ and each incubation step was followed by three PBS wash steps. After blocking with PBS $+0.05 \%$ Bovine Serum Albumin (BSA), fixed cells were incubated successively with a Chlamydia specific monoclonal antibody (1/50, RR402, DAKO, Glostrup, Denmark) and with a secondary Alexa Fluor 488 donkey anti-mouse IgG antibody (1/100, Molecular Probes, Oregon, USA). The presence of $\mathrm{Cpn}$ antigens was determined with an inverted fluorescent microscope (magnification of 400x) at different time points post infection in all cell lines. All experiments were performed in triplicate.

\section{$\underline{\text { Real-time PCR }}$}

DNA was isolated from cell pellets using methods previously described ${ }^{26}$. Lysis buffer was added to the frozen pellets together with $50 \mathrm{ng} / \mathrm{ml}$ proteinase $\mathrm{K}$ 
(Roche, Indianapolis, USA) and incubated for $60 \mathrm{~min}$ at $56^{\circ} \mathrm{C}$, while shaking. Subsequently, phenol:chloroform (1:1) was used to extract DNA, followed by precipitation with ethanol. DNA content of each sample was measured using The NanoDrop ${ }^{\circledR}$ ND-1000, a full-spectrum $(220-750 \mathrm{~nm})$ spectrophotometer. Next, real-time PCR (ABI Prism 7000, Applied Biosystems, Foster City, USA)

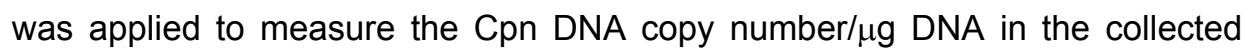
cells. The sequences of the primers and probes were based on a variable domain of the ompA gene, VD4, as described before ${ }^{27}$. PCR was performed with a total volume of $25 \mu \mathrm{l}$; consisting of $12.5 \mu \mathrm{l}$ TaqMan Universal Master Mix (Applied Biosystems, 2x concentrated), $300 \mathrm{nM}$ forward primer (5'TCCGCATTGCTCAGCC3'), $900 \mathrm{nM}$ reverse primer (5'AAACAATTTGCATGAAGTCTGAGAA3'), $200 \mathrm{mM}$ probe (5'-FAMTAAACTTAACTGCATGGAACCCTTCTTTACTAGG3'-TAMRA), $3.5 \mu \mathrm{l}$ NASBA water and $1 \mu \mathrm{g}$ DNA. Serial dilutions of the plasmid, containing the VD4 part of the Cpn ompA gene (GenBank, accession number AY426607) and a negative control, containing reagents only were applied to create the standard curve. Concentrations of the plasmid dilutions were: $10^{6}, 10^{5}, 10^{4}, 10^{3}, 10^{2}$ copies of ompA plasmid. For the quantification of Cpn DNA in the samples, ABI Prism 7000 SDS software was applied. The number of Cpn DNA copies in each sample was determined twice and the average number was used. Thermal cycling started with UNG activation for $2 \mathrm{~min}$ at $50^{\circ} \mathrm{C}$, followed by activation of Taq during $10 \mathrm{~min}$ at $95^{\circ} \mathrm{C}$ and 42 cycles of amplification were performed consisting of 15 seconds at $95^{\circ} \mathrm{C}$ and $1 \mathrm{~min}$ at $60^{\circ} \mathrm{C}$.

\subsection{Assessment of productive infection}

When Cpn is able to replicate in cells, infectious elementary bodies will be present in the culture supernatant (extracellulary). Therefore, medium was collected from infected cells at 1 week after infection and transferred to Hep2 cells (susceptible cell line). Furthermore, intracellular infectious Cpn was determined. For that reason, infected cells were homogenized, centrifuged at $1200 \mathrm{rpm}$ and the supernatant was transferred onto Hep2 cells. The presence of $\mathrm{Cpn}$ antigens in these cells, $72 \mathrm{hr}$ after transfer, were determined by indirect immunofluorescence, as described above. Cells positive for Cpn and total number of cells were counted in 5 fields (magnification: 200x) per well and the average percentage positive cells was calculated for two wells. 


\subsection{Apoptosis/necrosis}

To examine whether Cpn infection results in apoptotic or necrotic cell death, the following experiment was performed. At 1 hour, 3, 6, 12, 24, 48, 72 and 168 hours after inoculation, $\mathrm{Cpn}$ and mock infected cells were incubated with Hoechst 33258 (HO) (Sigma, St. Louis, USA) and propidium iodide (PI) (Sigma, St. Louis, USA), as described in a previous study ${ }^{28}$. HO stock solution $(1 \mathrm{mg} / \mathrm{ml})$ is added directly to the culture medium with a final concentration of $1 \mu \mathrm{g} / \mathrm{mL}$ for an incubation period of $30 \mathrm{~min}$ at room temperature. After incubation with $\mathrm{HO}$, without any washing procedures, cells are counter-stained with $\mathrm{PI}$ in a final concentration of $5 \mu \mathrm{g} / \mathrm{mL}$ (stock solution $0.5 \mathrm{mg} / \mathrm{ml}$ ) and cells are kept in the dark at room temperature during $5 \mathrm{~min}$. Then, cells were examined on an inverted fluorescence microscope, without any additional wash step. Viable, apoptotic and necrotic cells were counted in 10 fields (magnification: 400x) per well and the average percentage apoptotic/necrotic cells was determined for three wells at the different time points, in both infected and non-infected cells. The experiment was performed in duplicate. The $\mathrm{HO}$ dye freely enters living cells and stains the nuclei of these cells. Apoptotic cells, however, can be distinguished from the rest by chromatin condensation and nuclear fragmentation. On the other hand, PI enters only cells with damaged cell membranes and stains therefore only necrotic and late apoptotic cells ${ }^{28}$.

\subsection{Statistical analysis}

SPSS 11.0 for Windows was applied for the statistical analysis. The difference in Cpn DNA copies between the different cell lines at a certain time point was analysed using the Mann-Whitney $U$-test. In every cell line, the change in number of copies over time was determined by the Kruskal-Wallis $\mathrm{H}$ test. To determine the differences in the percentage necrotic cells over time between Cpn and mock infected cells, the Univariate Analysis of Variance was performed. A p-value of $<0.05$ was considered significant.

\section{Results}

Thus, a reference epithelial cell layer and three brain cell lines were infected with Chlamydia pneumoniae (MOI 5). The presence of Cpn antigens and DNA in these cell lines was determined, using immunofluorescent techniques and real-time PCR respectively. A productive Cpn infection was also analysed. Therefore, Cpn fluorescent signal was investigated in a "susceptible cell layer" after transferring medium of infected cells. Finally, a double-staining with 
Hoechst 33258 and propidium iodide revealed whether Cpn infection causes apoptosis or necrosis in the epithelial, astrocyte, microglial and neuronal cell line.

\subsection{Chlamydia pneumoniae infection}

\section{Immunofluorescence}

The microglial, neuronal and astrocyte cell line were infected with Cpn to determine their susceptibility to this pathogen. Cells were fixed at various time points p.i. and the presence of $\mathrm{Cpn}$ was demonstrated using immunofluorescent staining. An epithelial cell line (Hep2) was used as the "reference cell line".

\section{i) Hep2 cells}

When the Hep2 cell layer was inoculated with Cpn, variable sizes of the Cpn inclusion bodies were detected (Figure 1, A-E). At early time points post infection ( $1 \mathrm{hr}-6 \mathrm{hr}$ ), small inclusions were observed in the majority of the cells ( $\pm 60 \%$ of infected cells). These small omnipresent bodies represent the elementary bodies as described ${ }^{29}$. After $24 \mathrm{hr}$ of incubation, inclusion body size starts to increase with maximal sizes seen at later stages of the developmental cycle (48 hr - $72 \mathrm{hr}$ ), most likely denoting multiplying reticulate bodies accumulating inside the inclusion body. At $72 \mathrm{hr}$ p.i., a peak in the number of infected cells can be detected, as $\sim 75 \%$ of all cells show signs of infection. One week p.i., the Hep2 cells display a large variety in Cpn inclusion body sizes. At that stage, the signal seems to be diminished compared to $72 \mathrm{hr}$ p.i. but still a pronounced fluorescent signal is present in most of the infected Hep2 cells. In Figure 2, the estimated percentage of infected cells is displayed at different time points.

\section{ii) Murine brain cells}

In Figure 1, typical examples of immunofluorescent staining of various brain cell lines, infected with $\mathrm{Cpn}$ (astrocyte cell line: F-J, microglial cell line: K-O and neuronal cell line: $P-T$ ), are shown. In these cells, large inclusion bodies were detected at late stages p.i. (48 - $72 \mathrm{hr}$ ) compared with earlier time points (1 - 24 hr p.i.). At 1 week post infection, again a mixture of inclusion body sizes could be detected. Although no striking differences were found between the cell lines in the early hours p.i., infection profiles markedly diverged from 24 hours post infection (Figure 1+2). From this time point, fluorescent signal could be detected in less than $5 \%$ of all MMC, while $>60 \%$ of all neurons and astrocytes stained 
positive for $\mathrm{Cpn}$ antigens. These striking distinctions remained up to one week p.i. suggesting that $\mathrm{Cpn}$ replication takes place in the astrocyte and neuronal cell line at a comparable level as seen in Hep2 cells while Cpn positive signal was almost absent in MMC.
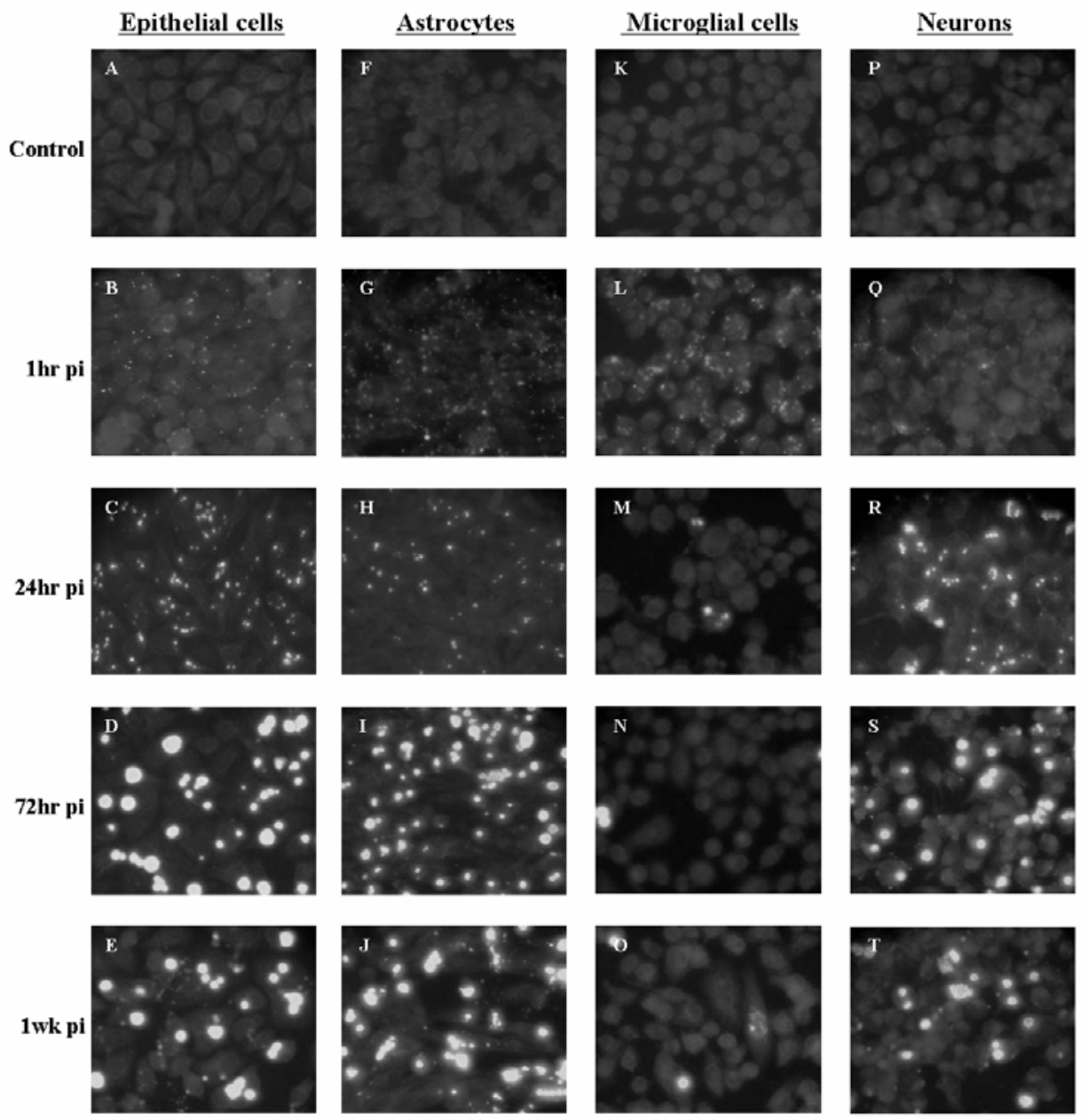

Figure 1. Immunofluorescent detection of Chlamydia pneumoniae (Cpn) antigens in microglial cells at 1, 6 (not shown), 24, 48 (not shown), $72 \mathrm{hr}$ and 1 week post infection (p.i.). Staining was performed with a primary antibody directed against the Cpn major membrane outer protein (MOMP) and a secondary Alexa Fluor 488 labelled antibody (green signal). Evan's blue (red signal) was applied for counterstaining. Original magnification, 400x. (See coloured illustration inserted at the back of this thesis). 


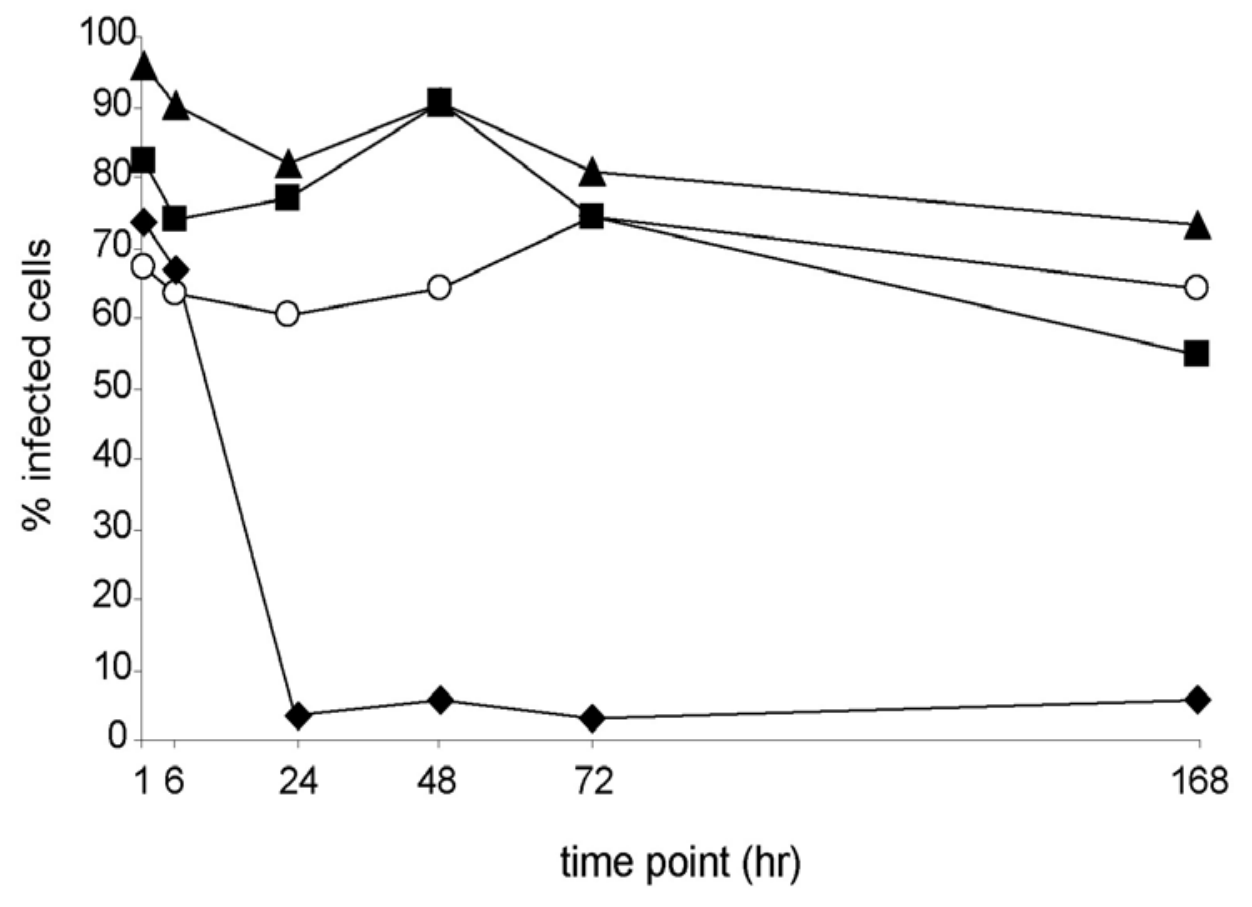

$\multimap-$ epithelial cells $\longrightarrow$ astrocytes $\longrightarrow$ microglial cells $\longrightarrow$ - neurons

Figure 2. Percentages infected microglial cells (MMC) at different time points post infection.

\section{$\underline{\text { Real-time PCR }}$}

Also, the presence of Cpn DNA was determined as an indication of the susceptibility of different cell lines to $\mathrm{Cpn}$. The number of Cpn DNA copies was determined by real-time PCR at various time points post infection. For each cell type, the number of copies per $\mu \mathrm{g}$ DNA is shown in Figure 3. In MMC, the number of Cpn genomic copies remained relatively constant over time with no significant differences between the time points. In the neuronal cell line, a similar copy number as in MMC was found during the first stages of the developmental cycle. However, starting at $24 \mathrm{hr}$ p.i., a significant increase in Cpn DNA copies was demonstrated when compared to MMC. A similar pattern as in neuronal cell line was detected in the astrocyte and epithelial cell line. In conclusion, the epithelial, astrocyte and neuronal cell line display a similar infection pattern with a 100-/1000-fold increase in the number of Cpn copies. In MMC, however, no significant changes in Cpn DNA were detected, suggesting no replication of $\mathrm{Cpn}$ in these cells. 


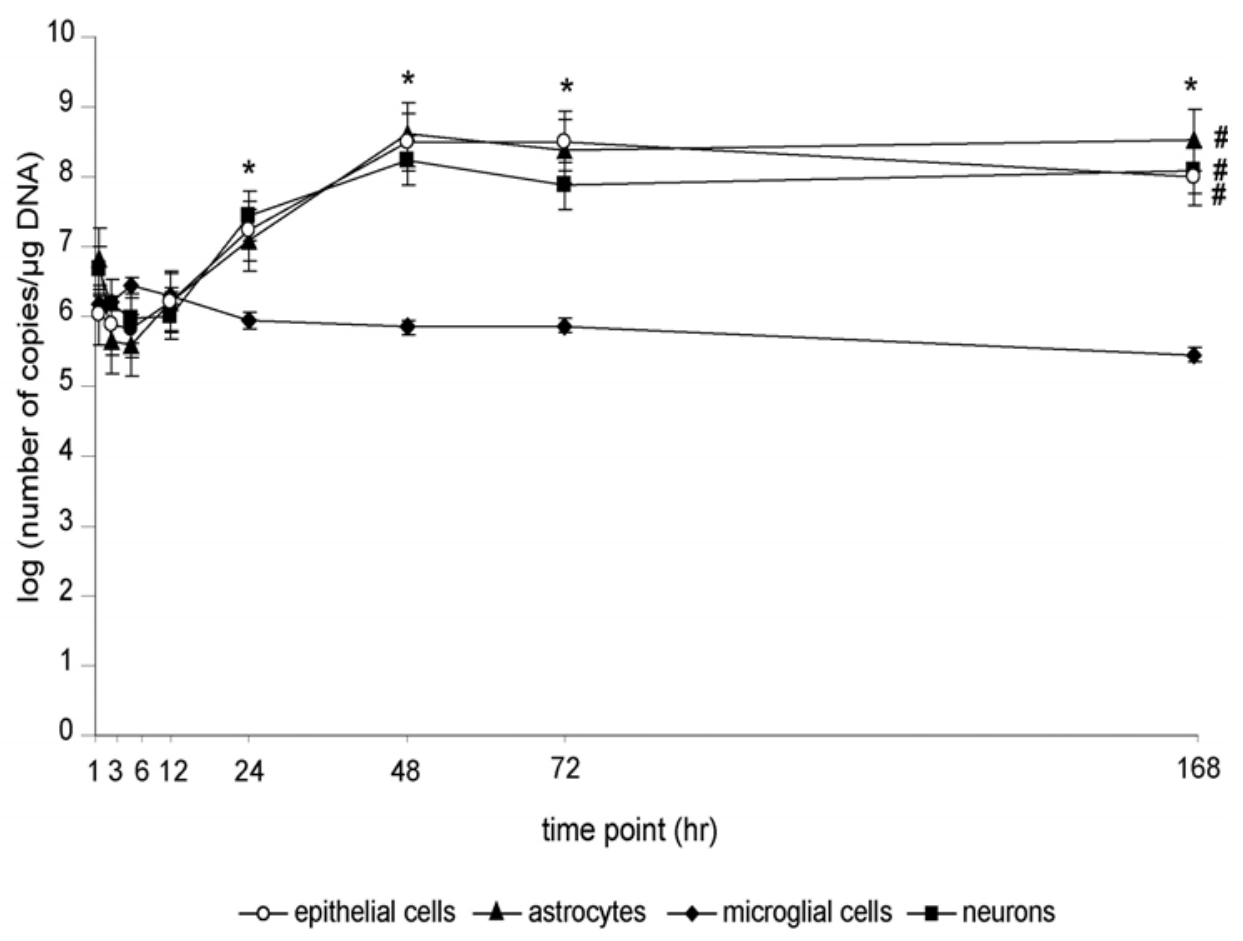

Figure 3. Presence of Cpn DNA in the infected microglial, neuronal, astrocyte and epithelial cell line, determined by real-time PCR. At different time points after inoculation the logarithm of the number of copies per $\mu \mathrm{g}$ DNA is displayed, the number of copies presented here are the mean values of an in triplicate performed experiment. * $p<0.05$ microglial cells vs. neurons, astrocytes and epithelial cells per time point. $\# p<0.05$ over time for the marked cell lines. Error bars, SE of the means.

\subsection{Assessment of productive infection}

Productive Cpn infection in the astrocyte, microglial and neuronal cell line was investigated at various time points. Hep2 cells were used as the reference cell line. In all cell lines, infectious progeny could be established at $72 \mathrm{hr}$ and 1 week p.i. since transfer of supernatant revealed positive staining in recipient Hep2 cells. The mean percentage of these infected epithelial cells was calculated (Figure 4). At 72 hours post infection, no significant differences were found in the various cell lines (data not shown), while at 1 week p.i., the production of infectious Cpn was significantly different between the four cell lines used. As shown in Figure 4, infectious progeny could be found in the astrocyte and neuronal cell line but a significant lower content was shown in the latter, while it was almost completely absent in the microglial cell line. These 
data suggest that large amounts of extracellular $\mathrm{Cpn}$ are produced in the epithelial and astrocyte cell line while low or no production occurred in the neuronal and microglial cell line.

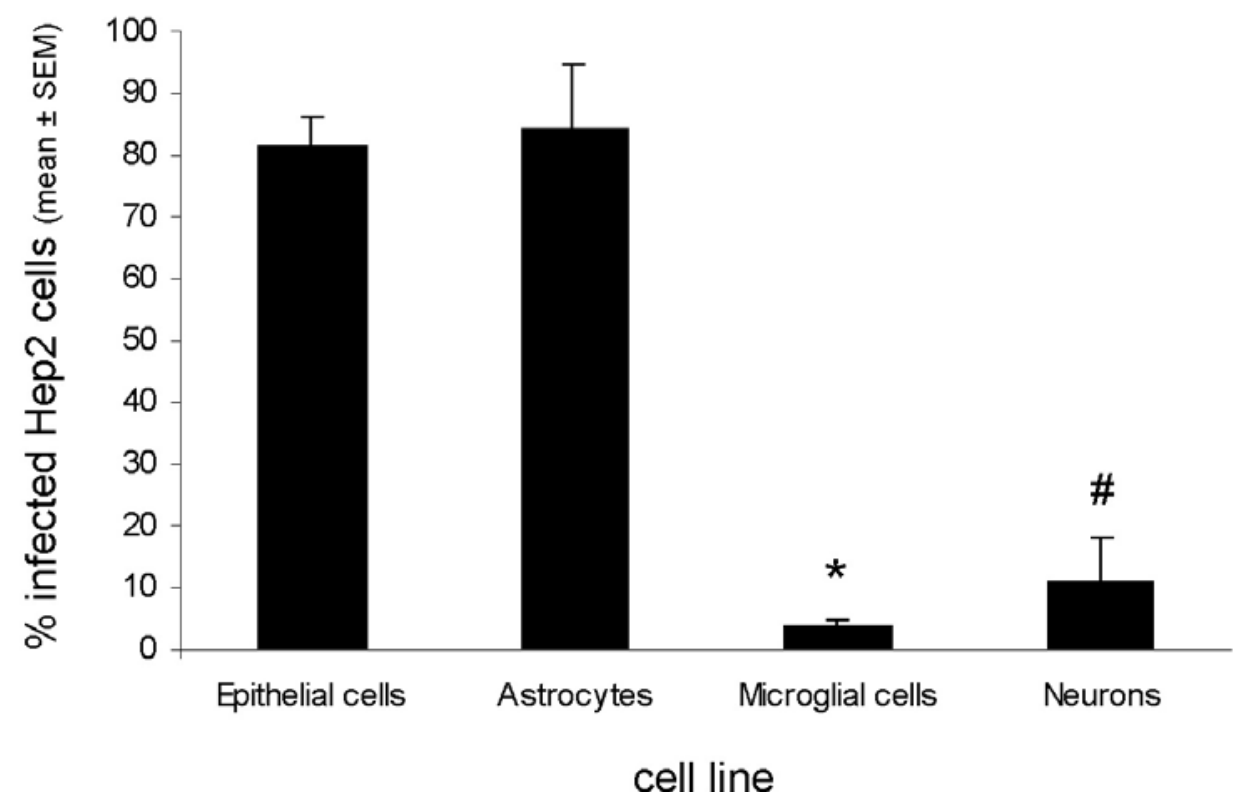

Figure 4. Infection of Hep2 cells inoculated with the supernatant of infected cells from the epithelial, astrocyte, microglial and neuronal cell line at 1 wk post infection. Positive immunofluorescent signal was detected and the percentage Cpn positive cells for two wells was calculated. The experiment was performed in duplicate. ${ }^{*} p<0.05$ vs. neurons, astrocytes and epithelial cells. $\# p<0.05$ vs. astrocytes and epithelial cells. Error bars, SE of the means.

\subsection{Apoptosis/necrosis}

We suggested that Cpn infection may result in degeneration of brain cell lines. To establish whether this is the result of either apoptotic or necrotic cell death, HO-PI double-staining was used. The dye PI stains only necrotic cells and under UV excitation these cells stain red. The living and healthy cells display the faint blue by $\mathrm{HO}$, while apoptotic cells appear more bright with nuclear fragmentation (Figure 5). 


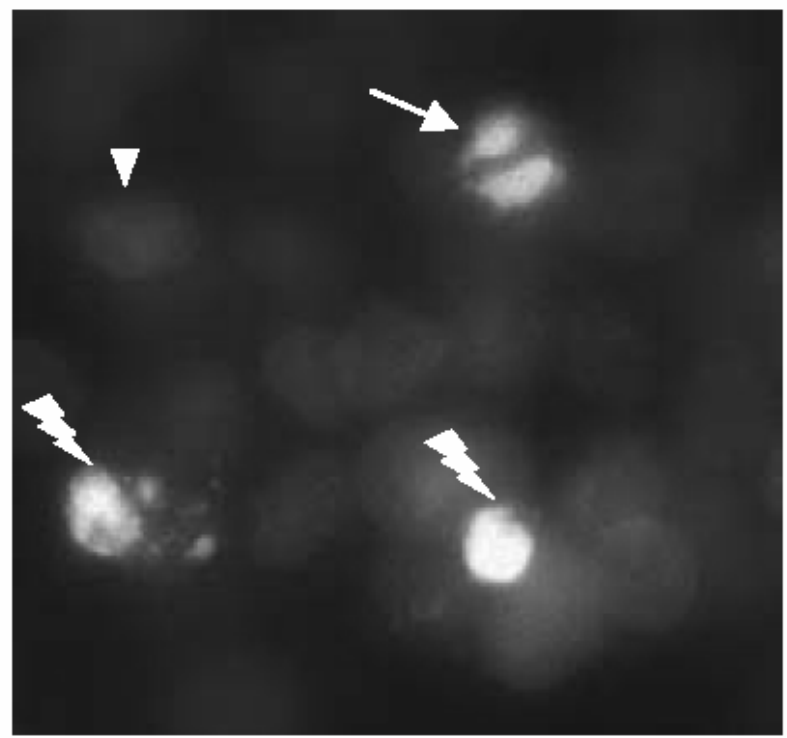

Figure 5. Example of epithelial cells stained with HO-PI. Faint blue cells represent the healthy and living cells $(\vec{c})$. Apoptotic cells show a brighter blue or almost white, displaying nuclear fragmentation $(\rightarrow)$. PI only gets into necrotic cells and results in a red staining under UV excitation ( $)$. Magnification 400x. (See coloured illustration inserted at the back of this thesis).

Viable, apoptotic and necrotic cells were counted for each cell line at the different time points p.i. and the results were expressed as percentages apoptotic or necrotic cells. For all cell lines used, apoptotic percentages did not exceed $10 \%$ and no remarkable differences were observed when $\mathrm{Cpn}$ and mock infected cells were compared (data not shown). However, in the neuronal, astrocyte and epithelial cell line, the percentage of necrotic cells increased significantly more rapidly over time in Cpn infected cells than in mock infected cells with a maximal difference at $168 \mathrm{hr}$ (or 1 week) post infection. In MMC however, no significant difference was found in the percentage necrotic cells between $\mathrm{Cpn}$ and mock infected cells (Figure 6). 


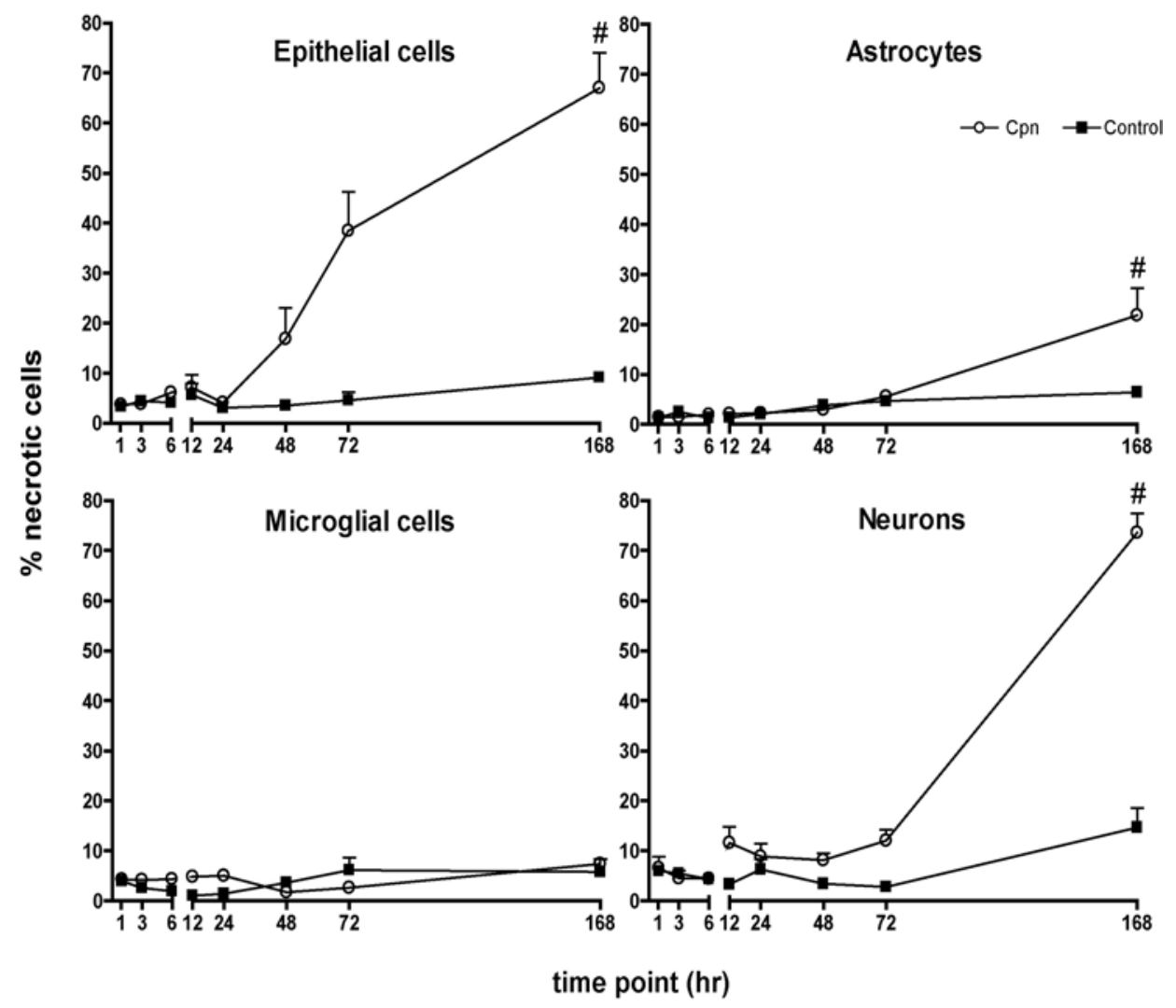

Figure 6. Necrosis in Cpn and mock infected cells from the microglial, neuronal, astrocyte and epithelial cell line, determined by a HO-PI double staining. At various time points post infection, the mean percentages of necrotic cells is showed. $\# p<0.05$ increase in the difference in necrosis between Cpn and mock infected cells over time with maximal significant difference at $168 \mathrm{hr}$ post infection. Error bars, SE of the means.

\section{Discussion}

Chlamydia pneumoniae (Cpn), an obligate intracellular Gram-negative bacterium, has been associated with both acute (meningitis-encephalitis) as well as chronic diseases (multiple sclerosis) of the central nervous system ${ }^{6,30-32}$. Also, recent evidence suggests a role for $C p n$ in $A D^{14}$. Nevertheless, the data published so far do not prove any causative role for Cpn in $A D$ and many questions have to be answered before we can attribute a definite role to $\mathrm{Cpn}$ in the pathogenesis of $A D$. For example, although Cpn's presence in tissues other than lungs has been demonstrated compellingly in animal studies, it is unknown 
whether Cpn is able to enter the (healthy) brain. In addition, it remains to be verified whether brain cells are susceptible to Cpn infection. Therefore, in the present report, Cpn tropism was investigated in vitro in certain brain cell lines: a microglial cell line (BV-2), a neuronal cell line (NB41A3) and an astrocyte cell line (C8D1A), while an epithelial cell line was applied as a reference cell line.

Both the entry as well as the ultrastructural events throughout the Cpn developmental cycle have been described in detail before in epithelial cell lines $^{29}$. Our microscopic results in the Hep2 cell line are in accordance with these earlier data. Briefly, while early time points p.i. (1, 3 and $12 \mathrm{hr})$ are characterized by the appearance of small inclusions in almost all cells, inclusion body size starts to increase after $24 \mathrm{hr}$ of incubation, while maximal sizes were seen at later stages of the developmental cycle ( $48 \mathrm{hr}-72 \mathrm{hr}$ ). At these later time points, positive signal was no longer observed in all cells, but the majority still seemed to be infected. One and two weeks post infection, the Hep2 cells display a large variety in $\mathrm{Cpn}$ inclusion body sizes. Furthermore, at these stages, the signal seemed to be diminished compared to $72 \mathrm{hr}$ p.i. but still a pronounced fluorescent signal was present in most of the infected Hep2 cells.

In our experiment, the astrocyte cell line showed identical infection patterns to the Hep2 cell line, indicating that these cells are highly permissive for Cpn infection in vitro. Cpn tropism was also similar in the neuronal cell line, except for the limited production of infectious Cpn elementary bodies (EB) at later stages p.i., as shown in the medium transfer experiments. Yet, observations in the microglial cell line (MMC) were markedly different.

MMC primarily serve the tissue defence and may, as such, be considered the macrophage equivalent of the $\mathrm{CNS}^{33}$. With respect to these more systemic cells, it has previously been demonstrated that $\mathrm{Cpn}$ is able to infect both alveolar and peritoneal monocytes/macrophages $(\mathrm{m} \varphi)^{34}$. Interestingly, as in our $M M C$, the number of infected alveolar $\mathrm{m} \varphi$ diminished in time, although less rapid and less profound than in MMC. Secondly, when MMC were Cpn infected, a marked reduction in viable progeny was observed when compared to astrocytes or neuronal cells. Similar results have been demonstrated in human alveolar or PBMC-derived macrophages ${ }^{35,36}$. In these cells, the lack of viable progeny may be due to an unfinished developmental cycle, with an incomplete conversion from reticulate bodies (RB) to EB and a subsequent lower growth rate. Interestingly, similar limited replication was also found in cytomegalovirus infected macrophage-like cells, postulating a role for this cell type in serving as an anatomical and functional filter in protecting more permissive cell types, such as neuronal cells ${ }^{37}$. Such a protective interplay between different brain cells has already been demonstrated elegantly by others ${ }^{38}$.

As expected, a significant increase in the number of Cpn DNA copies was detected in the prominently infected cell lines (neuronal cells and astrocytes) 
with real-time PCR. Yet, although the amount of immunohistochemically detectable inclusion bodies decreased dramatically in the MMC, the number of Cpn DNA copies did not change notably in time. This suggests that, although not detectable, Cpn is still present in these MMC. Indeed, earlier studies already demonstrated that, in contrast to Hep2 cells, Cpn is able to persist in monocytes even in the presence of macrolides ${ }^{39}$. Also, Cpn mRNA could be isolated from these infected monocytes exposed to rifampicin and azithromycin, indicating that $\mathrm{Cpn}$ is metabolically active in these cells. However, as protein expression patterns may drastically change during persistent infection ${ }^{40}$, we suggest that the lack of immunofluorescence in MMC is potentially due to such altered protein expression profiles.

Alzheimer's disease is not only characterized by the massive deposition of betaamyloid in the brain but also by cerebral inflammation, neurodegeneration and regionalized neuronal death. Here, we demonstrate that $\mathrm{Cpn}$ infection may be a cause of neuronal cell death. In contrast, the percentage of cell death in the astrocyte cell line was $\sim 2$-fold lower than in the neuronal and Hep2 cell line, while hardly any cell death was observed in MMC. This further emphasizes the assertion that neuronal cells need the surveillance of other cells, and in particular MMC, to survive under infectious conditions ${ }^{38}$. Interestingly, we were unable to detect significant amounts of apoptosis in all cell type examined, although it has been suggested that in $A D$ neurodegeneration may primarily result from apoptosis. However, it remains to be established whether neurons truly die of apoptosis in AD. Although the initial stages can be observed in $A D$, the stereotypical manifestations that define the terminal phases of apoptosis such as chromatin condensation, apoptotic bodies and blebbing seem to be absent in $A D^{41,42}$. In our experiments, cells were only scored as apoptotic when the final stages of apoptosis - chromatin condensation and intense fluorescent staining - were detected. As it is questionable whether these features can truly be detected in $A D$, the low amount of late apoptotic cells, detected in the present study, may be representative of what actually is found in AD.

In summary, inspired by the suggested associations between neurological diseases and infections, we determined the susceptibility of various brain cells to Cpn. Our data demonstrate that under isolated conditions, both the neuronal and astrocyte cell line are highly sensitive to $\mathrm{Cpn}$, produce viable progeny and are prone to die shortly after infection although slight differences were observed between both cell lines. In contrast, MMC seemed highly resistant to Cpn infection as no immunohistological signs of infection could be observed later than $24 \mathrm{hr}$ p.i.. Nevertheless, significant amounts of Cpn DNA could still be detected at these later time points, suggesting that $\mathrm{Cpn}$ is able to persist in $M M C$ even without producing significant amounts of viable progeny. In the original in vivo study on Cpn and AD, Cpn could be detected in astrocytes and 
microglial cells, while we found only evidence for Cpn persistence in $\mathrm{MMC}^{14}$. This discrepancy proves that further research is warranted to determine whether these cell types show the same sensitivity to Cpn in an in vivo setting, thereby providing further evidence for a role for Cpn in neurodegenerative diseases, such as Alzheimer's disease.

\section{Acknowledgements}

This work was supported by the International Alzheimer's Research Foundation (ISAO; The Netherlands). We would like to thank the students and Selma Herngreen for their technical assistance.

\section{References}

1. Lin, W.R., et al., Cytomegalovirus is present in a very high proportion of brains from vascular dementia patients. Neurobiol Dis, 2002. 9(1): p. 82-7.

2. Dobson, C.B. and R.F. Itzhaki, Herpes simplex virus type 1 and Alzheimer's disease. Neurobiol Aging, 1999. 20(4): p. 457-65.

3. Hemling, N., et al., Herpesviruses in brains in Alzheimer's and Parkinson's diseases. Ann Neurol, 2003. 54(2): p. 267-71.

4. Kolson, D.L. and F. Gonzalez-Scarano, HIV and HIV dementia. J Clin Invest, 2000. 106(1): p. 11-3.

5. Swanborg, R.H., J.A. Whittum-Hudson, and A.P. Hudson, Infectious agents and multiple sclerosis--are Chlamydia pneumoniae and human herpes virus 6 involved? J Neuroimmunol, 2003. 136(1-2): p. 1-8.

6. Stratton, C.W. and S. Sriram, Association of Chlamydia pneumoniae with central nervous system disease. Microbes Infect, 2003. 5(13): p. 1249-53.

7. Kuo, C.C., et al., Chlamydia pneumoniae (TWAR). Clin Microbiol Rev, 1995. 8(4): p. 451-61.

8. Grayston, J.T., et al., Evidence that Chlamydia pneumoniae causes pneumonia and bronchitis. J Infect Dis, 1993. 168(5): p. 1231-5.

9. Grayston, J.T., et al., A new respiratory tract pathogen: Chlamydia pneumoniae strain TWAR. J Infect Dis, 1990. 161(4): p. 618-25.

10. Weinberger, M., Respiratory infections and asthma: current treatment strategies. Drug Discov Today, 2004. 9(19): p. 831-7.

11. Ezzahiri, R., et al., Chlamydia pneumoniae infection induces an unstable atherosclerotic plaque phenotype in LDL-receptor, ApoE double knockout mice. Eur J Vasc Endovasc Surg, 2003. 26(1): p. 88-95.

12. Kuo, C.C., et al., Chlamydia pneumoniae (TWAR) in coronary arteries of young adults (15-34 years old). Proc Natl Acad Sci U S A, 1995. 92(15): p. 6911-4.

13. Yucesan, C. and S. Sriram, Chlamydia pneumoniae infection of the central nervous system. Curr Opin Neurol, 2001. 14(3): p. 355-9.

14. Balin, B.J., et al., Identification and localization of Chlamydia pneumoniae in the Alzheimer's brain. Med Microbiol Immunol (Berl), 1998. 187(1): p. 23-42.

15. Balin, B.J. and D.M. Appelt, Role of infection in Alzheimer's disease. J Am Osteopath Assoc, 2001. 101(12 Suppl Pt 1): p. S1-6. 
16. Little, C.S., et al., Chlamydia pneumoniae induces Alzheimer-like amyloid plaques in brains of BALB/c mice. Neurobiol Aging, 2004. 25(4): p. 419-29.

17. Bruunsgaard, H., et al., Proinflammatory cytokines, antibodies to Chlamydia pneumoniae and age-associated diseases in Danish centenarians: is there a link? Scand J Infect Dis, 2002. 34(7): p. 493-9.

18. Gieffers, J., et al., Failure to detect Chlamydia pneumoniae in brain sections of Alzheimer's disease patients. J Clin Microbiol, 2000. 38(2): p. 881-2.

19. Nochlin, D., et al., Failure to detect Chlamydia pneumoniae in brain tissues of Alzheimer's disease. Neurology, 1999. 53(8): p. 1888.

20. Ring, R.H. and J.M. Lyons, Failure to detect Chlamydia pneumoniae in the late-onset Alzheimer's brain. J Clin Microbiol, 2000. 38(7): p. 2591-4.

21. Taylor, G.S., et al., Failure to correlate C. pneumoniae with late onset Alzheimer's disease. Neurology, 2002. 59(1): p. 142-3.

22. Squire, L.R., et al., Cellular and Molecular Neuroscience. 2 ed. Fundamental Neuroscience, ed. L.R. Squire, et al. 2003, California: Academic Press, Elsevier Science. 49-339.

23. Roblin, P.M., W. Dumornay, and M.R. Hammerschlag, Use of HEp-2 cells for improved isolation and passage of Chlamydia pneumoniae. J Clin Microbiol, 1992. 30(8): p. 1968-71.

24. Blasi, E., et al., Immortalization of murine microglial cells by a v-raf/v-myc carrying retrovirus. J Neuroimmunol, 1990. 27(2-3): p. 229-37.

25. Kuo, C.C. and J.T. Grayston, A sensitive cell line, HL cells, for isolation and propagation of Chlamydia pneumoniae strain TWAR. J Infect Dis, 1990. 162(3): p. 755-8.

26. Kaptein, S.J., et al., The r131 gene of rat cytomegalovirus encodes a proinflammatory CC chemokine homolog which is essential for the production of infectious virus in the salivary glands. Virus Genes, 2004. 29(1): p. 43-61.

27. Tondella, M.L., et al., Development and evaluation of real-time PCR-based fluorescence assays for detection of Chlamydia pneumoniae. J Clin Microbiol, 2002. 40(2): p. 575-83.

28. Mazzini, G., C. Ferrari, and E. Erba, Dual excitation multi- fluorescence flow cytometry for detailed analyses of viability and apoptotic cell transition. Eur J Histochem, 2003. 47(4): p. 289-98.

29. Wolf, K., E. Fischer, and T. Hackstadt, Ultrastructural analysis of developmental events in Chlamydia pneumoniae-infected cells. Infect Immun, 2000. 68(4): p. 2379-85.

30. Guglielminotti, J., et al., Severe meningoencephalitis: an unusual manifestation of Chlamydia pneumoniae infection. Clin Infect Dis, 2000. 30(1): p. 209-10.

31. Sriram, S., et al., Chlamydia pneumoniae infection of the central nervous system in multiple sclerosis. Ann Neurol, 1999. 46(1): p. 6-14.

32. Wimmer, M.L., et al., Association of chlamydial infection with cerebrovascular disease. Stroke, 1996. 27(12): p. 2207-10.

33. Streit, W.J., Microglia as neuroprotective, immunocompetent cells of the CNS. Glia, 2002. 40(2): p. 133-9.

34. Redecke, V., et al., Interaction of Chlamydia pneumoniae and human alveolar macrophages: infection and inflammatory response. Am J Respir Cell Mol Biol, 1998. 19(5): p. 721-7.

35. Gaydos, C.A., et al., Replication of Chlamydia pneumoniae in vitro in human macrophages, endothelial cells, and aortic artery smooth muscle cells. Infect Immun, 1996. 64(5): p. 161420.

36. Haranaga, S., et al., Chlamydia pneumoniae infection of alveolar macrophages: a model. J Infect Dis, 2003. 187(7): p. 1107-15.

37. Hanson, L.K., et al., Replication of murine cytomegalovirus in differentiated macrophages as a determinant of viral pathogenesis. J Virol, 1999. 73(7): p. 5970-80.

38. Levitt, D., R. Danen, and P. Levitt, Selective infection of astrocytes by Chlamydia trachomatis in primary mixed neuron-glial cell cultures. Infect Immun, 1986. 54(3): p. 913-6. 
39. Gieffers, J., et al., Chlamydia pneumoniae infection in circulating human monocytes is refractory to antibiotic treatment. Circulation, 2001. 103(3): p. 351-6.

40. Molestina, R.E., et al., Proteomic analysis of differentially expressed Chlamydia pneumoniae genes during persistent infection of HEp-2 cells. Infect Immun, 2002. 70(6): p. 2976-81.

41. Perry, G., et al., Apoptosis and Alzheimer's disease. Science, 1998. 282(5392): p. 1268-9.

42. Raina, A.K., et al., Abortive apoptosis in Alzheimer's disease. Acta Neuropathol (Berl), 2001. 101(4): p. 305-10. 



\section{Chapt er}

\section{Inflammatory responses following Chlamydia pneumoniae infection of glial cells}

Ellen Boelen, Harry WM Steinbusch, Inge Pronk, Gert Grauls, Paul Rennert, Veronique Bailly, Cathrien A Bruggeman, Frank RM Stassen European Journal of Neuroscience (2007) 25 (3): 753-760 


\section{Abstract}

Recently, infections have been implicated in the pathogenesis of Alzheimer's disease. Apart from direct effects of pathogens, it can be hypothesized that inflammatory mechanisms, like the production of pro-inflammatory mediators by resident glia, may result in neurotoxicity.

Here, we examined the inflammatory responses in murine microglial (MMC) and astrocyte cell lines following Chlamydia pneumoniae (Cpn) infection, a pathogen which has recently been associated with Alzheimer's disease. Furthermore, we determined whether these inflammatory responses are sufficient to cause neuronal cell death in vitro.

MMC and astrocytes were infected with Cpn. Subsequently, various chemoand cytokines were determined in the culture supernatant of infected/control cells at different time points post infection (p.i.). Significant higher levels of MCP-1, IL-6, TNF- $\alpha$ and IL-1 $\beta$ were found in supernatants of infected MMC compared to controls. In contrast, in the supernatant of infected astrocytes, only MCP-1 and IL-6 displayed significantly higher levels compared to controls. Moreover, neurotoxicity was examined up to $72 \mathrm{hr}$ after transferring conditioned supernatant to a neuronal cell layer. No neuronal cell death was observed when supernatants from infected/mock treated astrocytes were transferred. However, when neurons were exposed to conditioned supernatant from infected MMC, a significant increase in cell death was observed compared to mock. Furthermore, adding neutralizing antibodies against IL- 6 and TNF- $\alpha$ to that conditioned supernatant prevented neuronal cell death by $\sim 50 \%$. In conclusion, these data suggest that $\mathrm{Cpn}$ infection results in a pro-inflammatory milieu, particularly by activating $\mathrm{MMC}$, which ultimately results in neurodegeneration with prominent roles for both IL- 6 and TNF- $\alpha$. 


\section{Introduction}

Currently, the role of inflammation is being increasingly appreciated in neurological diseases ${ }^{1-4}$. Moreover, viral infections like human immunodeficiency virus (HIV), herpes simplex virus or cytomegalovirus have been shown to stimulate these inflammatory responses, and may as such contribute to the process of neurodegeneration ${ }^{5-10}$. Recent data suggest that Chlamydia pneunoniae ( $\mathrm{Cpn}$ ) should be added to the list of pathogens potentially involved in the pathogenesis of some of these diseases ${ }^{11}$. Cpn is a widespread respiratory Gram-negative bacterium, able to infect a diversity of eukaryotic cell types ${ }^{12}$. Infections with this obligate intracellular pathogen frequently cause acute respiratory infections, including pneumonia, sinusitis, bronchitis and pharyngitis ${ }^{13,14}$. In addition, Cpn has been linked with chronic diseases like asthma ${ }^{15}$, atherosclerosis ${ }^{16,17}$ and rheumatoid arthritis. Intriguingly, potential links between $\mathrm{Cpn}$ and several disorders of the central nervous system (CNS) have even proposed ${ }^{18}$.

One of these neurological diseases associated with Cpn is Alzheimer's disease (AD). Recent data from human and animal studies showed evidence for a role of $C p n$ in $A D$ pathology $y^{19-22}$, although others failed in correlating $C p n$ with $A D^{23-}$ ${ }^{27}$. Moreover, recent data from our lab, demonstrating that $\mathrm{Cpn}$ is able to infect neurons and cause neuronal cell death in vitro ${ }^{28}$, are in line with a role for Cpn in neurodegenerative diseases. Besides its direct effects on neuronal cells, Cpn might also cause neurodegeneration by alternative pathways. Previously, it has been demonstrated that infections of glial cells induce the production of cytokines. As most of these pro-inflammatory cytokines are potentially neurotoxic, neuronal damage - promoted by the neurotoxic products of infected glial cells - should also be considered. Here we examined the release of cytokines by Cpn infected glial cells and determined whether these cytokines are able to cause neuronal cell death. The glial cells, investigated in the present study, are astrocytes and microglial cells. In contrast to neuronal cells, these cells are most likely the first ones to encounter invading pathogens and their release of cytokines might subsequently result in neuronal damage. Confirmation of this hypothesis in vitro may then offer a potential mechanism by which micro-organisms contribute to neurodegenerative diseases like $A D$, even when the presence of the pathogen in the brain is limited.

So, in this study, our aim was to investigate the inflammatory response of microglial cells and astrocytes upon Cpn infection, by measuring the production of various cytokines and chemokines. Moreover, we examined the neurotoxic potential of these compounds. 


\section{Material and methods}

\subsection{Chlamydia pneumoniae (Cpn)}

The Cpn strain, TWAR 2043, was obtained from the American Type Culture Collection (ATCC VR-1355) and continuously propagated on Hep2 cells as described previously ${ }^{29}$.

By titration in Hep2 cells, as described by Ezzahiri ${ }^{16}$, bacterial titres were determined and expressed as the number of inclusion forming units per millilitre (IFU/mL). Staining was performed with a Chlamydia LPS-specific mononuclear antibody followed by a FITC-conjugated secondary antibody (RR402, Glostrup, DAKO, Denmark).

\subsection{Cell cultures}

Murine microglial cells (MMC - BV-2) were kindly provided by the laboratory of dr. M. Leinonen (Oulu, Finland) ${ }^{30}$ and grown in Dulbecco's Modified Eagle's medium (DMEM) (GIBCO, Grand Island, NY, USA) supplemented with $10 \%$ foetal bovine serum, $5 \mathrm{M}$ Hepes and $2 \mathrm{mM}$ L-glutamine.

Murine Astrocyte type I cells (C8D1A; ATCC CRL-2541) (Rockville, MD, USA) were maintained in DMEM (GIBCO, Grand Island, NY, USA). Culture medium was supplemented with $4 \mathrm{mM} \mathrm{L-glutamine}$ and $10 \%$ horse serum.

Murine Neuroblasts (ATCC CCL-147) were cultured in Kaighn's modification of Ham's F12 medium (GIBCO, NY, USA) supplemented with $15 \%$ horse serum and $2.5 \%$ foetal bovine serum.

For infection of MMC and astrocytes, Cpn was diluted in the original culture medium but serum concentrations were reduced by $50 \%$ and cycloheximide, which has been described to enhance infectivity ${ }^{31}$, was added to the media. In the two cell cultures, different concentrations of cycloheximide were applied (MMC, $0.03 \mu \mathrm{g} / \mathrm{mL}$; astrocytes, $0.5 \mu \mathrm{g} / \mathrm{mL}$ ). Previous pilot experiments in our laboratory showed that optimal infection efficiency and growth of $\mathrm{Cpn}$ could be obtained with these concentrations.

All cells were cultured in $75-\mathrm{cm}^{2}$ flasks at $37^{\circ} \mathrm{C}$ with $5 \% \mathrm{CO}_{2}$ and saturated humidity.

\subsection{Infection protocol}

A confluent cell monolayer was achieved within $24 \mathrm{hr}$ in 24-well tissue culture plates (Corning Incorporated, NY, USA) by seeding MMC at a density of $10^{5}$ cells per well and astrocytes at $5 \times 10^{5}$ cells/well. When confluency was reached, 
cells were infected by replacing the original culture medium by a culture medium containing $\mathrm{Cpn}$ at a multiplicity of infection (MOI) of 5. Cells were then incubated for $1 \mathrm{hr}$ at $20^{\circ} \mathrm{C}$ and $4500 \mathrm{rpm}$. Subsequently, the inoculum was removed, the cells were washed three times, the appropriate infection medium without $\mathrm{Cpn}$ or cycloheximide was re-applied and cells were cultivated for different times at $37^{\circ} \mathrm{C}$. Controls, (mock infected) consisting of cells incubated with sucrose-phosphate-glucose solution (SPG, solution for storage of Cpn), were also included and processed in the same manner as Cpn infected cells.

\subsection{Cytokine assays}

At various time points post infection (1, 3, 6, 12, 24, 48, 72 and $168 \mathrm{hr})$, medium of infected/control microglial cells and astrocytes was collected. Medium was centrifuged for $10 \mathrm{~min}$ at $20^{\circ} \mathrm{C}$ and $1200 \mathrm{rpm}$ and the supernatant was used for analysis.

As a control of the infection protocol, the presence of $\mathrm{Cpn}$ in these brain cells was checked by immunofluorecent techniques, as described before ${ }^{28}$.

\section{Cytometric Bead Assay (CBA)}

A simultaneous measurement of interleukin (IL)-12p70, IL-6, IL-10, IL-4, tumour necrosis factor (TNF)- $\alpha$, interferon (INF)- $\gamma$, monocyte chemoattractant protein (MCP)-1, IL-5 and IL-2 in these media was performed, using a commercially available multiplex cytometric bead assay (mouse Th-1/Th-2 and inflammation kit) (Becton Dickinson Biosciences, Alphen aan den Rijn, The Netherlands). This assay was carried out as described before ${ }^{32}$, with minor modifications. Only $5 \mu \mathrm{L}$ of the sample, capture bead suspension and detection reagent was used. Finally, the bead pellet was resuspended in $100 \mu \mathrm{L}$ of wash buffer and analysed on a FACS Calibur flow cytometer (BD Biosciences, Alphen aan den Rijn, The Netherlands), according to the manufacturers protocol.

At every time point, the cytokine production was measured in the medium of three different wells. The experiment was performed in triplicate.

\section{DuoSet ELISA development kit}

For the measurement of mouse IL- $1 \beta$ (DY401, R\&D systems, USA) and TGF- $\beta 1$ (DY1679, R\&D systems, USA) in the collected cell culture supernatants, DuoSet ELISA development assays were performed according to the instructions of the manufacturer. The detection limit of each of the cytokines was $50 \mathrm{pg} / \mathrm{mL}$. 


\subsection{Apoptosis/necrosis}

To examine whether infection of microglial cells and astrocytes creates an environment which might be lethal for neuronal cells, the following experiment was performed. At 24 hours post infection (p.i.), when cytokine production by infected microglial cells peaked (see results section), the medium of infected/control MMC was collected and filtrated through a $0,2 \mu \mathrm{m}$ filter (Schleicher and Schuell) to ensure the removal of all Cpn infectious particles. The same procedure was followed with the medium of infected astrocytes at one week post infection, when maximal cytokine production by this cell type was found. The filtrated medium of both cell lines was then transferred to a confluent neuronal monolayer. This layer was achieved within $24 \mathrm{hr}$ in 24-well tissue culture plates (Corning Incorporated, NY, USA) by seeding neurons at a density of $5 \times 10^{5}$ cells/well. At $3,6,12,24,48$ and 72 hours after inoculation, neuronal cells were incubated with Hoechst 33258 (HO) (Sigma, St. Louis, USA) and propidium iodide (PI) (Sigma, St. Louis, USA), as described previously ${ }^{28}$. Viable, apoptotic and necrotic cells were counted in 10 fields (magnification: 400x, $\sim 170$ cells in each field) per well and the average percentage apoptotic/necrotic cells was determined for three wells at different time points, in both infected/control cell lines. The experiment was performed in triplicate. The $\mathrm{HO}$ dye freely enters living cells and stains the nuclei of these cells. Apoptotic cells, however, can be distinguished from the rest by chromatin condensation and nuclear fragmentation. On the other hand, PI enters only cells with damaged cell membranes and stains therefore only necrotic and late apoptotic cells ${ }^{33}$.

\subsection{IL-6, TNF- $\alpha$ and MCP-1 neutralization assay}

IL-6 in the culture medium of MMC was neutralized by the addition of $30 \mathrm{ng} / \mathrm{ml}$ of a rabbit polyclonal anti-IL-6 (Abcam Ltd., Cambridge, UK) to the medium of MMC, infected $24 \mathrm{hr}$ prior to the collection of the medium ( 10x excess of the amount measured in MMC media at $24 \mathrm{hr}$ p.i.). After pre-incubation for $30 \mathrm{~min}$ at $37^{\circ} \mathrm{C}$, the medium containing the neutralized IL-6 was transferred to a neuronal cell monolayer. Subsequently, neuronal death was investigated after 48 and $72 \mathrm{hr}$, as described above. The TNF- $\alpha$ and MCP-1 neutralization assays were performed in a similar way, with $30 \mathrm{ng} / \mathrm{ml}$ of a TNF- $\alpha$ neutralizing antibody (rat monoclonal anti- TNF- $\alpha$, Abcam Ltd., Cambridge, UK) or $60 \mathrm{ng} / \mathrm{ml}$ of a MCP1 neutralizing antibody. These concentrations were 10 -fold the concentration of the amounts of TNF and MCP-1, measured in the MMC medium collected $24 \mathrm{hr}$ p.i.. Furthermore, to evaluate whether the effects of TNF- $\alpha$ and IL-6 are 
additive, conditioned MMC medium was prepared containing a mixture of IL-6 (30 ng/ml) and TNF- $\alpha(30 \mathrm{ng} / \mathrm{ml})$ neutralizing antibodies. Isotypical controls for the IL-6, TNF- $\alpha$ and MCP-1 antibodies were used as controls in the neutralization assay.

\subsection{Data analysis}

In the transfer experiments, the number of apoptotic and necrotic cells was expressed as the percentage of the total number of cells, counted in the 10 fields examined in each well. In the neutralization experiments, the total number of necrotic or apoptotic cells in control experiments was designated at $100 \%$ and the results of all interventions was expressed as a fraction thereof. All experiments were performed in triplicate and each individual experiment consisted of 4 individual measurements. Data are expressed as means \pm SEM $(n=3)$.

For the statistical analysis of our results, SPSS 11.0 for Windows was used. Levels of significance were determined using the Mann-Whitney U-test. A pvalue of $\leq 0.05$ was considered significant.

\section{Results}

\subsection{Chlamydia pneumoniae infection}

At various time points post infection (1,24 and $72 \mathrm{hr})$, astrocytes and microglial cells were fixed and the presence of $\mathrm{Cpn}$ was evaluated using immunofluorescent techniques. Although no striking differences were found between the infected cell lines in the early hours post infection, infection profiles markedly diverged starting at 24 hours p.i. (Figure 1). From this time point, positive staining was only observed in less than $5 \%$ of all MMC while $>60 \%$ of all astrocytes stained positive for $\mathrm{Cpn}$ antigens. Among control cells, no fluorescent signal could be detected. 

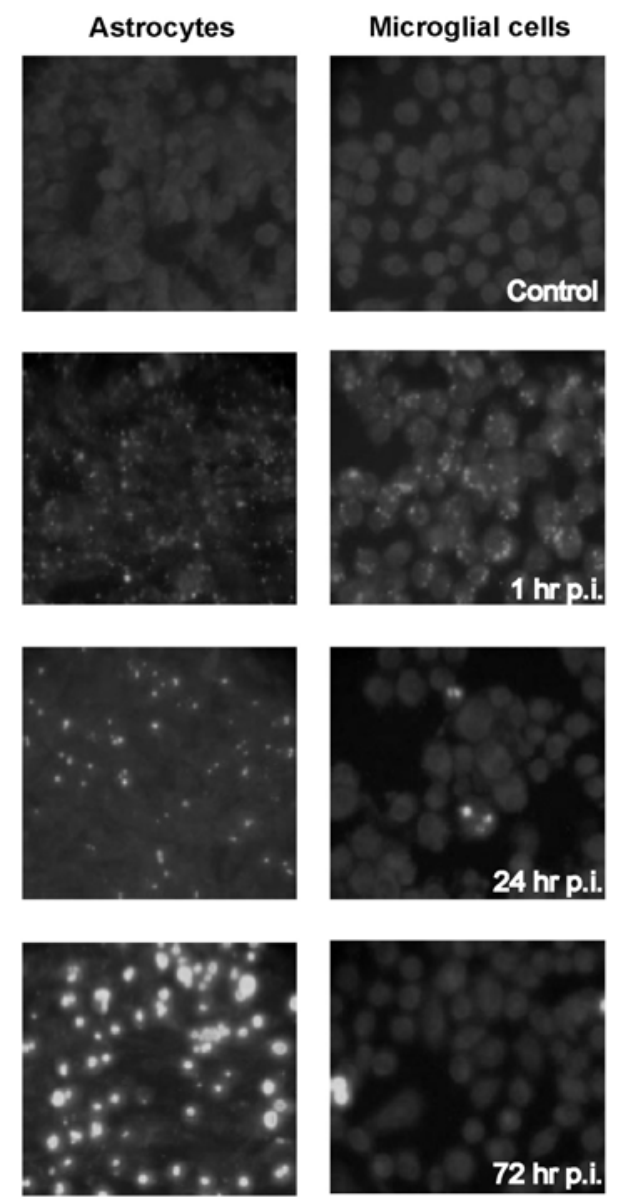

Microglial cells

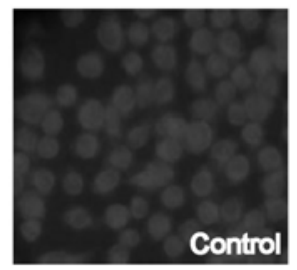

Figure 1. Detection of Chlamydia pneumoniae (Cpn) antigens in astrocytes and microglial cells. Cells were fixed at various time points post infection; 1, 24 and $72 \mathrm{hr}$. Immunofluorescent staining was performed with a primary antibody directed against the Cpn major membrane outer protein (MOMP) and a secondary Alexa Fluor 488 labelled antibody. For the control, a time point was randomly chosen. Evan's blue (red signal) was used for counterstaining. Original magnification, 400x. (See coloured illustration inserted at the back of this thesis).

\subsection{Cytokine assays}

At different time points post infection (1, 3, 6, 12, 24, 48, 72 and $168 \mathrm{hr}$ ), supernatants of infected or mock treated microglial cells and astrocytes were collected and cytokine profiles were determined herein by CBA and ELISA.

At none of the time points examined, the levels of IL-4, INF- $\gamma$, IL-5 and IL- 2 in supernatants of either infected or control microglial cells were above the detection limit (data not shown). However, concentrations of MCP-1, IL-6, TNF$\alpha, I L-1 \beta, I L-12 p$ and IL-10 were significantly elevated in the supernatant of infected $\mathrm{MMC}$ at various time points p.i. when compared to the concentrations determined in the supernatant of non-infected MMC (Figure 2). The production of most cytokines peaked around $24 \mathrm{hr}$ post infection. 
In astrocytes, cytokine production was not as pronounced as seen in microglial cells and the concentration of most cytokines remained below the detection limit. Nevertheless, significant amounts of MCP-1 and IL- 6 could be detected at various time points with maximal levels seen at 1 week post infection. Cytokine levels of infected astrocytes cells were significant higher as the corresponding controls at 48, 72, $168 \mathrm{hr}$ post infection (Figure 3).

Remarkably, we also found elevated levels of TNF- $\alpha$, IL-10 and most prominently MCP-1 at later time points in the supernatant of both astrocytes and MMC, cultured under control conditions. It might be speculated that this is due to activation of cells, because of the lack of nutrients or the accumulation of waist products as the medium was not changed up to one week after the start of the experiments.
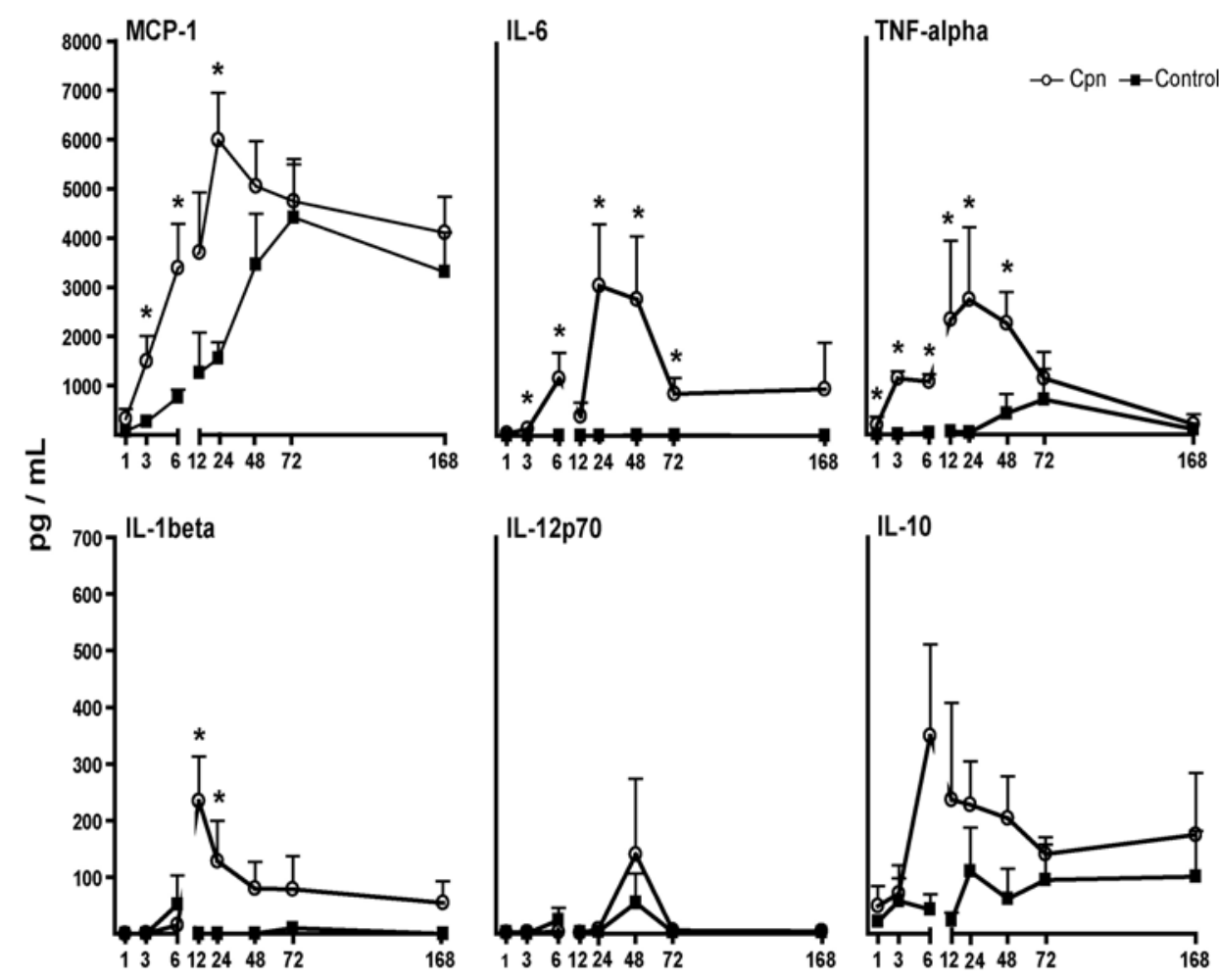

time point (hr)

Figure 2. MCP-1, IL-6, TNF- $\alpha, \mathrm{IL}-1 \beta, \mathrm{IL}-12 \mathrm{p} 70$ and IL-10 levels in media of infected/control microglial cells at $1,3,6,12,24,48,72$ and $168 \mathrm{hr}$ post infection. The data, determined by ELISA and CBA, are presented as the mean levels of an in triplicate performed experiment $\pm \mathrm{SE}$ of the means. ${ }^{*} \mathrm{p} \leq 0.05$ infected vs. control microglial cells per time point. 


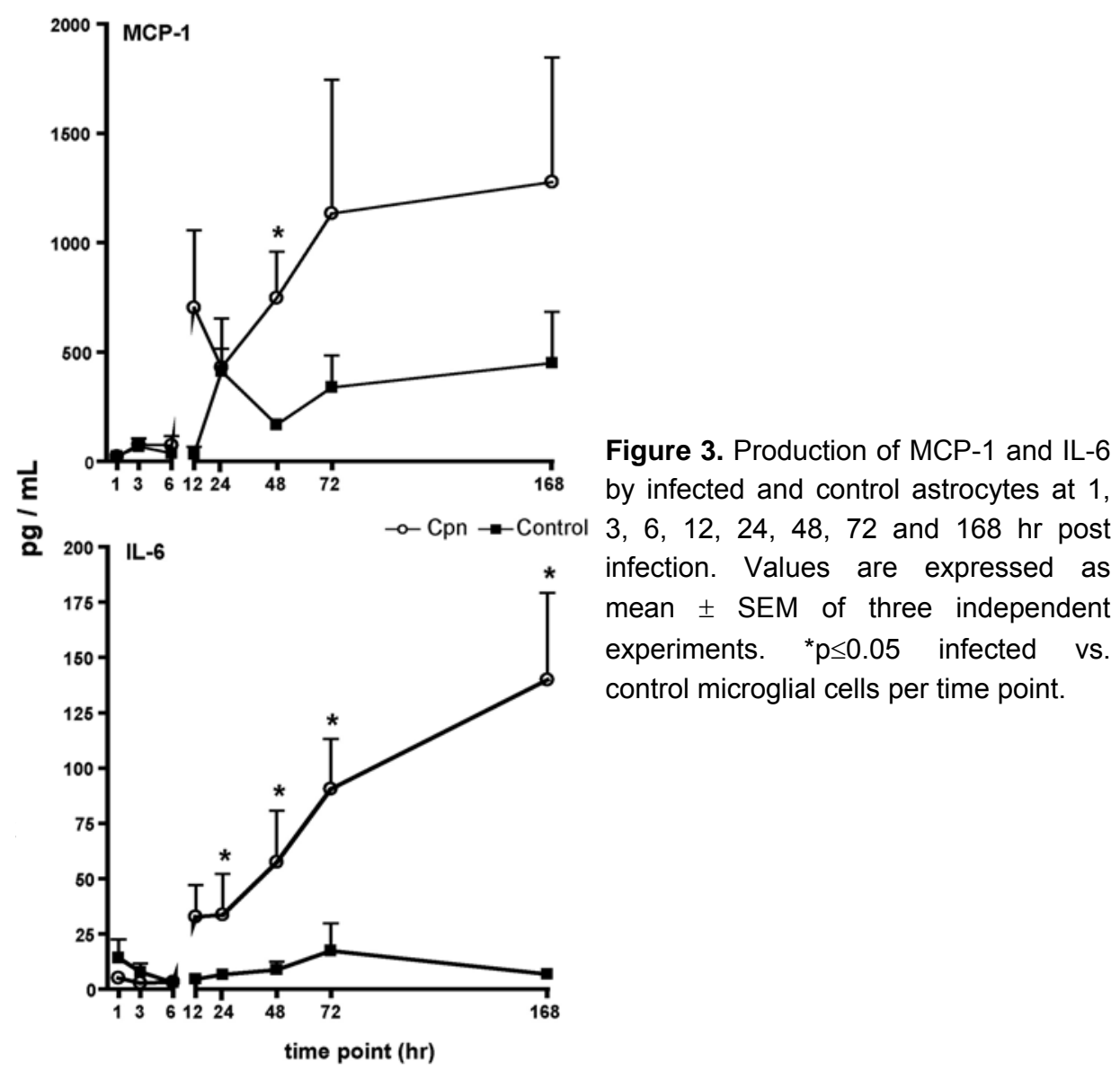

The previous experiment revealed that cytokine production peaked at $24 \mathrm{hr}$ p.i. (MMC) and $168 \mathrm{hr}$ p.i. (astrocytes). Therefore, we decided to use the supernatant from these time points for our transfer experiments. To prevent confounding effects of contaminating infectious chlamydial particles, potentially present in the supernatant, samples were filtrated through a $0,2 \mu \mathrm{m}$ filter and subsequently transferred to a neuronal cell layer. Previous experiments revealed that this pre-treatment is sufficient to remove all residual infectious particles from the supernatants (data not shown). Then neuronal cells were fixed and stained after $3,6,12,24,48$ and $72 \mathrm{hr}$ to detect the levels of apoptosis and necrosis.

As shown in Figure 4, no significant differences, neither in apoptotic nor necrotic neuronal cell death were detected when cells were incubated with supernatants of infected or control astrocytes. However, when supernatant from infected MMC was transferred, the percentages of necrotic neuronal cells were significantly increased at various time points after transfer, when compared to 
the necrotic cell death, observed after exposure to medium from non-infected MMC. Similarly, and although overall levels were relatively low, exposure to supernatant from infected $M M C$ resulted in a significant increase in the percentage of apoptotic neuronal cells at 3 and $6 \mathrm{hr}$ after transfer.
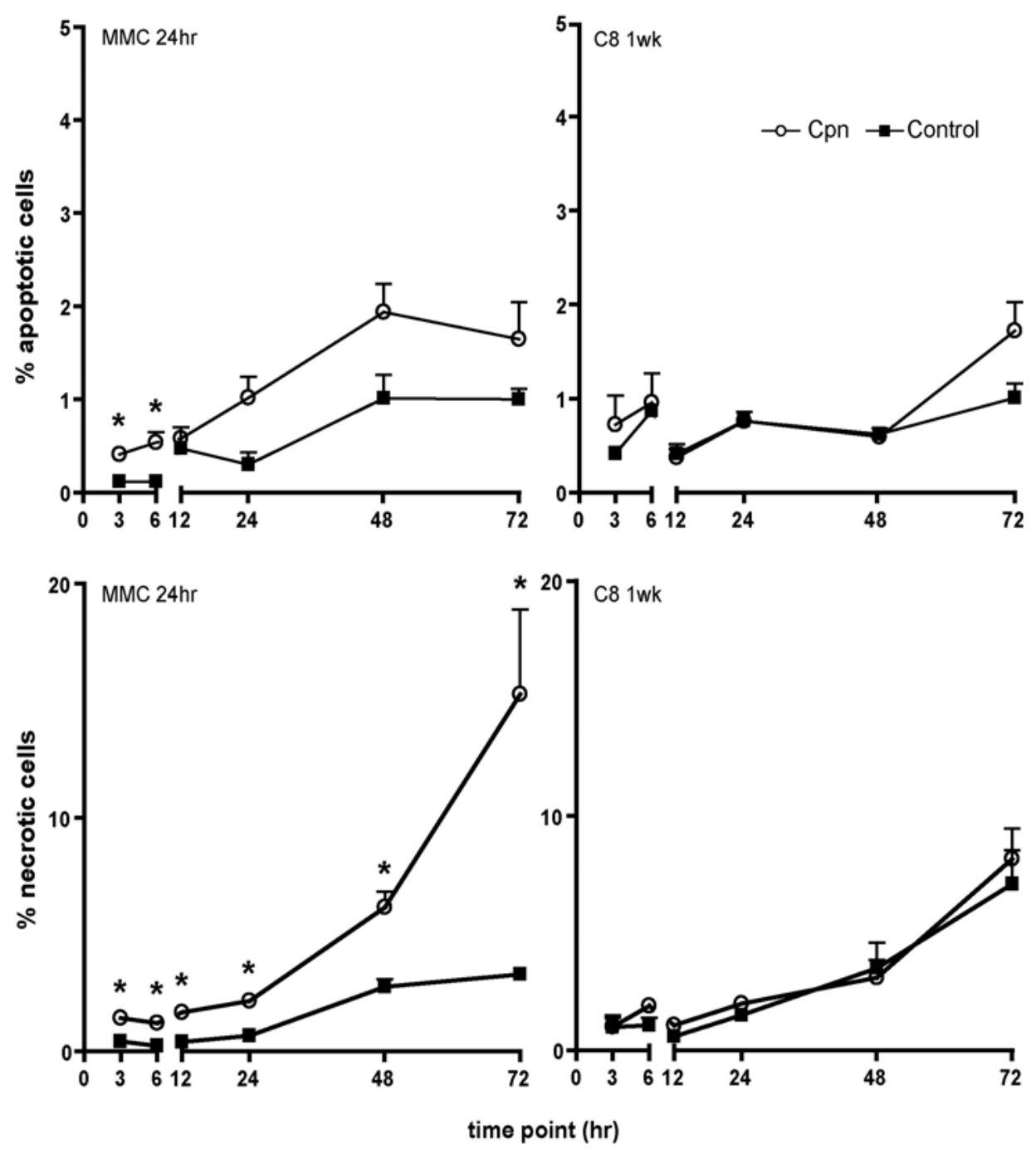

Figure 4. Apoptosis and necrosis, determined by HO-PI double staining, in neurons after medium transfer of infected/control MMC (24 hr p.i.) and C8 (168 hr p.i.). At various time points post transfer, the mean percentages of apoptotic/necrotic neurons is showed. ${ }^{*} p \leq 0.05$ infected vs. control apoptotic/necrotic cells per time point. Error bars, SE of the means. 


\subsection{IL-6 and TNF- $\alpha$ neutralization assay}

To reveal whether IL- 6 and/or TNF- $\alpha$, prominently produced by infected microglial cells, play a role in the death of neuronal cells, these cytokines were neutralized by pre-incubating the supernatants with neutralizing antibodies before transfer onto the neuronal cells. First, these cytokines were neutralized separately and secondly, a combination of an IL- 6 and TNF- $\alpha$ antibody was applied to the supernatants. As the MCP-1 concentration was also markedly elevated in the supernatant of infected MMC, the effect of neutralizing this chemokine on apoptosis/necrosis of neuronal cells was also investigated. As a control, medium without neutralizing antibodies was used. Pre-treated supernatants obtained from infected MMC $24 \mathrm{hr}$ p.i. were once again transferred to a neuronal cell layer and the percentage of apoptosis/necrosis was determined after 48 and $72 \mathrm{hr}$. Finally, to confirm the specificity of these neutralizing antibodies, the medium containing the corresponding isotypical controls was processed in the same manner.

Interestingly, although the production of MCP-1 by infected MMC was the most pronounced, neutralizing this chemokine did not affect the percentage of necrotic or apoptotic neuronal cells (Figure 5). Similarly, pre-incubation with the isotypical controls of all the antibodies revealed no significant differences in apoptosis/necrosis when compared to the results obtained when neuronal cells were exposed to untreated supernatant of infected MMC (data not shown). Nonetheless, when supernatant derived from infected MMC was pre-treated with neutralizing antibodies against IL- 6 and TNF- $\alpha$, some remarkable differences were observed (Figure 5). Firstly, at both time points, the percentage of apoptotic cells was reduced by $\sim 50 \%$ when TNF- $\alpha$ was removed from the supernatant. Also, pre-treatment with an IL-6 neutralizing antibody reduced the percentage of apoptotic cells by $\sim 30 \%$, although this reduction was not statistically significant. No additive effect on apoptosis reduction was observed when an mixture of both neutralizing antibodies was applied to the supernatant. Secondly, the effects on the percentage necrotic cells was even more pronounced. Percentages of necrotic cells were significantly reduced down to $\sim 30-50 \%$ of control values at both time points when supernatants were pre-treated with neutralizing antibodies against IL- 6 and TNF- $\alpha$. Nevertheless, no synergistic effect was observed when a mixture was applied. 

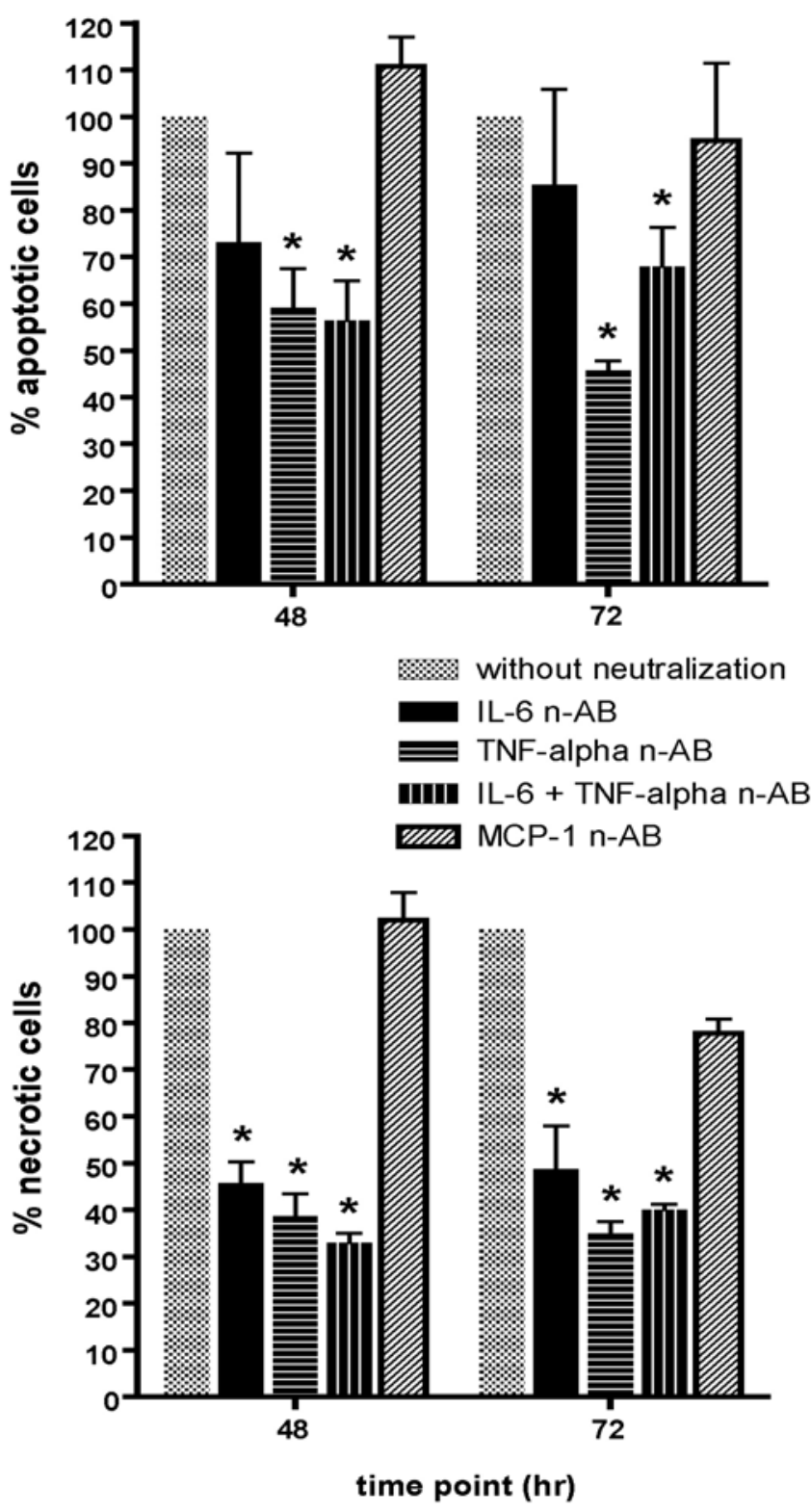

Figure 5. Percentages apoptotic/necrotic neurons after transfer of untreated, IL-6, TNF- $\alpha$ or IL- 6 + TNF- $\alpha$ neutralizing antibody (n-AB) treated medium of infected microglial cells $24 \mathrm{hr}$ p.i., determined by a HO$\mathrm{PI}$ double staining. At 48 and $72 \mathrm{hr}$ post transfer, the mean percentages apoptotic/necrotic neurons of three experiments is showed. ${ }^{*} p \leq 0.05$ in neuronal apoptosis/necrosis vs. medium transfer of untreated MMC medium per time point. Error bars, SE of the means. 


\section{Discussion}

Nowadays, there is compelling evidence that cerebral amyloid-beta deposition in $A D$ is associated with a local inflammatory response, which is initiated by the activation of microglia and the recruitment of astrocytes. These cells secrete a number of cytokines, like IL-6, IL-1, TGF- $\beta$, and TNF- $\alpha$, and neurotoxic products that may contribute to neuronal degeneration and cell death ${ }^{1,4,34}$. Recently, infections have been suggested as a potential cause of this neuroinflammation and thus as a contributing factor in neurodegenerative diseases. For example, it has been demonstrated that HIV-1 activates microglia, thereby triggering localized inflammation through the release of cytokines and neurotoxins. This will result ultimately in neural cell death and dysfunction in adjacent cells not infected by the virus ${ }^{35,36}$. Likewise, Chlamydia pneumoniae (Cpn) has been suggested to be an important factor in AD. We previously demonstrated that $\mathrm{Cpn}$ is able to infect and kill neurons in vitro ${ }^{28}$. However, in vivo, a similar process may be less likely as neurons are densely surrounded, predominantly by astrocytes. Furthermore, once the pathogen has entered the brain it will also encounter microglial cells, which are considered to be the cerebral equivalent of tissue macrophage analogous to Langerhans' cells or Kupffer cells. Activation of these cells by LPS results in the substantial production of pro-inflammatory cytokines like TNF- $\alpha$, IL- 6 or IL- $1 \alpha / \beta^{37}$. Thus far, no data regarding the effect of Cpn infection on cytokine production by microglial cells were available so far. Here, we demonstrate that $\mathrm{Cpn}$ infection of microglial cells results in the substantial production of various inflammatory cytokines, including IL-6, IL-1 $\beta$ and TNF- $\alpha$. This is in accordance with previous data on primary bone marrowderived macrophages or alveolar macrophages, showing similar cytokine profiles following $\mathrm{Cpn}$ infection ${ }^{38-40}$. Interestingly, although others consistently demonstrated a prominent synthesis of IFN- $\gamma$ by infected mononuclear cells, microglial cells do not seem to produce significant amounts of this cytokine post infection. Previously, it has been demonstrated that the production of proinflammatory cytokines, including IFN- $\gamma$, is under the tight control of IL-10, since the release of cytokines by murine glial cells following bacterial or viral infections is markedly increased in cells derived from $\mathrm{IL}-10^{-/-}$mice. As significant amounts of IL-10 could be detected in the supernatant of infected MMC, this might explain the absence of relevant amounts of IFN- $\gamma$ in the supernatants ${ }^{41}$. Nevertheless, despite the fact that microglial cells do not seem to produce significant amounts of IFN- $\gamma$, they do seem to be able to control an intracellular infection as delineated by the presence of significant amounts of Cpn DNA in MMC up to 7 days post infection without prominent signs of productive infection ${ }^{28}$. This is in contrast with previous findings by Rothfuchs et al., who 
suggested that INF- $₹$ production may be a prerequisite to control an intracellular Cpn infection ${ }^{41}$. Further studies are required to further elucidate this obvious discrepancy.

Exposure of astrocytes to microbial challenge has also been demonstrated to induce cytokine production. In particular large amounts of cytokines like TNF- $\alpha$ or IL-1 $\beta$ are released by astrocytes following exposure to LPS ${ }^{42}$. As Cpn is a Gram-negative bacterium containing LPS ${ }^{43}$, we expected that astrocytes would also release these cytokines in response to Cpn infection. Nonetheless, only significant amounts of IL- 6 and MCP-1 could be detected in the supernatant of infected astrocytes. Interestingly, most studies demonstrating the prominent release of other cytokines have been performed on isolated rat astrocytes ${ }^{44}$ while we applied a murine astrocyte cell line. The different origin of astrocytes could possibly explain the variation in cytokine profiles. On the other hand, we speculate that the absence of the classical LPS receptor Toll-like receptor 4 (TLR4) in our astrocyte cell line may eventually explain the variations between our results and earlier data in rat astrocytes. Moreover, the identified distinction in inflammatory responses between the glial cell lines in our conditions may be due to diverse TLR4 expression profiles ${ }^{45}$. While it is commonly accepted that this receptor is present in microglial cells ${ }^{45-47}$, the results for astrocytes are rather controversial. Failure in detecting TLR4 expression in astrocytes has been described in several studies ${ }^{46-48}$ but on the contrary, some others reported a low constitutive expression of the receptor ${ }^{49}$. Interestingly, in response to various concentrations of LPS, we were unable to detect any nitric oxide production by the $\mathrm{C} 8$ astrocyte cell line used in the present study (in contrast to the microglial cells) (unpublished data), further emphasizing the possible lack of the TLR4 receptor in these cells. IL-6 and MCP-1 production, on the other hand, seemed TLR4 independent as significant amounts could be detected following Cpn infection.

Previously, it has been demonstrated that pro-inflammatory cytokines exert cytotoxic effects on adjacent neuronal cells ${ }^{50}$. Accordingly, it can be hypothesized that the release of pro-inflammatory cytokines by glial cells, following Cpn infection, causes local brain damage, thereby offering a potential mechanisms by which $\mathrm{Cpn}$ may contribute to neurodegenerative diseases like $A D$. Thus, we evaluated whether neuronal cell death could be induced by the mixture of cytokines, released by glial cells in response to Cpn. Therefore, the supernatant of infected and control cells (MMC: $24 \mathrm{hr}$ p.i.; astrocytes: $168 \mathrm{hr}$ p.i.) was filtrated to remove remnant $\mathrm{Cpn}$ elementary bodies and transferred to a neuronal monolayer to analyse subsequent apoptosis/necrosis. When the conditioned medium of infected or control astrocytes was transferred, no differences in neuronal apoptosis or necrosis were found, indicating that the amount of chemo-/cytokines released by infected astrocytes is insufficient to 
cause neuronal cell death. Conversely, incubation of neurons with conditioned medium of infected microglial cells resulted in significant enhancement of the percentage neuronal cells, undergoing either apoptosis and, even more pronounced, necrosis. Then, we tested to what extent the cytokines, released by infected MMC, were responsible for the observed neuronal cell death. In these experiments, we primarily focused on IL-6, TNF- $\alpha$ and MCP-1, as the production of these compounds was most pronounced. Also, IL- 6 and TNF- $\alpha$ have been frequently linked to neurodegeneration in $A D^{1}$. Therefore, neutralizing antibodies were added to the conditioned medium before it was transferred to the neuronal cell layer. Results demonstrated, in particular, the importance of IL- 6 and TNF- $\alpha$, as neuronal cell death was reduced up to $50 \%$ following neutralization of these two cytokines. Neutralization of MCP-1, on the other hand, was without any effect on neuronal cell death. Although this chemokine has previously been linked with inflammatory neurological disease ${ }^{51}$, this is not supported by our present data.

In conclusion, our results demonstrate that $\mathrm{Cpn}$ infection of murine glial cells results in the pronounced release of various pro-inflammatory cytokines, including TNF- $\alpha$, IL-6 and MCP-1. These data suggest that Cpn, once it enters the brain, might create a pro-inflammatory cerebral milieu, particularly by activating MMC, which ultimately results in neuronal cell death and progression or even initiation of neurodegenerative diseases like AD. Further research is warranted to determine whether similar processes occur in vivo and as such provide a mechanism explaining the suggested effect of $C p n$ on $A D$.

\section{Acknowledgements}

This work was supported by the International Alzheimer's Research Foundation (ISAO; The Netherlands).

\section{References}

1. Akiyama, H., et al., Inflammation and Alzheimer's disease. Neurobiol Aging, 2000. 21(3): p. 383-421.

2. Hald, A. and J. Lotharius, Oxidative stress and inflammation in Parkinson's disease: is there a causal link? Exp Neurol, 2005. 193(2): p. 279-90.

3. Perry, V.H., The influence of systemic inflammation on inflammation in the brain: implications for chronic neurodegenerative disease. Brain Behav Immun, 2004. 18(5): p. 407-13.

4. Weiner, H.L. and D.J. Selkoe, Inflammation and therapeutic vaccination in CNS diseases. Nature, 2002. 420(6917): p. 879-84.

5. Dobson, C.B. and R.F. Itzhaki, Herpes simplex virus type 1 and Alzheimer's disease. Neurobiol Aging, 1999. 20(4): p. 457-65. 
6. Hemling, N., et al., Herpesviruses in brains in Alzheimer's and Parkinson's diseases. Ann Neurol, 2003. 54(2): p. 267-71.

7. Kolson, D.L. and F. Gonzalez-Scarano, HIV and HIV dementia. J Clin Invest, 2000. 106(1): p. 11-3.

8. Lin, W.R., et al., Cytomegalovirus is present in a very high proportion of brains from vascular dementia patients. Neurobiol Dis, 2002. 9(1): p. 82-7.

9. Swanson, R.A., et al., Neuronal regulation of glutamate transporter subtype expression in astrocytes. J Neurosci, 1997. 17(3): p. 932-40.

10. Wucherpfennig, K.W., Infectious triggers for inflammatory neurological diseases. Nat Med, 2002. 8(5): p. 455-7.

11. Stratton, C.W. and S. Sriram, Association of Chlamydia pneumoniae with central nervous system disease. Microbes Infect, 2003. 5(13): p. 1249-53.

12. Kuo, C.C., et al., Chlamydia pneumoniae (TWAR). Clin Microbiol Rev, 1995. 8(4): p. 451-61.

13. Grayston, J.T., et al., Evidence that Chlamydia pneumoniae causes pneumonia and bronchitis. J Infect Dis, 1993. 168(5): p. 1231-5.

14. Grayston, J.T., et al., A new respiratory tract pathogen: Chlamydia pneumoniae strain TWAR. $J$ Infect Dis, 1990. 161(4): p. 618-25.

15. Weinberger, M., Respiratory infections and asthma: current treatment strategies. Drug Discov Today, 2004. 9(19): p. 831-7.

16. Ezzahiri, R., et al., Chlamydia pneumoniae infection induces an unstable atherosclerotic plaque phenotype in LDL-receptor, ApoE double knockout mice. Eur J Vasc Endovasc Surg, 2003. 26(1): p. 88-95.

17. Kuo, C.C., et al., Chlamydia pneumoniae (TWAR) in coronary arteries of young adults (15-34 years old). Proc Natl Acad Sci U S A, 1995. 92(15): p. 6911-4.

18. Yucesan, C. and S. Sriram, Chlamydia pneumoniae infection of the central nervous system. Curr Opin Neurol, 2001. 14(3): p. 355-9.

19. Balin, B.J., et al., Identification and localization of Chlamydia pneumoniae in the Alzheimer's brain. Med Microbiol Immunol (Berl), 1998. 187(1): p. 23-42.

20. Balin, B.J. and D.M. Appelt, Role of infection in Alzheimer's disease. J Am Osteopath Assoc, 2001. 101(12 Suppl Pt 1): p. S1-6.

21. Little, C.S., et al., Age alterations in extent and severity of experimental intranasal infection with Chlamydophila pneumoniae in BALB/c mice. Infect Immun, 2005. 73(3): p. 1723-34.

22. Little, C.S., et al., Chlamydia pneumoniae induces Alzheimer-like amyloid plaques in brains of $B A L B / c$ mice. Neurobiol Aging, 2004. 25(4): p. 419-29.

23. Bruunsgaard, H., et al., Proinflammatory cytokines, antibodies to Chlamydia pneumoniae and age-associated diseases in Danish centenarians: is there a link? Scand J Infect Dis, 2002. 34(7): p. 493-9.

24. Gieffers, J., et al., Failure to detect Chlamydia pneumoniae in brain sections of Alzheimer's disease patients. J Clin Microbiol, 2000. 38(2): p. 881-2.

25. Nochlin, D., et al., Failure to detect Chlamydia pneumoniae in brain tissues of Alzheimer's disease. Neurology, 1999. 53(8): p. 1888.

26. Ring, R.H. and J.M. Lyons, Failure to detect Chlamydia pneumoniae in the late-onset Alzheimer's brain. J Clin Microbiol, 2000. 38(7): p. 2591-4.

27. Taylor, G.S., et al., Failure to correlate C. pneumoniae with late onset Alzheimer's disease. Neurology, 2002. 59(1): p. 142-3.

28. Boelen, E., et al., Chlamydia pneumoniae infection of brain cells: an in vitro study. Neurobiol Aging, 2007. 28(4): p. 524-32.

29. Roblin, P.M., W. Dumornay, and M.R. Hammerschlag, Use of HEp-2 cells for improved isolation and passage of Chlamydia pneumoniae. J Clin Microbiol, 1992. 30(8): p. 1968-71.

30. Blasi, E., et al., Immortalization of murine microglial cells by a $v$-raf/v-myc carrying retrovirus. J Neuroimmunol, 1990. 27(2-3): p. 229-37. 
31. Kuo, C.C. and J.T. Grayston, A sensitive cell line, HL cells, for isolation and propagation of Chlamydia pneumoniae strain TWAR. J Infect Dis, 1990. 162(3): p. 755-8.

32. Reitsma, P.H. and F.R. Rosendaal, Activation of innate immunity in patients with venous thrombosis: the Leiden Thrombophilia Study. J Thromb Haemost, 2004. 2(4): p. 619-22.

33. Mazzini, G., C. Ferrari, and E. Erba, Dual excitation multi- fluorescence flow cytometry for detailed analyses of viability and apoptotic cell transition. Eur J Histochem, 2003. 47(4): p. 289-98.

34. Remarque, E.J., et al., Patients with Alzheimer's disease display a pro-inflammatory phenotype. Exp Gerontol, 2001. 36(1): p. 171-6.

35. Epstein, L.G. and H.E. Gendelman, Human immunodeficiency virus type 1 infection of the nervous system: pathogenetic mechanisms. Ann Neurol, 1993. 33(5): p. 429-36.

36. Pulliam, L., et al., Human immunodeficiency virus-infected macrophages produce soluble factors that cause histological and neurochemical alterations in cultured human brains. J Clin Invest, 1991. 87(2): p. 503-12.

37. Nakamura, Y., Q.S. Si, and K. Kataoka, Lipopolysaccharide-induced microglial activation in culture: temporal profiles of morphological change and release of cytokines and nitric oxide. Neurosci Res, 1999. 35(2): p. 95-100.

38. Naiki, Y., et al., MyD88 is pivotal for the early inflammatory response and subsequent bacterial clearance and survival in a mouse model of Chlamydia pneumoniae pneumonia. J Biol Chem, 2005. 280(32): p. 29242-9.

39. Quinn, T.C. and C.A. Gaydos, In vitro infection and pathogenesis of Chlamydia pneumoniae in endovascular cells. Am Heart J, 1999. 138(5 Pt 2): p. S507-11.

40. Redecke, V., et al., Interaction of Chlamydia pneumoniae and human alveolar macrophages: infection and inflammatory response. Am J Respir Cell Mol Biol, 1998. 19(5): p. 721-7.

41. Rothfuchs, A.G., et al., IFN-alpha beta-dependent, IFN-gamma secretion by bone marrowderived macrophages controls an intracellular bacterial infection. J Immunol, 2001. 167(11): p. 6453-61.

42. Takeshita, S., et al., Activation of microglia and astrocytes by CpG oligodeoxynucleotides. Neuroreport, 2001. 12(14): p. 3029-32.

43. Bos, M.P. and J. Tommassen, Biogenesis of the Gram-negative bacterial outer membrane. Curr Opin Microbiol, 2004. 7(6): p. 610-6.

44. Chung, I.Y. and E.N. Benveniste, Tumor necrosis factor-alpha production by astrocytes. Induction by lipopolysaccharide, IFN-gamma, and IL-1 beta. J Immunol, 1990. 144(8): p. 2999-3007.

45. Bsibsi, M., et al., Broad expression of Toll-like receptors in the human central nervous system. J Neuropathol Exp Neurol, 2002. 61(11): p. 1013-21.

46. Laflamme, N. and S. Rivest, Toll-like receptor 4: the missing link of the cerebral innate immune response triggered by circulating Gram-negative bacterial cell wall components. Faseb J, 2001. 15(1): p. 155-163.

47. Lehnardt, S., et al., The toll-like receptor TLR4 is necessary for lipopolysaccharide-induced oligodendrocyte injury in the CNS. J Neurosci, 2002. 22(7): p. 2478-86.

48. Farina, C., et al., Preferential expression and function of Toll-like receptor 3 in human astrocytes. J Neuroimmunol, 2005. 159(1-2): p. 12-9.

49. Bowman, C.C., et al., Cultured astrocytes express toll-like receptors for bacterial products. Glia, 2003. 43(3): p. 281-91.

50. Luterman, J.D., et al., Cytokine gene expression as a function of the clinical progression of Alzheimer disease dementia. Arch Neurol, 2000. 57(8): p. 1153-60.

51. Cinque, P., et al., Elevated cerebrospinal fluid levels of monocyte chemotactic protein-1 correlate with HIV-1 encephalitis and local viral replication. Aids, 1998. 12(11): p. 1327-32. 




\section{Chapt er}

\section{Possible pathways involved in the control of intracellular Chlamydia pneumoniae infection by microglial cells}

Ellen Boelen, Harry WM Steinbusch, André JAM van der Ven, Gert Grauls, Cathrien A Bruggeman, Frank RM Stassen

\section{Submitted for publication}




\section{Abstract}

Over the past decades, the respiratory pathogen Chlamydia pneumoniae (Cpn) has been frequently associated with a variety of chronic, predominantly inflammatory diseases. Recently, $\mathrm{Cpn}$ has even been related to various neurological diseases. Lately, we demonstrated the susceptibility of various brain cells to $\mathrm{Cpn}$ and found, among others, a striking similarity between monocytes/macrophages and microglial cells (MMC). This inspired us to study whether MMC use pathways similar to bone marrow-derived macrophages, implying a role for IFN- $\gamma$ and nitric oxide, to control intracellular growth of $\mathrm{Cpn}$. However, in contrast to our expectations, adding an IFN- $\gamma$ - neutralizing antibody or an iNOS inhibitor did not change the course of the infection whatsoever. Therefore, we examined whether MMC are able, like bone marrow-derived macrophages, to secrete significant amounts of IFN- $\gamma$ and other cytokines after Cpn infection. To our surprise, no detectable amounts of IFN- $\gamma$ were demonstrated in the supernatants of MMC, at any given time point. On the contrary, TNF- $\alpha$, already implicated in the control of Chlamydia infections, and IL-6 were prominently produced. However, incubation with antibodies against those cytokines did not alter the amount of Cpn DNA copies in infected MMC. In conclusion, the control of intracellular $\mathrm{Cpn}$ growth by MMC is independent of pathways involving either IFN- $\gamma$, nitric oxide, TNF- $\alpha$ or IL-6. Yet, further research is warranted to elucidate the pathways underlying the control of $\mathrm{Cpn}$ infection by MMC. 


\section{Introduction}

Besides being involved in the pathogenesis of cardiovascular diseases and arthritis $^{1-4}$, the obligate intracellular Gram-negative pathogen Chlamydia pneumoniae has recently been suggested to play a role in the progression or even initiation of Alzheimer's disease $(A D)^{5-8}$. In line with this, we recently demonstrated the susceptibility of various brain cell lines to Cpn infection ${ }^{9}$. In particular, neuronal cells and astrocytes were highly sensitive to Cpn infection. In contrast, microglial cells seemed rather resistant as inclusion bodies could only be demonstrated sparsely in these cells. Furthermore, no infectious progeny could be demonstrated despite the continuing presence of Cpn DNA in the cells. These data suggested that microglial cells, in contrast to neurons and astrocytes, are well able to control the infection.

Microglia share phenotypic characteristics (as well as lineage properties) with peripheral monocytes/macrophages ${ }^{10}$. Intriguingly, it has been demonstrated earlier that Cpn infection of the latter reveals similar characteristics as Cpn infection of microglial cells: small or even absent inclusion bodies and no infectious progeny, despite the presence of genomic material ${ }^{11-13}$. Recently, in a set of elegant experiments, Rottenberg and colleagues disclosed an autocrine/paracrine activation pathway, involving a crucial role for type I interferon-alphabeta-dependent interferon gamma (IFN- $\gamma$ ) and iNOS induction in response to $\mathrm{Cpn}$ infection, which protects macrophages against intracellulair bacterial growth ${ }^{14}$. In the present study, we investigated whether microglial cells use similar pathways to control the bacterium.

\section{Material and methods}

\subsection{Chlamydia pneumoniae (Cpn)}

The Cpn strain, TWAR 2043, was obtained from the American Type Culture Collection (ATCC VR-1355) and continuously propagated on Hep2 cells as described previously ${ }^{15}$. Bacterial titres were established by titration in Hep2 cells, as described by Ezzahiri ${ }^{1}$, and expressed as the number of inclusion forming units per millilitre (IFU/mL). Staining was executed by a mononuclear chlamydia LPS-specific antibody succeeded by a secondary FITC-conjugated antibody (RR402, DAKO, Glostrup, Denmark). 


\subsection{Cell cultures}

Murine microglial cells (MMC - BV-2) ${ }^{16}$ were cultured in Dulbecco's Modified Eagle's medium (DMEM) (GIBCO, Grand Island, NY, USA) supplemented with $10 \%$ foetal bovine serum, $5 \mathrm{M}$ Hepes and $2 \mathrm{mM}$ L-glutamine.

Human Epithelial cells (Hep2; ATCC CCL-23) were grown in Eagle's Minimal Essential Medium (EMEM) (Bambrex BioScience, Verviers, Belgium) supplemented with $2 \mathrm{mM}$ L-glutamine, $10 \%$ foetal calf serum and $0.1 \mathrm{mM}$ nonessential amino acids.

MMC were infected by applying a dilution of $\mathrm{Cpn}$ in the original culture medium with only $2 \%$ foetal calf serum and addition of $0.03 \mu \mathrm{g} / \mathrm{mL}$ cycloheximide, which has been described to enhance infectivity ${ }^{17}$. Optimal infection efficiency and growth of $\mathrm{Cpn}$ were achieved with this concentration of cycloheximide, as shown previously our laboratory'.

All cells were cultured in $75-\mathrm{cm}^{2}$ flasks at $37^{\circ} \mathrm{C}$ with $5 \% \mathrm{CO}_{2}$ and saturated humidity.

\subsection{Infection protocol}

By growing MMC in 24-well tissue culture plates (Corning Incorporated, NY, USA) at a density of $10^{5}$ cells per well for 24 hours (hr), confluency was obtained. After removing the original culture medium, this confluent cell monolayer was infected by incubation with culture medium containing $\mathrm{Cpn}$ at a multiplicity of infection (MOI) of 5 for 1 hour at $20^{\circ} \mathrm{C}$ and $4500 \mathrm{rpm}$. Subsequently, the inoculum was removed, the cells were washed three times, the appropriate infection medium without $\mathrm{Cpn}$ or cycloheximide was re-applied and cells were cultivated for different periods at $37^{\circ} \mathrm{C}$. Controls (mock infected), consisting of cells incubated with sucrose-phosphate-glucose solution (SPG, solution for storage of $\mathrm{Cpn}$ ), were also included and processed in the same manner as Cpn infected cells.

\subsection{IFN- $\gamma$ and NO neutralization assay}

As interferon gamma (IFN- $\gamma$ ) and nitric oxide (NO) were shown to control intracellular $\mathrm{Cpn}$ infection in bone-marrow-derived macrophages ${ }^{14}$, we treated infected cells with either an IFN- $\gamma$-neutralizing antibody, with an inhibitor of iNOS, N-nitro-L-arginine (N-LA) (Sigma-Aldrich, St. Louis, USA) or a combination of both. Therefore, post $\mathrm{Cpn} /$ mock infection, inoculum was replaced by infection medium without $\mathrm{Cpn}$ or cycloheximide but supplemented 
with $5 \mathrm{ng} / \mathrm{mL}$ (according to the manufacturer's manual) anti-IFN- $\gamma$ (rabbit polyclonal anti-mouse IFN- $\gamma$; Abcam Ltd., Cambridge, UK) or N-LA, a NO inhibitor $(30-100 \mu \mathrm{M})$. Additionally, a combination of $5 \mathrm{ng} / \mathrm{mL}$ anti-IFN- $\gamma$ and $100 \mu \mathrm{M} N$-LA was applied to the infection medium. Effectiveness of the iNOS inhibition was confirmed by measuring the amount of $\mathrm{NO}^{2-}$ in the supernatant (see below).

\subsection{IFN- $\gamma$, IL-6 and TNF- $\alpha$ cytokine assay}

In order to assess cytokine production after $\mathrm{Cpn}$ infection, medium of infected/control microglial cells was collected at various time points post infection (1, 3, 6, 12, 24, 48 and $72 \mathrm{hr})$. Subsequently, after centrifugation of the medium for $10 \mathrm{~min}$ at $20^{\circ} \mathrm{C}$ and $1200 \mathrm{rpm}$, the supernatant was applied for analysis. Various cytokines were measured simultaneously, using a commercially available multiplex cytometric bead assay (mouse Th-1/Th-2 and inflammation kit) (Becton Dickinson Biosciences, Alphen aan den Rijn, The Netherlands), as described before ${ }^{18}$. In short, a mixture of $5 \mu \mathrm{L}$ of the sample, capture bead suspension and detection reagent were used. After resuspending the bead pellet, it was analysed on a FACS Calibur flow cytometer (BD Biosciences, Alphen aan den Rijn, The Netherlands). The detection limit of IFN$\gamma$, interleukin(IL)-6 and tumour necrosis factor(TNF)- $\alpha$ was $2.5 \mathrm{pg}$ per ml. For every condition, cytokine levels were calculated in three different wells. Total experiment was performed in fourfold.

\subsection{TNF- $\alpha$ and IL-6 neutralization assays}

Based on the high amounts of TNF- $\alpha$ and IL- 6 produced by infected MMC, and on the previously reported role for at least TNF- $\alpha$ in controlling the intracellular growth of Chlamydia ${ }^{19,20}$, we decided to study the possible contribution of these cytokines to the control of Cpn infection by MMC. Therefore, IL-6 was neutralized by the addition of $30 \mathrm{ng} / \mathrm{ml}(\sim 10 \mathrm{x}$ excess of the maximal amount measured in MMC post infection) of a rabbit polyclonal anti-IL-6 (Abcam Ltd., Cambridge, UK) to fresh infection medium post Cpn/mock infection (p.i.). TNF- $\alpha$ neutralization was performed in a similar way, with $30 \mathrm{ng} / \mathrm{ml}$ (10-fold the concentration measured in MMC p.i.) of a TNF- $\alpha$ neutralizing antibody (rat monoclonal anti- TNF- $\alpha$, Abcam Ltd., Cambridge, UK). Furthermore, to evaluate whether the effects of TNF- $\alpha$ and IL-6 are additive, a mixture of IL-6 $(30 \mathrm{ng} / \mathrm{ml})$ and TNF- $\alpha(30 \mathrm{ng} / \mathrm{ml})$ neutralizing antibodies was applied. 
As a control, standard infection protocols were followed as described in 2.3.. For each condition, 3 wells were included and total experiment was performed in fourfold. MMC were screened for intracellular Cpn by real-time PCR.

\subsection{Measurement of iNOS activity}

For the determination of iNOS activity, nitric oxide (NO) levels were assessed in the supernatant of microglial cells under several conditions. However, $\mathrm{NO}$ is a molecule with only a short half-life that is rapidly converted to its oxidation products nitrite $\left(\mathrm{NO}_{2}{ }^{-}\right)$and nitrate $\left(\mathrm{NO}_{3}{ }^{-}\right)$. Fortunately, as a measure for $\mathrm{NO}$ production, the stable end product $\mathrm{NO}_{2}^{-}$can easily be determined using the Griess method. Therefore, $50 \mu \mathrm{L}$ of the supernatants of microglial cells, treated for 24, 48 and $72 \mathrm{hr}$ with various conditioned media, were mixed in a 96-well microtitreplate (Sarstedt, Sevelen, Switzerland) with $50 \mu \mathrm{L}$ Griess reagent, consisting of sulphanilamide, $\mathrm{N}$-1-naphtyl-ethylediamine and $25 \% \mathrm{H}_{2} \mathrm{SO}_{4}$. Next, optical densities were measured at a wavelength of $550 \mathrm{~nm}$, using a spectrophotometer (Powerwave X Select) and concentrations were calculated.

\subsection{Intracelllar Cpn detection}

\section{Immunofluorescence}

At various time intervals after incubation (24, 48 and $72 \mathrm{hr}$ ), monolayers were washed with phosphate-buffered saline (PBS) and fixed with methanol. Staining for Cpn detection was performed as described previously ${ }^{9}$ and viewed with an inverted fluorescent microscope (magnification of 400x). Finally, the number of infected MMC and total number of cells were calculated in 5 fields per well.

\section{$\underline{\text { Real-time PCR }}$}

DNA was isolated from frozen cell pellets at 24,48 and $72 \mathrm{hr}$ post incubation, using methods previously described ${ }^{21}$. Lysis buffer together with $50 \mathrm{ng} / \mathrm{ml}$ proteinase $\mathrm{K}$ (Roche, Indianapolis, USA) were added to the pellets. After incubation for $60 \mathrm{~min}$ at $56^{\circ} \mathrm{C}$, DNA was extracted by phenol:chloroform (1:1) and precipitated with ethanol. The NanoDrop $®$ ND-1000, a full-spectrum (220$750 \mathrm{~nm}$ ) spectrophotometer was applied to measure the DNA content of each sample. Finally, the amount of Cpn DNA copy number/ $\mu \mathrm{g}$ DNA was measured in the collected cells by real-time PCR (ABI Prism 7000, Applied Biosystems, Foster City, USA), as described previously ${ }^{9}$. 


\subsection{Extracellular Cpn detection}

If the replication cycle of $\mathrm{Cpn}$ can be completed in microglial cells, infectious elementary bodies will be released in the culture supernatant (extracellularly). Therefore, media of the various conditions, described in 2.4.-2.6., were collected after $72 \mathrm{hr}$ of incubation and transferred to Hep2 cells (susceptible cell line). Seventy-two hours later, the presence of $\mathrm{Cpn}$ antigens in these cells was analysed by indirect immunofluorescence, as described. Cells positive for $\mathrm{Cpn}$ and total number of cells were counted in 5 fields (magnification: 200x) per well and the average percentage positive cells was calculated for three wells. Total experiment was performed in fourfold.

\subsection{Data analysis}

All experiments were conducted in fourfold and each individual experiment consisted of 3 individual measurements. Data are expressed as means \pm standard error of the means (SEM) $(n=4)$. For the statistical analysis of our results, SPSS 11.0 for Windows was used. Levels of significance were determined using the Mann-Whitney $U$-test. A $p$-value of $\leq 0.05$ was considered significant.

\section{Results}

\subsection{Presence of Chlamydia pneumoniae}

First, we studied the course of infection with immunofluorescense. When cells were infected with an $\mathrm{MOI}$ of 5 , a biphasic pattern was observed, which is in accordance with earlier data (Figure 1$)^{9}$. Initially, multiple small inclusions were observed which were then replaced at 48 and $72 \mathrm{hr}$ by larger inclusion bodies. In contrast to the small initial inclusion, these larger inclusion bodies were only observed in a limited number of cells $(<1 \%)$. When we evaluated the course of infection by determining the number of DNA copies present per $\mu \mathrm{g}$ of total DNA, a decline could be observed after $48 \mathrm{hr}$ (Figure 2). It should be noted that although the number of cells containing the larger inclusion bodies is limited, the total amount of Cpn DNA is still considerable at $72 \mathrm{hr}$ post infection (p.i.) ( \pm $5000 \mathrm{Cpn}$ DNA copies per $\mu \mathrm{g}$ DNA). Moreover, only limited infectious progeny was produced at later time points as the percentage of Cpn positive Hep2 cells was low when these cells were incubated for $72 \mathrm{hr}$ with conditioned supernatants, obtained from infected MMC (Figure 3). 

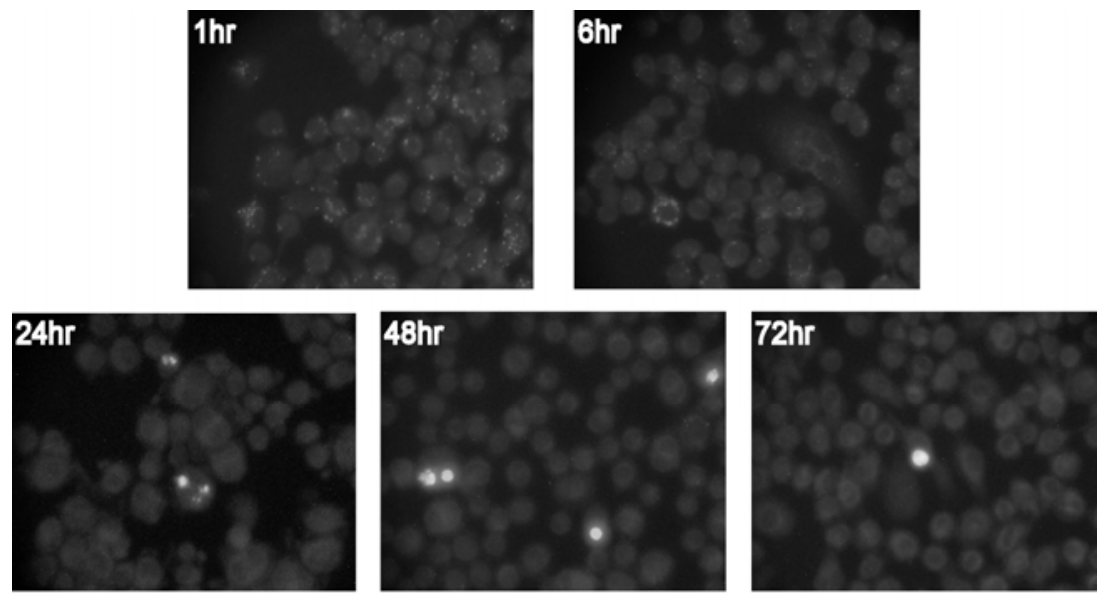

Figure 1. Immunofluorescent detection of Chlamydia pneumoniae (Cpn) antigens in microglial cells at 1, 6, 24, 48 and $72 \mathrm{hr}$ post infection (p.i.). Staining was performed with a primary antibody directed against the Cpn major membrane outer protein (MOMP) and a secondary Alexa Fluor 488 labelled antibody (green signal). Evan's blue (red signal) was applied for counterstaining. Original magnification, 400x. (See coloured illustration inserted at the back of this thesis).

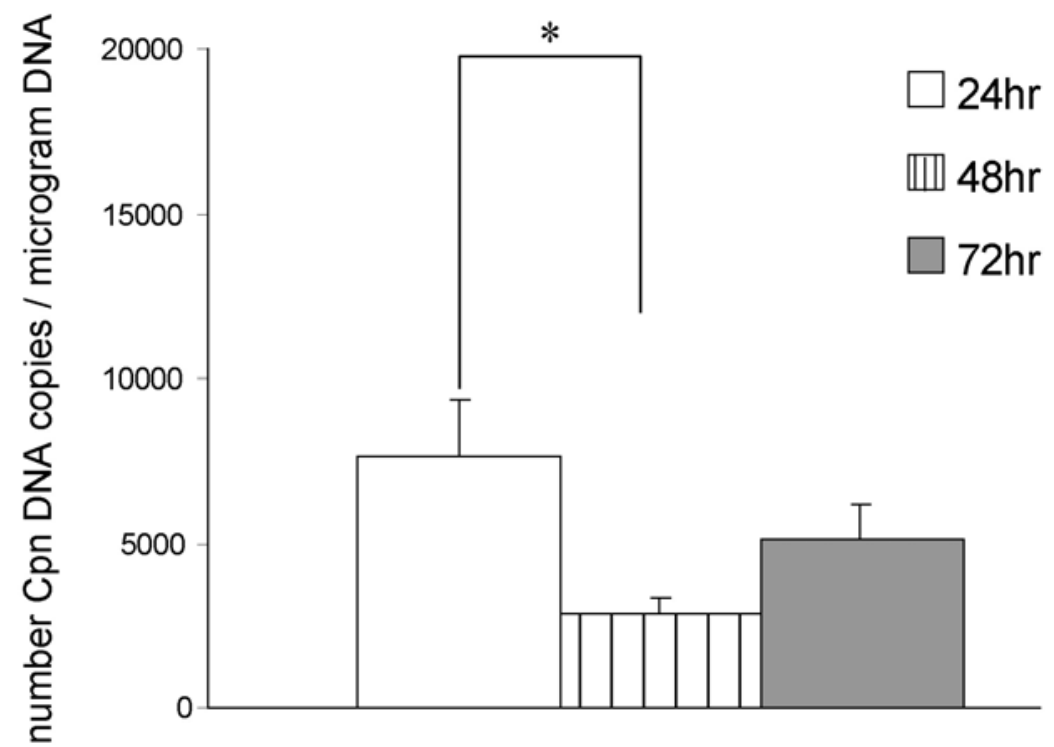

Figure 2. Determination of Cpn DNA in infected microglial cells by real-time PCR. The mean number of Cpn DNA copies per $\mu \mathrm{g}$ DNA was shown at 24, 48 and $72 \mathrm{hr}$ post Cpn infection. Total experiment was performed in fourfold and error bars represent the SE of the means. *significant difference between the time points indicated $(p<0.05)$. 


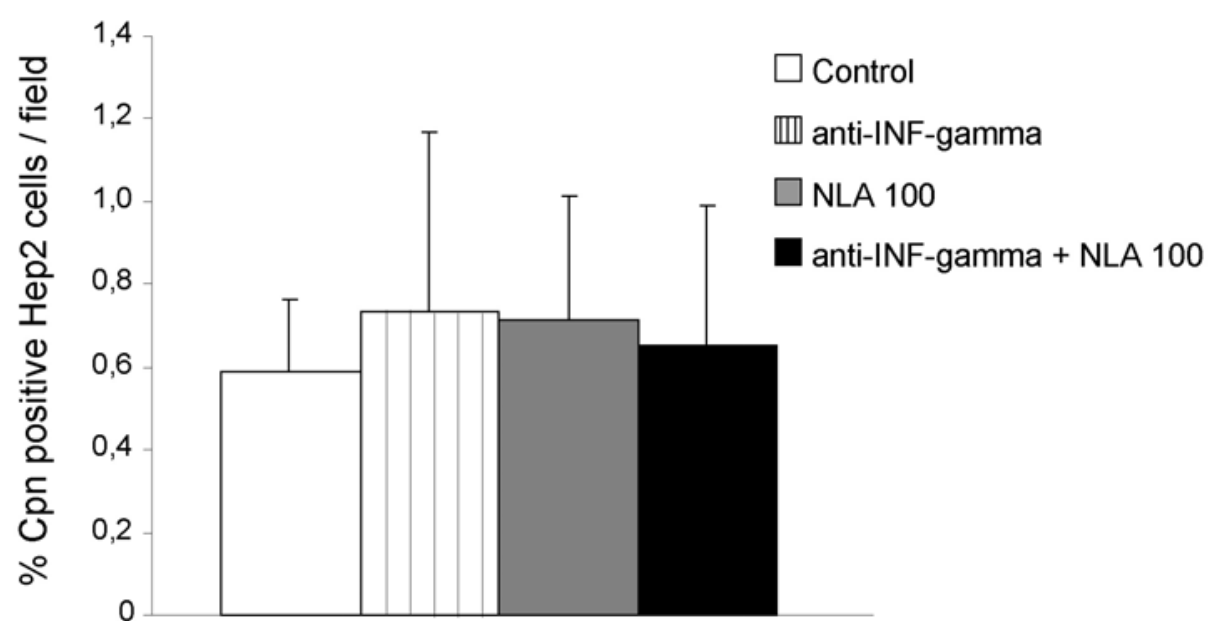

Figure 3. Detection of $\mathrm{Cpn}$ in Hep2 cells after inoculation for $72 \mathrm{hr}$ with either untreated or anti-IFN-gamma, NLA $(100 \mu \mathrm{M})$ and anti-IFN-gamma + NLA treated supernatant of $\mathrm{Cpn}$ infected microglial cells at $72 \mathrm{hr}$ post infection. Immunofluorescent positive cells were counted in 5 fields per well and the average percentage Cpn positive cells/field was calculated for three wells. Total experiment was performed in fourfold. Error bars, SE of the means.

\subsection{The control of Cpn infection in microglial cells}

\section{NO and IFN- $\gamma$ neutralization}

Previously, both IFN- $\gamma$ and nitric oxide have been implicated in the control of intracellular $\mathrm{Cpn}$ infections ${ }^{14}$. Indeed, we were able to detect a significant increase in the nitrite levels of supernatants collected from Cpn infected microglial cells. This NO production could be inhibited up to $72 \mathrm{hr}$ p.i. by the addition of the iNOS inhibitor N-LA (Figure 4). However, in contrast to our hypothesis, inhibition of the NO production did not affect the percentage of $\mathrm{Cpn}$ positive microglial cells up to $72 \mathrm{hr}$ p.i. (Figure 5). Likewise, no effect of NO inhibition was observed on the production of infectious progeny as the percentage of Hep2 cells, that showed signs of infection following exposure to supernatant from MMC, was unaffected by treatment (Figure 3).

Then, we evaluated the effects of an IFN- $\gamma$-neutralizing antibody on the course of infection in MMC. MMC were again infected with $\mathrm{Cpn}$ and subsequently incubated with anti-IFN- $\gamma(5 \mathrm{ng} / \mathrm{ml})$ for up to 5 days. However, no effects were observed either on i) the percentage of Cpn-positive cells (Figure 5), ii) the production of infectious progeny (Figure 3), or iii) the number of Cpn DNA copies per $\mu \mathrm{g}$ total DNA (Figure 6). These data suggest that, in contrast to its suggested role in bone marrow-derived macrophages, IFN- $\gamma$ does not play a 
significant role in controlling $\mathrm{Cpn}$ in MMC. This is further corroborated by our finding that infected MMC do not produce any detectable IFN- $\gamma$ at any time point p.i.. Also, the simultaneous inhibition of NO production and the neutralization of IFN- $\gamma$ did not reveal any effect on any parameter evaluated (Figure 3-6).

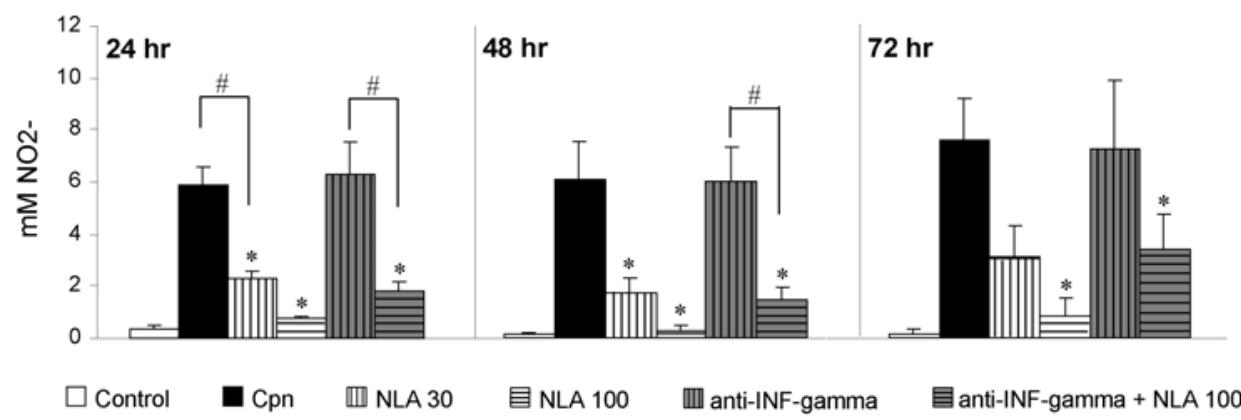

Figure 4. $\mathrm{NO}^{2-}$ measurements in the supernatant of mock infected (control) or $\mathrm{Cpn}$ infected microglial cells, either untreated or treated with an iNOS inhibitor (NLA) at a concentration of 30 and $100 \mu \mathrm{M}$, with an antibody against IFN-gamma or a combination of NLA $100 \mu \mathrm{M}$ and anti-IFN-gamma. At 24,48 and $72 \mathrm{hr}$ post infection under the various conditions, mean $\mathrm{NO}^{2-}$ levels were calculated for three wells per condition and total experiment was performed in fourfold. ${ }^{*} p<0.05$ vs. untreated $\mathrm{Cpn}$ infected microglial cells. \#significant difference between the conditions indicated $(p<0.05)$. Error bars, $S E$ of the means.

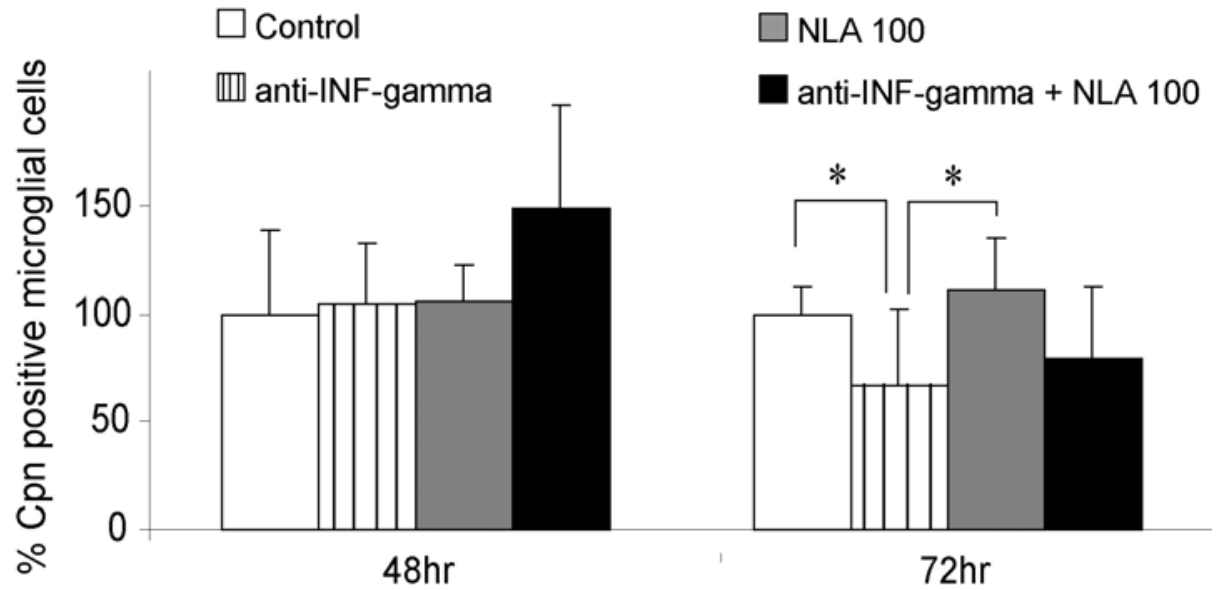

Figure 5. Percentages infected microglial cells (MMC) after normal Cpn infection ( $\square$ ) or with addition of either an IFN-gamma antibody ( 四), an iNOS inhibitor (NLA 100 $\mu \mathrm{M})(\square)$ or a combination of anti-IFN-gamma + NLA 100 ( $)$. At 48 and $72 \mathrm{hr}$ post infection, the mean percentages normal infected microglial cells were designated at $100 \%$ and the results of all interventions were expressed as a fraction thereof. ${ }^{*}$ significant difference between conditions indicated $(p<0.05)$. Error bars, SE of the means. 


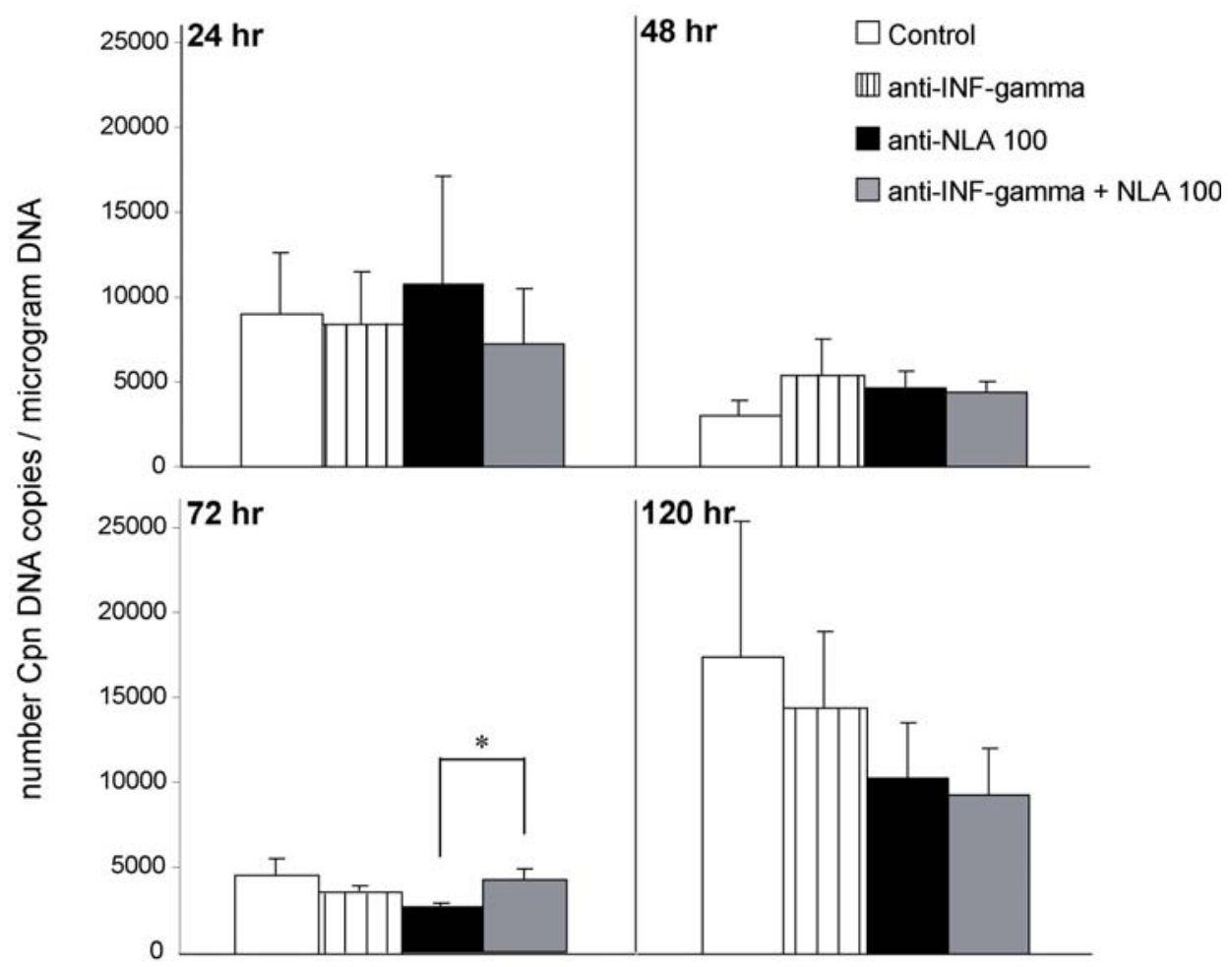

Figure 6. Presence of Cpn DNA in Cpn infected microglial cells, either untreated (control) or treated with an antibody against IFN-gamma, an iNOS inhibitor at a concentration of $100 \mu \mathrm{M}$ (NLA 100) or anti-IFN-gamma + NLA 100. The mean number of Cpn DNA copies per $\mu \mathrm{g}$ DNA was calculated by real-time PCR in three wells/condition at 24, 48, 72 and $120 \mathrm{hr}$ post infection. Total experiment was conducted in fourfold. *significant difference between the conditions indicated $(p<0.05)$. Error bars, SE of the means.

\section{$\underline{\text { LL-6 }}$ and TNF- $\alpha$ neutralization}

Previously, it has been shown by others that Chlamydia infection results in the release of various inflammatory cytokines by different cell types. Most prominently, IL-6 and TNF- $\alpha$ have been shown to be produced by e.g. smooth muscle cells, epithelial cells, endothelial cells and macrophages ${ }^{22-25}$. Likewise, MMC are able to produce these cytokines in response to Cpn (Table 1). 
Table 1. Cytokine production of microglial cells at 24,48 and $72 \mathrm{hr}$ post mock/Cpn infection.

\begin{tabular}{lc|c|c} 
& & & \\
& & Mock infection & Cpn infection \\
\hline IL-12p (pg/mL) & $24 \mathrm{hr}$ & $1.9 \pm 1.1$ & $8.1 \pm 4.1$ \\
& $48 \mathrm{hr}$ & $90.1 \pm 52$ & $140.3 \pm 133.8$ \\
& $72 \mathrm{hr}$ & $3.1 \pm 1.8$ & $6.2 \pm 2.0$ \\
\hline IL-6 $(\mathrm{pg} / \mathrm{mL})$ & & & \\
& $24 \mathrm{hr}$ & $3.5 \pm 0.1$ & $3063 \pm 1254^{*}$ \\
& $48 \mathrm{hr}$ & $10.6 \pm 3.8$ & $2783 \pm 1285^{*}$ \\
\hline TNF- $\alpha(\mathrm{pg} / \mathrm{mL})$ & & $10.0 \pm 2.9$ & $2722 \pm 1462^{*}$ \\
& $24 \mathrm{hr}$ & $43 \pm 10$ & $2244 \pm 633^{*}$ \\
& $48 \mathrm{hr}$ & $431 \pm 382$ & $1138 \pm 530$
\end{tabular}

Cytokine levels were expressed as the mean value of four independent experiments, together with the corresponding standard error of the mean. ${ }^{*} p<0.05$ vs. mock infection.

Interestingly, it has previously been shown that TNF- $\alpha$ is able to inhibit the development of Chlamydia trachomatis in Hep2 cells ${ }^{19,20}$. As MMC also produce significant amounts of TNF- $\alpha$ in response to $\mathrm{Cpn}$ infection, we hypothesized that instead of IFN- $\gamma$ and NO, TNF- $\alpha$ might be the prominent factor in controlling $\mathrm{Cpn}$ infection in MMC. Therefore, MMC were treated with a neutralizing TNF- $\alpha$ antibody, immediately following infection. Nevertheless, apart from a small, though significant reduction in the number of Cpn DNA copies at $24 \mathrm{hr}$ p.i., neutralizing TNF- $\alpha$ did not affect the number of Cpn DNA copies at any time point p.i., suggesting that TNF- $\alpha$ is also dispensable for controlling Cpn in MMC (Figure 7).

Although it is well established that many Chlamydia infected cells are a source of IL-6 ${ }^{24,26}$, it is unclear whether the cytokine plays a role in controlling Chlamydia infections. To study this we incubated our Cpn infected MMC, which also produce large amounts of IL-6, with a IL-6 neutralizing antibody for up to 5 days. However, as already observed for TNF- $\alpha$, neutralizing IL- 6 did not alter the course of infection, as determined by the number of Cpn DNA copies per $\mu \mathrm{g}$ 
of total DNA (Figure 7). Also, the simultaneous neutralization of IL-6 and TNF- $\alpha$ did not affect the number of Cpn DNA copies at any time point.

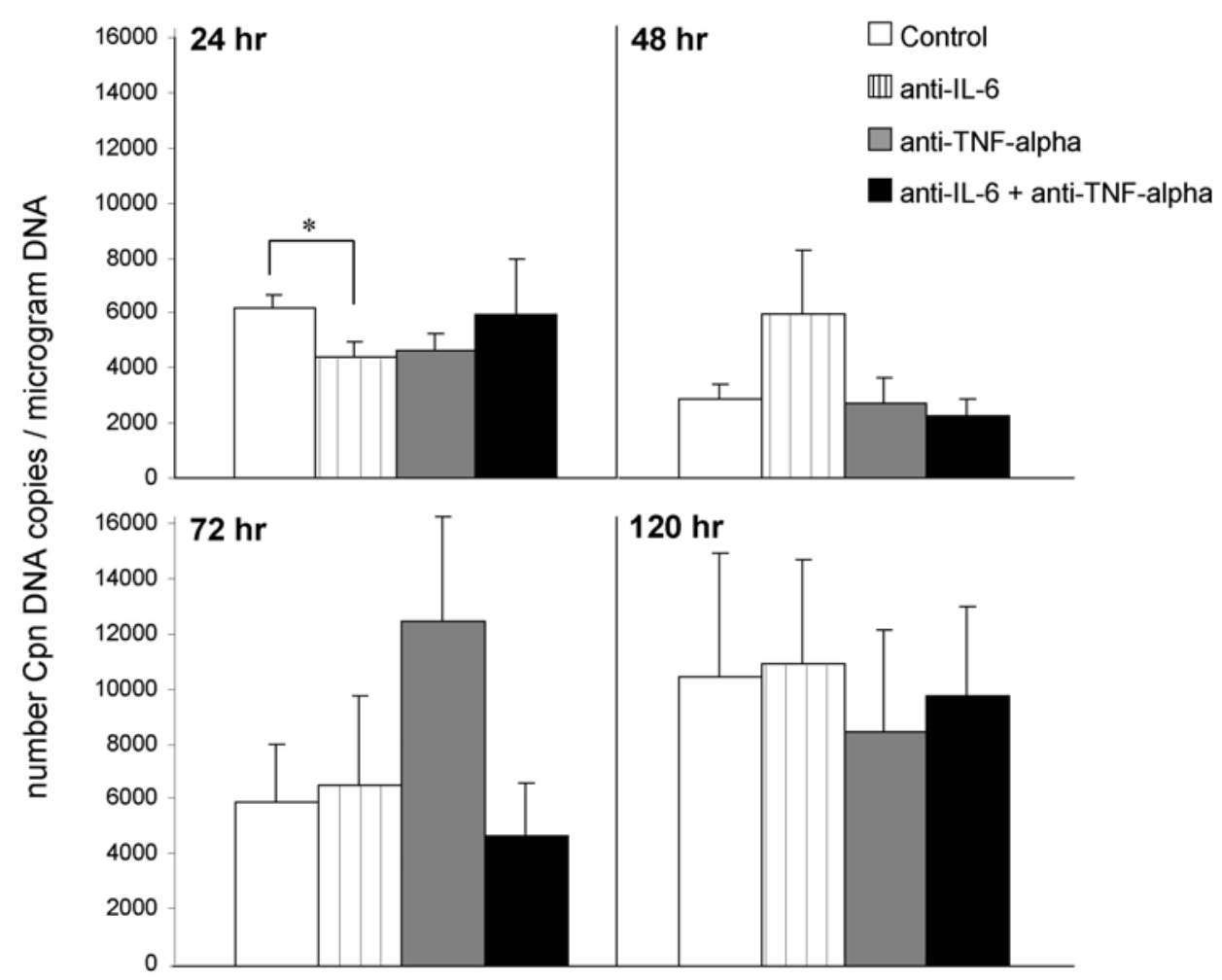

Figure 7. Presence of $\mathrm{Cpn}$ DNA in $\mathrm{Cpn}$ infected microglial cells either untreated (control) or treated with an antibody against IL-6, TNF-alpha or a combination of anti-IL-6 + anti-TNF-alpha. The mean number of Cpn DNA copies per $\mu \mathrm{g}$ DNA was calculated by real-time PCR in three wells/condition at $24,48,72$ and $120 \mathrm{hr}$ post infection. Total experiment was performed in fourfold. *significant difference between the conditions indicated $(p<0.05)$. Error bars, SE of the means.

Taken together, these results suggest that neither IFN- $\gamma$, TNF- $\alpha$, IL-6 nor nitric oxide play an important role in controlling $\mathrm{Cpn}$ infection by MMC. 


\section{Discussion}

Chlamydia pneumoniae (Cpn) was originally identified as a respiratory pathogen and a major cause of community-acquired pneumonia ${ }^{27,28}$. Over the past decades, however, $\mathrm{Cpn}$ has frequently been associated with a large variety of chronic diseases, which are predominantly inflammatory in nature. For instance, strong serological evidence exists demonstrating an association between $\mathrm{Cpn}$ and cardiovascular diseases, like atherosclerosis ${ }^{2,29,30}$. Also, some studies have suggested a possible association between $\mathrm{Cpn}$ and acute exacerbations of asthma ${ }^{31,32}$ or chronic obstructive pulmonary disease $(\mathrm{COPD})^{33,34}$. Others demonstrated the presence of $\mathrm{Cpn}$ in the synovium and suggested that it might be involved in the pathogenesis of arthritis ${ }^{4}$. More recently, Cpn has also been associated with neurological diseases, like multiple

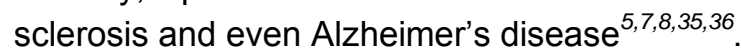

Although Cpn primarily infects the respiratory tract, it is well established that the pathogen disseminates throughout the whole body, as has been demonstrated in various animal models ${ }^{37,38}$. Although the exact mechanism is still not completely unravelled, it has been proposed that Cpn infected alveolar macrophages transmigrate through the mucosal barrier and give the pathogen access to the lymphatic system and the systemic circulation. Then, infected peripheral blood monocytes may act as the vector system within the bloodstream and transmit the infection ${ }^{39}$. Furthermore, it has been demonstrated that $\mathrm{Cpn}$, once inside a monocyte, enters a persistent state not covered by an otherwise effective antichlamydial treatment ${ }^{40}$. Recently, a molecular mechanism, involving an IFN $\alpha / \beta$-dependent release of IFN- $\gamma$ and $\mathrm{NO}$, has been shown to be responsible for the control of an intracellular Cpn infection in bone marrow-derived macrophages ${ }^{14}$.

In our laboratory, we are interested in the possible role of $\mathrm{Cpn}$ in neurodegenerative diseases, like Alzheimer's disease. Recently, we demonstrated the susceptibility of various brain cells to $\mathrm{Cpn}^{9}$ and one of our main findings was the striking similarity between monocytes/macrophages and microglial cells, the monocyte/macrophage equivalent in the brain $^{41}$, with respect to the course of infection ${ }^{42-44}$. This observation and the current consensus that microglia are derived from circulating blood monocytes, that originate from the bone marrow and are seeded within the nervous system around the time of birth and postnatally ${ }^{45}$, inspired us to study whether MMC use pathways similar to bone marrow-derived macrophages to control intracellular growth of Cpn.

As shown before ${ }^{9}$, immunofluorescent staining revealed a biphasic pattern in the course of infection. Initially, a significant amount of internalised elementary 
bodies could be observed early p.i.. However, at later time points (48/72 $\mathrm{hr}$ p.i.), only a limited percentage of all MMC showed positive staining for Cpn. In line with this is the relative absence of infectious progeny as $<1 \%$ of all Hep2 cells stained positive in the reporter assay. Also, the number of Cpn DNA copies/ $\mu \mathrm{g}$ total DNA declined in time but still a significant amount was detected. All these findings are indicative of a persistent infection phenotype, as has been demonstrated before in other cell types of the myeloid origin ${ }^{11,40}$. However, in contrast to our expectations, adding an IFN- $\gamma$ - neutralizing antibody did not change the course of the infection whatsoever. No effect was observed either on the number of Cpn DNA copies/ $\mu$ g total DNA, the number or immunopositive MMC or the production of infectious progeny. Therefore, we examined whether MMC are able to secrete significant amounts of IFN- $\gamma$. To our surprise and in contrast to earlier findings in bone marrow-derived macrophages ${ }^{14}$, no detectable amounts of IFN- $\gamma$ were demonstrated in the supernatants of MMC at any given time point, which may explain the absence of an effect of the IFN- $\gamma$ neutralizing antibody. Previously, it has been shown that the presence of IL-12 and eventually IL-18 may be a prerequisite for the production of IFN- $\gamma$ by myeloid cells ${ }^{46-48}$. Although we didn't measure these cytokines in the present study, we previously demonstrated that MMC are well capable of producing at least IL-12 following Cpn infection ${ }^{18}$, thereby excluding the possibility that a necessary auto/paracrine signal for the induction of IFN- $\gamma$ is missing. Additionally, there has been some debate whether macrophages are truly capable of producing IFN- $\gamma$ as none of the well established macrophage cell lines seem to be able to express mRNA or protein following stimulation ${ }^{49}$. Hence, it has been suggested that the detectable amounts of IFN- $\gamma$, measured in primary cell cultures of either bone marrow-derived macrophages, peritoneal or splenic macrophages, might be due to possible contamination by lymphocytes $^{50-52}$. As our MMC are also a cell line and the presence of lymphocytes is therefore excluded, this may explain the absence of IFN- $\gamma$ in the supernatant of infected MMC, despite the presence of measurable amounts of IL-12.

Rothfuchs and colleagues also demonstrated a prominent role for nitric oxide (NO) in the control of intracellular growth of $\mathrm{Cpn}$ by bone marrow-derived macrophages. Here, we demonstrate that MMC are also able to produce NO in response to Cpn infection. Furthermore, the iNOS inhibitor N-LA was readily able to inhibit the NO production. Nevertheless, as with the IFN- $\gamma$ neutralizing antibody, no effects were seen on the course of the Cpn infection. Similarly, the simultaneous addition of N-LA and IFN- $\gamma$ neutralizing antibody did not affect the Cpn infection. These findings suggests that, although MMC are well able to 
control intracellular Cpn growth and the production of infectious progeny, IFN- $\gamma$ and $\mathrm{NO}$ do not play a prominent role in this process.

Apart from IFN- $\gamma$ and NO, TNF- $\alpha$ has also been implicated in the control of Chlamydia infections $^{19,20,53}$, most likely through the transcriptional activation of indoleamine dioxygenase, which causes a depletion of intracellular tryptophan $^{54,55}$. As $\mathrm{Cpn}$ infection of $\mathrm{MMC}$ also resulted in the prominent production of TNF- $\alpha$, we evaluated the potential role of this cytokine in controlling intracellular Cpn growth. Yet, incubation with TNF- $\alpha$ neutralizing antibodies also did not affect the number of Cpn DNA copies. Moreover, similar results were obtained when IL-6, a cytokine also produced in large quantities by infected MMC, was neutralized in the supernatant.

In conclusion, these data show that, in contrast to previous data obtained in bone marrow-derived macrophages, the control of intracellular Cpn growth by MMC is independent of pathways involving either IFN- $\gamma$ or nitric oxide. Moreover, we demonstrated that adding TNF- $\alpha$ or IL-6 neutralizing antibodies to the culture medium of Cpn infected MMC did not alter the course of infection, thereby excluding a prominent role for these cytokines. Yet, further research is warranted to elucidate the pathways underlying the control of $\mathrm{Cpn}$ by MMC.

\section{Acknowledgements}

This work was supported by the International Alzheimer's Research Foundation (ISAO; The Netherlands). We would like to thank the students for their technical assistance.

\section{References}

1. Ezzahiri, R., et al., Chlamydia pneumoniae infection induces an unstable atherosclerotic plaque phenotype in LDL-receptor, ApoE double knockout mice. Eur J Vasc Endovasc Surg, 2003. 26(1): p. 88-95.

2. Kuo, C.C., et al., Chlamydia pneumoniae (TWAR) in coronary arteries of young adults (15-34 years old). Proc Natl Acad Sci U S A, 1995. 92(15): p. 6911-4.

3. Moling, O., et al., Chlamydia pneumoniae--reactive arthritis and persistent infection. $\mathrm{Br} \mathrm{J}$ Rheumatol, 1996. 35(11): p. 1189-90.

4. Braun, J., et al., Chlamydia pneumoniae--a new causative agent of reactive arthritis and undifferentiated oligoarthritis. Ann Rheum Dis, 1994. 53(2): p. 100-5.

5. Balin, B.J., et al., Identification and localization of Chlamydia pneumoniae in the Alzheimer's brain. Med Microbiol Immunol (Berl), 1998. 187(1): p. 23-42.

6. Little, C.S., et al., Chlamydia pneumoniae induces Alzheimer-like amyloid plaques in brains of BALB/c mice. Neurobiol Aging, 2004. 25(4): p. 419-29.

7. Stratton, C.W. and S. Sriram, Association of Chlamydia pneumoniae with central nervous system disease. Microbes Infect, 2003. 5(13): p. 1249-53. 
8. Yucesan, C. and S. Sriram, Chlamydia pneumoniae infection of the central nervous system. Curr Opin Neurol, 2001. 14(3): p. 355-9.

9. Boelen, E., et al., Chlamydia pneumoniae infection of brain cells: an in vitro study. Neurobiol Aging, 2007. 28(4): p. 524-32.

10. Squire, L.R., et al., Cellular and Molecular Neuroscience. 2 ed. Fundamental Neuroscience, ed. L.R. Squire, et al. 2003, California: Academic Press, Elsevier Science. 49-339.

11. Airenne, S., et al., Chlamydia pneumoniae infection in human monocytes. Infect Immun, 1999. 67(3): p. 1445-9.

12. Airenne, S., et al., The resistance of human monocyte-derived macrophages to Chlamydia pneumoniae infection is enhanced by interferon-gamma. Apmis, 2000. 108(2): p. 139-44.

13. Wolf, K., E. Fischer, and T. Hackstadt, Degradation of Chlamydia pneumoniae by peripheral blood monocytic cells. Infect Immun, 2005. 73(8): p. 4560-70.

14. Rothfuchs, A.G., et al., IFN-alpha beta-dependent, IFN-gamma secretion by bone marrowderived macrophages controls an intracellular bacterial infection. J Immunol, 2001. 167(11): p. 6453-61.

15. Roblin, P.M., W. Dumornay, and M.R. Hammerschlag, Use of HEp-2 cells for improved isolation and passage of Chlamydia pneumoniae. J Clin Microbiol, 1992. 30(8): p. 1968-71.

16. Blasi, E., et al., Immortalization of murine microglial cells by a v-raf/v-myc carrying retrovirus. J Neuroimmunol, 1990. 27(2-3): p. 229-37.

17. Kuo, C.C. and J.T. Grayston, A sensitive cell line, HL cells, for isolation and propagation of Chlamydia pneumoniae strain TWAR. J Infect Dis, 1990. 162(3): p. 755-8.

18. Boelen, E., et al., Inflammatory responses following Chlamydia pneumoniae infection of glial cells. Eur J Neurosci, 2007. 25(3): p. 753-60.

19. Holtmann, H., et al., Inhibition of growth of Chlamydia trachomatis by tumor necrosis factor is accompanied by increased prostaglandin synthesis. Infect Immun, 1990. 58(10): p. 3168-72.

20. Shemer-Avni, Y., D. Wallach, and I. Sarov, Reversion of the antichlamydial effect of tumor necrosis factor by tryptophan and antibodies to beta interferon. Infect Immun, 1989. 57(11): p. 3484-90.

21. Kaptein, S.J., et al., The r131 gene of rat cytomegalovirus encodes a proinflammatory CC chemokine homolog which is essential for the production of infectious virus in the salivary glands. Virus Genes, 2004. 29(1): p. 43-61.

22. Kol, A., et al., Chlamydial and human heat shock protein 60 s activate human vascular endothelium, smooth muscle cells, and macrophages. J Clin Invest, 1999. 103(4): p. 571-7.

23. Rasmussen, S.J., et al., Secretion of proinflammatory cytokines by epithelial cells in response to Chlamydia infection suggests a central role for epithelial cells in chlamydial pathogenesis. $J$ Clin Invest, 1997. 99(1): p. 77-87.

24. Netea, M.G., et al., Acellular components of Chlamydia pneumoniae stimulate cytokine production in human blood mononuclear cells. Eur J Immunol, 2000. 30(2): p. 541-9.

25. Netea, M.G., et al., Non-LPS components of Chlamydia pneumoniae stimulate cytokine production through Toll-like receptor 2-dependent pathways. Eur J Immunol, 2002. 32(4): p. 1188-95.

26. Kaukoranta-Tolvanen , S.S., et al., Growth of Chlamydia pneumoniae in cultured human peripheral blood mononuclear cells and induction of a cytokine response. Microb Pathog, 1996. 21(3): p. 215-21.

27. Grayston, J.T., et al., A new respiratory tract pathogen: Chlamydia pneumoniae strain TWAR. J Infect Dis, 1990. 161(4): p. 618-25.

28. Kuo, C.C., et al., Chlamydia pneumoniae (TWAR). Clin Microbiol Rev, 1995. 8(4): p. 451-61.

29. Grayston, J.T., Does Chlamydia pneumoniae cause atherosclerosis? Arch Surg, 1999. 134(9): p. 930-4.

30. Kuo, C.C. and L.A. Campbell, Chlamydial infections of the cardiovascular system. Front Biosci, 2003. 8: p. e36-43. 
31. Weinberger, M., Respiratory infections and asthma: current treatment strategies. Drug Discov Today, 2004. 9(19): p. 831-7.

32. Hahn, D.L., T. Anttila, and P. Saikku, Association of Chlamydia pneumoniae IgA antibodies with recently symptomatic asthma. Epidemiol Infect, 1996. 117(3): p. 513-7.

33. Branden, E., et al., Chronic Chlamydia pneumoniae infection is a risk factor for the development of COPD. Respir Med, 2005. 99(1): p. 20-6.

34. Siritantikorn, S., et al., Prevalence and incidence of Chlamydia pneumoniae antibodies among the healthy elderly and patients with chronic obstructive pulmonary diseases. J Med Assoc Thai, 2004. 87(4): p. 377-81.

35. Sriram, S., et al., Chlamydia pneumoniae infection of the central nervous system in multiple sclerosis. Ann Neurol, 1999. 46(1): p. 6-14.

36. Munger, K.L., et al., Infection with Chlamydia pneumoniae and risk of multiple sclerosis. Epidemiology, 2003. 14(2): p. 141-7.

37. Moazed, T.C., et al., Evidence of systemic dissemination of Chlamydia pneumoniae via macrophages in the mouse. J Infect Dis, 1998. 177(5): p. 1322-5.

38. Yang, Z.P., C.C. Kuo, and J.T. Grayston, Systemic dissemination of Chlamydia pneumoniae following intranasal inoculation in mice. J Infect Dis, 1995. 171(3): p. 736-8.

39. Gieffers, J., et al., Phagocytes transmit Chlamydia pneumoniae from the lungs to the vasculature. Eur Respir J, 2004. 23(4): p. 506-10.

40. Gieffers, J., et al., Chlamydia pneumoniae infection in circulating human monocytes is refractory to antibiotic treatment. Circulation, 2001. 103(3): p. 351-6.

41. Streit, W.J., Microglia as neuroprotective, immunocompetent cells of the CNS. Glia, 2002. 40(2): p. 133-9.

42. Gaydos, C.A., et al., Replication of Chlamydia pneumoniae in vitro in human macrophages, endothelial cells, and aortic artery smooth muscle cells. Infect Immun, 1996. 64(5): p. 161420.

43. Haranaga, S., et al., Chlamydia pneumoniae infection of alveolar macrophages: a model. J Infect Dis, 2003. 187(7): p. 1107-15.

44. Redecke, V., et al., Interaction of Chlamydia pneumoniae and human alveolar macrophages: infection and inflammatory response. Am J Respir Cell Mol Biol, 1998. 19(5): p. 721-7.

45. Renzaie, P., Microglia in the Human Nervous System during Development. Neuroembrylogy, 2003. 2: p. 18-31.

46. Munder, M., et al., Murine macrophages secrete interferon gamma upon combined stimulation with interleukin (IL)-12 and IL-18: A novel pathway of autocrine macrophage activation. J Exp Med, 1998. 187(12): p. 2103-8.

47. Puddu, P., et al., IL-12 induces IFN-gamma expression and secretion in mouse peritoneal macrophages. J Immunol, 1997. 159(7): p. 3490-7.

48. Schindler, H., et al., The production of IFN-gamma by IL-12/IL-18-activated macrophages requires STAT4 signaling and is inhibited by IL-4. J Immunol, 2001. 166(5): p. 3075-82.

49. Bogdan, C. and U. Schleicher, Production of interferon-gamma by myeloid cells--fact or fancy? Trends Immunol, 2006. 27(6): p. 282-90.

50. Olstad, R., M. Degre, and R. Seljelid, Production of immune interferon (type II) in cocultures of mouse peritoneal macrophages and syngeneic tumour cells. Scand J Immunol, 1981. 13(6): p. 605-8.

51. Golab, J., et al., Direct stimulation of macrophages by IL-12 and IL-18--a bridge too far? Immunol Lett, 2000. 72(3): p. 153-7.

52. Zhang, T., et al., Interleukin-12 (IL-12) and IL-18 synergistically induce the fungicidal activity of murine peritoneal exudate cells against Cryptococcus neoformans through production of gamma interferon by natural killer cells. Infect Immun, 1997. 65(9): p. 3594-9.

53. Summersgill, J.T., et al., Inhibition of Chlamydia pneumoniae growth in HEp-2 cells pretreated with gamma interferon and tumor necrosis factor alpha. Infect Immun, 1995. 63(7): p. 2801-3. 
54. Robinson, C.M., K.A. Shirey, and J.M. Carlin, Synergistic transcriptional activation of indoleamine dioxygenase by IFN-gamma and tumor necrosis factor-alpha. J Interferon Cytokine Res, 2003. 23(8): p. 413-21.

55. Ishihara, T., et al., Inhibition of chlamydia trachomatis growth by human interferon-alpha: mechanisms and synergistic effect with interferon-gamma and tumor necrosis factor-alpha. Biomed Res, 2005. 26(4): p. 179-85. 



\section{Chapt er}

Impact of Chlamydia pneumoniae infection on astrocytic glutamate uptake - consequences for neurodegeneration

Ellen Boelen, Harry WM Steinbusch, Gert Grauls, André JAM van der Ven, Cathrien A Bruggeman, Frank RM Stassen

\section{Submitted for publication}




\section{Abstract}

Glutamate, a significant neurotransmitter in the central nervous system, is removed from the extracellular space, predominantly by $\mathrm{Na}^{+}$-dependent transporters on astrocytes, thereby preventing neurotoxic glutamate concentrations. Nowadays, evidence exists concerning the impairment of astrocytic glutamate clearance by pathogens like HIV or inflammatory factors, such as TNF- $\alpha$, resulting in neurodegeneration. Recently, the bacterium Chlamydia pneumoniae (Cpn) has been related to these disorders. Therefore, we investigated in the present study whether inflammatory factors, derived from Cpn infected microglial cells, affect glutamate uptake by astrocytes, resulting in neuronal death. High levels of neuronal necrosis were demonstrated when treated with glutamate-conditioned media of astrocytes, which were preincubated with supernatants of $\mathrm{Cpn}$ infected microglial cells. However, to our surprise, these conditions did not alter the mRNA expression of the major glutamate transporter, GLT-1, neither was glutamate uptake by astrocytes affected. Summarizing, we evaluated a potential new pathway by which $\mathrm{Cpn}$ may contribute to neurodegeneration. This involves the modification of astrocytes, after treatment with inflammatory compounds of Cpn infected microglial cells, which makes them respond differently, when exposed to glutamate. This may trigger a cascade of events that ultimately creates a neurotoxic milieu, followed by the death of surrounding neurons. However, to elucidate this hypothesis further and determine these factors, future experiments are mandatory. 


\section{Introduction}

Glutamate is the most important excitatory neurotransmitter in the mammalian central nervous system $(\mathrm{CNS})^{1}$. The metabolism of glutamate consists of glutamate removal from the extracellular space, followed by its return to neurons in the form of glutamine. Several high-affinity $\mathrm{Na}^{+}$-dependent glutamate transporters of the excitatory amino acid transporter (EAAT) family are responsible for the majority of glutamate clearance from the synapse ${ }^{2,3}$. In the rat brain, GLAST (EAAT1) and GLT-1 (EAAT2), predominantly expressed by astrocytes, account for the highest removal of glutamate ${ }^{4}$. Downregulation of these transporters will lead to high extracellular glutamate levels and neurotoxicity. Moreover, elevated synaptic glutamate concentrations have been associated with several neurodegenerative disorders, such as amyotrophic lateral sclerosis (ALS) and Alzheimer's disease (AD) ${ }^{4}$. Recently, infections and the subsequent release of inflammatory mediators, predominantly by microglial cells, have been described to be involved in these processes leading to neuronal death ${ }^{5}$. For example, the human immunodeficiency virus (HIV) has been shown to instigate an impairment in the glutamate uptake in vitro in astrocytes, probably by inhibiting the transcription of EAAT2 $2^{6,7}$. Furthermore, apart from these direct effects of HIV on glutamate processing by astrocytes, the impairment of glutamate uptake may also result from the release of inflammatory mediators following infection. The pro-inflammatory cytokine tumor necrosis factor $\alpha$ (TNF- $\alpha$ ), produced by HIV infected microglia, was shown to be responsible for a decrease in glutamate uptake by primary astrocytes ${ }^{6,8}$.

As already mentioned before, the importance of infections and inflammation in neurodegenerative diseases is increasingly being appreciated ${ }^{9-13}$. Next to several viruses ${ }^{14-16}$, the widespread bacterium Chlamydia pneumoniae (Cpn) has been suggested to be involved in the pathogenesis of several CNS disorders ${ }^{17}$. Cpn is a common Gram-negative pathogen with an obligate intracellular life cycle. Predominantly, infection with $\mathrm{Cpn}$ results in an acute respiratory disease, like pneumonia, but the pathogen has also been associated with more chronic respiratory diseases like $\operatorname{COPD}^{18-21}$. Currently, there is a growing body of evidence suggesting that $\mathrm{Cpn}$ may also be involved in disorders of the CNS, like Alzheimer's disease (AD) and multiple sclerosis $(\mathrm{MS})^{17,22,23}$. However, discrepancies remain about the impact of Cpn infection in these syndromes ${ }^{23-25}$. Recently, we demonstrated in our lab that Cpn can cause neuronal death in vitro both by directly infecting neurons and/or indirectly by inflammatory factors, predominantly IL- 6 and TNF- $\alpha$, produced by infected microglial cells ${ }^{26,27}$. Because of the increasing importance of infections, like 
$\mathrm{Cpn}$, in neurological diseases and the new insights of glutamate transport on the latter, we hypothesized that Cpn, like HIV, affects glutamate clearance by astrocytes and as such may contribute to neurodegenerative processes. As demonstrated before, Cpn infection of astrocytes already results in prominent necrosis of these cells, which already suggests that $\mathrm{Cpn}$ may affect extracellular glutamate concentrations by eliminating the number of astrocytes. In addition, an increase in the concentration of inflammatory mediators in the extracellular milieu, due to the release of these factors from e.g. infected microglial cells, might affect glutamate transport by astrocytes. Therefore, in this study we investigated whether the glutamate transport by astrocytes was affected when these cells were exposed to conditioned medium obtained from Cpn infected microglial cells. Also, we evaluated the possible consequences of such an impairment in glutamate transport on neuronal survival. This may provide an additional pathway by which $\mathrm{Cpn}$ contributes to neurodegenerative diseases like AD.

\section{Material and methods}

\subsection{Chlamydia pneumoniae (Cpn)}

Cpn (TWAR 2043; ATCC VR-1355) was propagated on Hep2 cell monolayers as described previously ${ }^{28}$. By titration in Hep2 cells and staining with a Chlamydia LPS-specific, FITC-conjugated mononuclear antibody (RR402, DAKO, Glostrup, Denmark $)^{29}$, the number of inclusion forming units per millilitre (IFU/ml) was established.

\subsection{Cell cultures}

Murine microglial cells (MMC - BV-2) ${ }^{30}$ were cultured in Dulbecco's Modified Eagle's medium (DMEM) (GIBCO, Grand Island, NY, USA) supplemented with $10 \%$ foetal bovine serum, $5 \mathrm{M}$ Hepes and $2 \mathrm{mM}$ L-glutamine.

Murine Astrocyte type I cells (C8D1A; ATCC CRL-2541) (Rockville, MD, USA) were grown in Dulbecco's Modified Eagle's medium (DMEM) (GIBCO, Grand Island, NY, USA). Culture medium was supplemented with $4 \mathrm{mM} \mathrm{L-glutamine}$ and $10 \%$ horse serum.

Murine Neuroblasts (ATCC CCL-147) were cultured in Kaighn's modification of Ham's F12 medium (GIBCO, Grand Island, NY, USA) supplemented with 15\% horse serum and $2.5 \%$ foetal bovine serum.

In the case of microglial infection, Cpn was diluted in the original culture medium. Serum concentrations were lowered to $2 \%$ and cycloheximide, which 
has been shown to enhance infectivity ${ }^{31}$, was added at a concentration of 0.5 $\mu \mathrm{g} / \mathrm{ml}^{26}$.

All cells were cultured in $75-\mathrm{cm}^{2}$ flasks at $37^{\circ} \mathrm{C}$ with $5 \% \mathrm{CO}_{2}$ and saturated humidity.

\subsection{Infection protocol}

Microglial cells were infected as described before ${ }^{26}$. In brief, cells were seeded in a 24-well tissue culture plate (Corning Incorporated, NY, USA) at a concentration of $10^{5}$ cells/well. The confluent cell layer was incubated with $\mathrm{Cpn}$ at a multiplicity of infection (MOI) of 5 for 1 hour (hr) at $20^{\circ} \mathrm{C}$ and $4500 \mathrm{rpm}$. Subsequently, cells were maintained in the appropriate infection medium without $\mathrm{Cpn}$ for different time points at $37^{\circ} \mathrm{C}$. Controls (mock infected) cells, incubated with sucrose-phosphate-glucose solution (SPG, solution for storage of $(p n)$ were included and processed in the same manner.

\subsection{Consequences of astrocyte pre-treatment with conditioned medium of Cpn infected microglial cells for neuronal cell survival}

The following experiment was performed to investigate whether Cpn infection of microglial cells leads to an impairment in glutamate clearance by astrocytes. Also, we investigated whether such an impairment resulted in neurotoxic glutamate levels in the medium of treated astrocytes by transferring glutamatecontaining medium from either control or treated astrocytes to neuronal cells.

At $24 \mathrm{hr}$ post infection (p.i.), when cytokine levels peaked ${ }^{27}$, medium of $\mathrm{Cpn}$ and mock infected microglial cells was collected and filtered through a 0,2 $\mu \mathrm{m}$ filter (Schleicher and Schuell, s-Hertogenbosch, The Netherlands) to guarantee the removal of all $\mathrm{Cpn}$ particles. Next, the filtered medium was transferred to a confluent astrocyte cell layer, obtained by seeding the cells $24 \mathrm{hr}$ earlier at a density of $5 \times 10^{5}$ cells/well in a 24 -well plate. At 2, 6 and $24 \mathrm{hr}$ post inoculation, the conditioned media were removed and after several wash steps with phosphate-buffered-saline (PBS) replaced by normal astrocyte growth medium without additional glutamine.

Then, $0.25 \mu \mathrm{M}$ L-glutamic acid (Sigma, St. Louis, USA) was added to the astrocytes for $15 \mathrm{~min}$. at $37^{\circ} \mathrm{C}$ to ensure activity of the glutamate transporters. This concentration was chosen because it already caused a maximal toxic effect on neurons in case the glutamic acid is not taken up and processed by the astrocytes (Figure 1). Furthermore, pilot experiments showed that optimal 
uptake was obtained with these concentration during this time period. As control conditions, incubation with glutamate at $0^{\circ} \mathrm{C}$ (transporters inactive) or incubation without any glutamate were included and processed in the same manner.

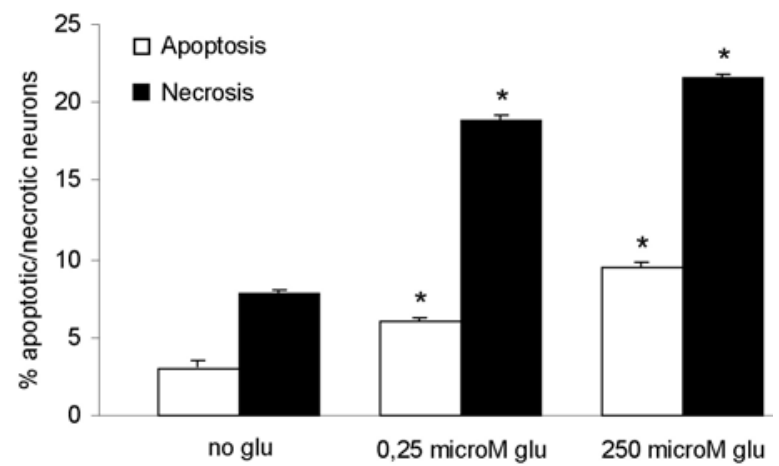

Figure 1 Percentage apoptotic and necrotic neurons after treatment with various concentrations of glutamate (glu). The mean percentage of apoptotic/necrotic neurons at $72 \mathrm{hr}$ after addition of glutamate is showed. ${ }^{*} p \leq 0.05$ in neuronal apoptosis/necrosis vs. no addition of glutamate. Error bars, standard errors of the means (SEM).

Subsequently, all media were collected and transferred to a confluent neuronal cell layer, achieved by seeding the cells $24 \mathrm{hr}$ earlier in a 24-well plate at a density of $5 \times 10^{5}$ cells/well. To establish the effect of the conditioned medium on neuronal necrosis/apoptosis, Hoechst 33258 (HO) (Sigma, St. Louis, USA) and propidium iodide (PI) (Sigma, St. Louis, USA) were added to the neuronal cells as described previously following $72 \mathrm{hr}$ of incubation ${ }^{26}$. By applying these different dyes, one is able to distinguish between living, apoptotic and necrotic cells. PI will stain only necrotic cells because it can only enter cells with a disrupted cell membrane. Healthy and apoptotic cells will both be marked by $\mathrm{HO}$ but the latter display chromatin condensation and nuclear fragmentation ${ }^{32}$. Using an inverted fluorescent microscope (magnification: 400x), the average percentage apoptotic/necrotic neurons was determined for three wells after counting the viable, apoptotic and necrotic cells in 8 fields per well for every condition. The experiment was performed in triplicate.

\subsection{Presence of glutamate transporters in the astrocyte cell line}

\section{GLT-1 mRNA detection}

In astrocytes, the GLT-1 transporter accounts for the majority of glutamate uptake $^{33}$. Moreover, only this transporter has been described to be affected by 
HIV proteins ${ }^{6}$. Therefore, it was investigated by real-time Reverse Transcriptase-Polymerase Chain Reaction (RT-PCR) whether its expression changes also after treatment of astrocytes with conditioned medium of $\mathrm{Cpn}$ or mock infected microglial cells.

Astrocytes were treated as mentioned before and after 2, 6 and $24 \mathrm{hr}$ of incubation with Cpn or mock infected microglia media, total RNA was isolated using TRIzol (Invitrogen, Breda, The Netherlands) according to the manufacturer's instructions. After DNAse treatment by applying DNAse I (0.362 $\mathrm{U}$, Amersham Pharmacia Biotech, Sweden), equal amounts of RNA were reverse transcribed into cDNA. For this reason, $4 \mu \mathrm{L} 5 \mathrm{x}$ iScript Reaction Mix, 1 $\mu \mathrm{L}$ iScript reverse Transcriptase and $10 \mu \mathrm{L}$ Nuclease-free water were added to every $5 \mu \mathrm{L}$ RNA template, according to the instructor's guide (Bio-Rad Laboratories, Hercules, USA). Post incubation, cDNA was obtained and processed further by real-time PCR. Therefore, a total volume of $25 \mu \mathrm{L}$, consisting of $12.5 \mu \mathrm{L}$ iQ Supermix (Bio-Rad, Hercules, USA), 30 pmol forward primer (5'GAAGCCATCATGCGATTGG3'), 30 pmol reverse primer (5'CCCTGCGATCAAGAAGAGGAT3'), $5 \mathrm{pmol}$ probe (5'-FAMCGCGGTGATAATGTGGTATGCGCCT-TAMRA-3'), $2 \mu \mathrm{L}$ NASBA water and 8 $\mu \mathrm{L}$ DNA template was analyzed in the MyiQ ${ }^{\mathrm{TM}}$ Single-Color Real-Time PCR Detection System (Bio-Rad Laboratories, Hercules, USA). Expression of the GLT-1 transporter was normalized to GAPDH-levels. The relative expression (ratio) of GLT-1 was calculated based on the efficiency $(E)$ and the Ct (Cycle Threshold) value of the sample (values at $6,24 \mathrm{hr}$ p.i.) versus a control (values of $2 \mathrm{hr}$ p.i.), and expressed in reference to GAPDH ${ }^{34}$. Ratios were calculated for $\mathrm{Cpn}$ and mock infected astrocytes collected from four wells for each incubation period and the average number was determined. The total experiment was performed in triplicate.

\section{Immunohistochemical detection of GLAST and GLT-1}

To further establish potential variations in glutamate transporter GLT-1 expression after astrocyte treatment with $\mathrm{Cpn}$-induced inflammatory mediators, transporter protein levels were also investigated by immunofluorescence.

First of all, the presence of this transporter was investigated in our astrocyte cell line under normal conditions. Twenty-four hours after seeding the cells in a 24well tissue plate, a confluent layer was achieved, as described above. This monolayer was rinsed with PBS and fixed with methanol. After blocking with PBS $+0.05 \%$ bovine serum albumin (BSA), cells were incubated overnight at room temperature with a mouse monoclonal antibody directed against human EAAT2 (1/100, Novocastra Laboratories Ltd., Newcastle, UK). Subsequently, a 
secondary Alexa Fluor 488 donkey anti-mouse IgG antibody (1/100, Molecular Probes, Oregon, USA) was applied to the astrocytes for 1 hour at room temperature. The astrocytic layer was finally counterstained by Evan's blue and screened for EAAT2 positive signal on an inverted microscope (magnification 400x).

Because astrocytes are also known to express another glutamate transporter, namely EAAT1, the presence of this transporter was also assessed in our astrocyte cell line by identical procedures as described for the EAAT1 with the exception of a primary mouse monoclonal antibody directed against EAAT1 (1/100, Novocastra Laboratories Ltd., Newcastle, UK).

\subsection{L-glutamate uptake assay}

In this assay, we assessed the actual glutamate uptake by astrocytes treated before with medium of $\mathrm{Cpn}$ or mock infected microglial cells versus non-treated astrocytes.

Microglial cells and astrocytes were cultured as described above with the following modifications. After incubation of astrocytes with $\mathrm{Cpn}$ or mock infected microglial cell medium, radio-labelled glutamate was added to the fresh glutamine-free medium. The uptake assay was performed as described by Yao et al. with some minor modifications ${ }^{35}$. L-[3,4- $\left.{ }^{3} \mathrm{H}\right]$-glutamate (NET-490, PerkinElmer Life Sciences Inc., Boston, USA) was added at a concentration of $0.25 \mu \mathrm{mol} / \mathrm{L}$ to each well for $15 \mathrm{~min}$. Thereafter, uptake was blocked by removing the media and washing the cells three times with ice-cold $0.9 \% \mathrm{NaCl}$. Next, astrocytes were harvested in $0.2 \mathrm{~mL}$ lysis buffer and immediately centrifuged at a speed of $11000 \mathrm{rpm}$ for $30 \mathrm{~min}$. at $4^{\circ} \mathrm{C}$. Finally, radioactivity was measured in the supernatant by liquid scintillation counting. Radioactivity was calculated in four wells per condition and expressed as the number of disintegrations per minute $(\mathrm{dpm})$ per $\mu \mathrm{g}$ protein content, measured using the Bradford method.

\subsection{Statistical analysis}

Our results were statistically analyzed using SPSS 11.0 for Windows. Significance was defined by the Mann-Whitney $U$-test. A p-value of $\leq 0.05$ was considered significant.

Percentages neuronal apoptosis/necrosis, GLT-1 mRNA expression and glutamate uptake data were expressed as means of three independent experiments \pm SEM. 


\section{Results}

\subsection{Consequences of astrocyte pre-treatment with conditioned medium of $\mathrm{Cpn}$ infected microglial cells for neuronal cell survival}

Cytokine assays in a previous study showed a maximal cytokine release by microglial cells at $24 \mathrm{hr}$ post $\mathrm{Cpn}$ infection ${ }^{27}$. Therefore, supernatants from this time point were transferred to the astrocyte cell layer for 2, 6 or $24 \mathrm{hr}$. Then, this conditioned microglia culture medium was removed and replaced by fresh astrocyte culture medium. Subsequently, $0.25 \mu \mathrm{M}$ L-glutamic acid was added for $15 \mathrm{~min}$ to the astrocytes. Next, this conditioned astrocyte medium was transferred to a neuronal cell line. Following $72 \mathrm{hr}$ of incubation, the neuronal layer was stained to detect levels of apoptosis and necrosis. As a negative control, the experiment was performed under identical conditions without the addition of L-glutamic acid. Under these L-glutamic acid-free conditions, no significant differences in the number of apoptotic/necrotic neurons were determined when neurons were incubated with medium of astrocytes, pretreated with supernatants of either $\mathrm{Cpn}$ or mock infected MMC at any given time point examined (data not shown). Similarly, no significant difference was found when L-glutamic acid containing astrocyte medium, pre-treated for only $2 \mathrm{hr}$ with supernatant of $\mathrm{Cpn}$ or mock infected MMC, was transferred to the neuronal cells. However, exposure to L-glutamic acid-containing medium of astrocytes, pre-treated for 6 and $24 \mathrm{hr}$ with supernatant of $\mathrm{Cpn}$ infected MMC, revealed a significant higher level of neuronal necrosis (Figure 2) when compared to astrocytes pre-treated with supernatant of mock infected MMC for 6 and $24 \mathrm{hr}$. The percentage of necrotic neurons in the latter reached levels only comparable to those found when cells were incubated with conditioned, L-glutamic acid-free medium. Furthermore, a time related increase was observed as incubation of astrocytes with supernatant of Cpn infected MMC during $24 \mathrm{hr}$ resulted in a significant higher percentage of necrotic neurons when compared to an exposure of only $6 \mathrm{hr}$. For apoptosis, on the other hand, no significant variations were detected in either one of the conditions. 

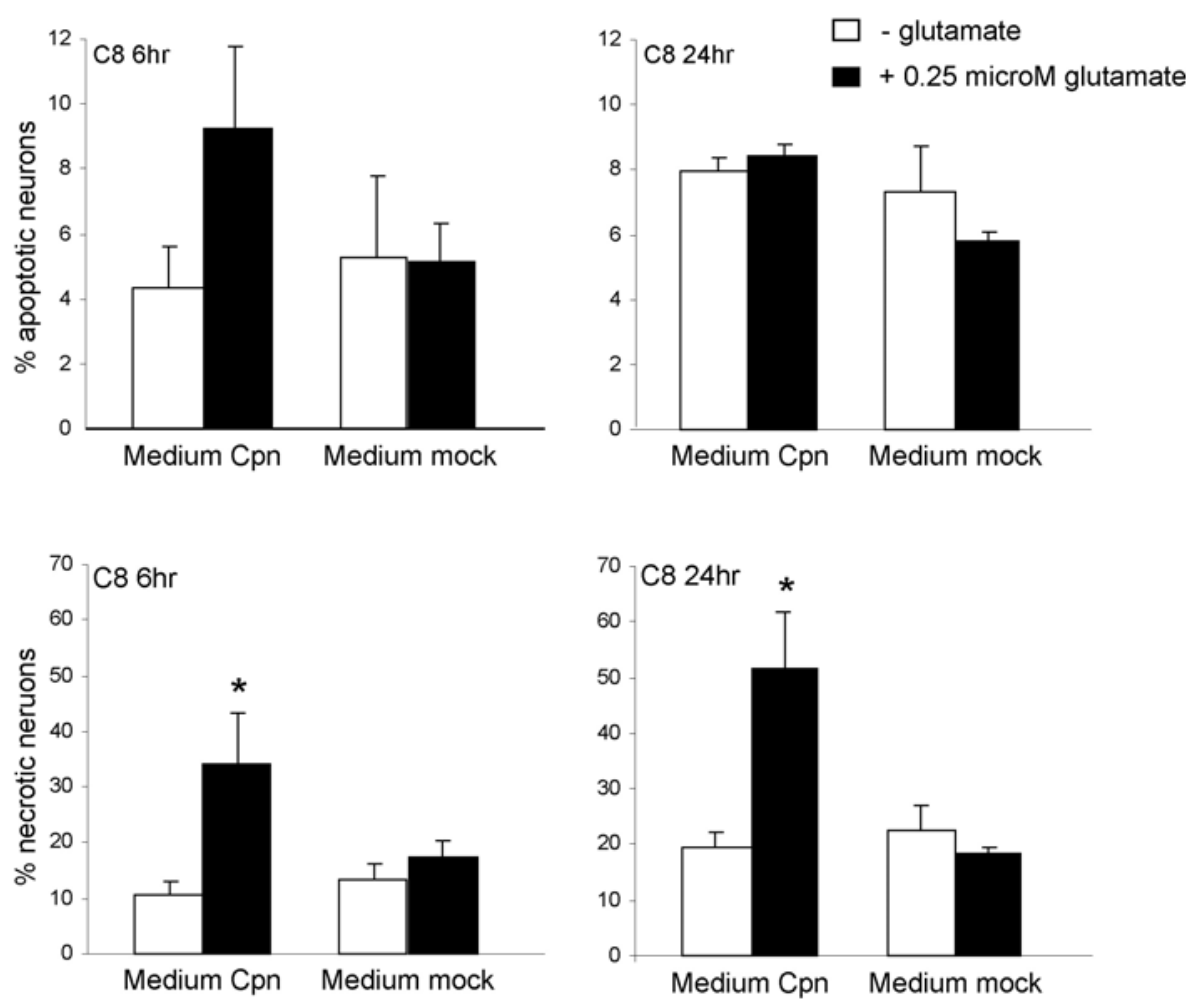

Figure 2. Apoptosis and necrosis, determined by HO-PI double staining, in neurons after medium transfer of (glutamate conditioned) astrocytes, exposed for 6 (C8 $6 \mathrm{hr}$ ) or $24 \mathrm{hr}$ (C8 $24 \mathrm{hr}$ ) to supernatants of infected (medium Cpn)/control (medium mock) MMC (24 hr p.i.). At $72 \mathrm{hr}$ post transfer, the mean percentages of apoptotic/necrotic neurons is showed. ${ }^{*} p \leq 0.05$ infected vs. control apoptotic/necrotic cells per time point. Error bars, standard errors of the means (SEM).

\subsection{Presence of glutamate transporters in the astrocyte cell line}

\section{GLT-1 mRNA detection}

To investigate whether the expression of the major astrocytic glutamate transporter GLT-1 is affected by the incubation of astrocytes with conditioned medium of Cpn or mock infected microglial cells, GLT-1 mRNA levels were determined by real time RT-PCR at 2, 6 and $24 \mathrm{hr}$ post incubation. As illustrated in Table 1, no significant changes in GLT-1 mRNA expression were detected after astrocyte exposure to supernatants of $\mathrm{Cpn}$ or mock infected microglial cells at any time point examined. 
Table 1. Relative GLT-1 mRNA expression in astrocytes, treated with the supernatants of $\mathrm{Cpn} /$ mock infected microglial cells during 2, 6 or $24 \mathrm{hr}$.

\begin{tabular}{lc}
\hline Sample & Mean relative expression \\
\hline $6 \mathrm{hr}$ Cpn infection & $1.25 \pm 0.59$ \\
$6 \mathrm{hr}$ mock infection & $1.20 \pm 0.40$ \\
\hline $24 \mathrm{hr}$ Cpn infection & $1.35 \pm 0.36$ \\
$24 \mathrm{hr}$ mock infection & $1.18 \pm 0.28$ \\
\hline $\begin{array}{l}\text { Relative expression was calculated as described in Material and } \\
\text { Methods and expressed as the mean value of three independent } \\
\text { experiments, together with the corresponding standard error of the } \\
\text { mean. }\end{array}$
\end{tabular}

\section{Immunofluorescence GLAST and GLT-1}

Variations in glutamate transporter GLT-1 (EAAT2) expression after astrocyte treatment with supernatants of $\mathrm{Cpn}$ infected microglial cells were also evaluated by immunohistochemical staining procedures. Nonetheless, even under basal conditions, no EAAT2 positive signals could be detected in our astrocytic cell line (Figure 3). In contrast, the other astrocytic glutamate transporter EAAT1 was abundantly expressed in our setting (Figure 3 ).
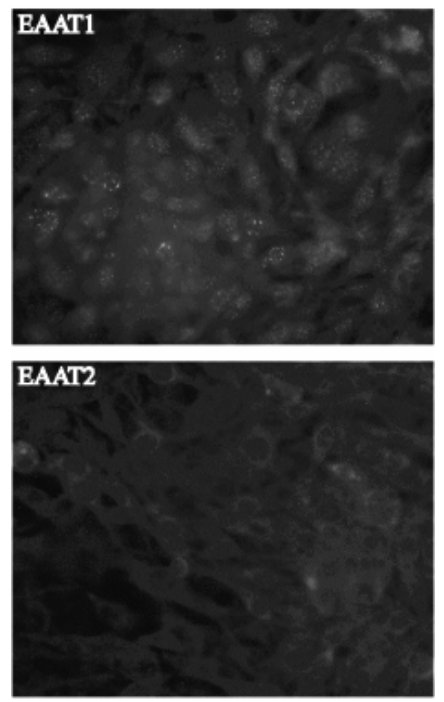

Figure 3. Immunofluorescent detection (green signal) of GLAST (EAAT1) and GLT-1 (EAAT2) transporters in an astrocyte cell line under normal conditions after confluence. Staining was performed with primary antibodies directed against human EAAT1 or EAAT2 and a secondary Alexa Fluor 488 labelled antibody. Counterstaining by Evan's blue. Original magnification 400x. (See coloured illustration inserted at the back of this thesis). 


\subsection{L-glutamate uptake assay}

The effect of conditioned MMC media on glutamate uptake by astrocytes was also assessed by determining the amount op L-[3,4- $\left.{ }^{3} \mathrm{H}\right]$-glutamate taken up by astrocytes following pre-treatment. In a first set of experiments we demonstrated the feasibility of this assay to study the glutamate uptake by astrocytes. When astrocytes were incubated for $15 \mathrm{~min}$ at $37^{\circ} \mathrm{C}$, significant amounts of L-[3,4- $\left.{ }^{3} \mathrm{H}\right]$-glutamate, expressed as $\mathrm{dpm} / \mathrm{\mu g}$ protein, could be detected in astrocytes. In contrast, we demonstrated that this depends on the active uptake of glutamate by astrocytes as no uptake was detected as cells were incubated with $\mathrm{L}-\left[3,4-{ }^{3} \mathrm{H}\right]$-glutamate at $0^{\circ} \mathrm{C}$. Nevertheless, no significant variations in uptake were detected when astrocytes were pre-treated for 2, 6 or 24h, either with Cpn or mock infected MMC supernatant (Figure 4).

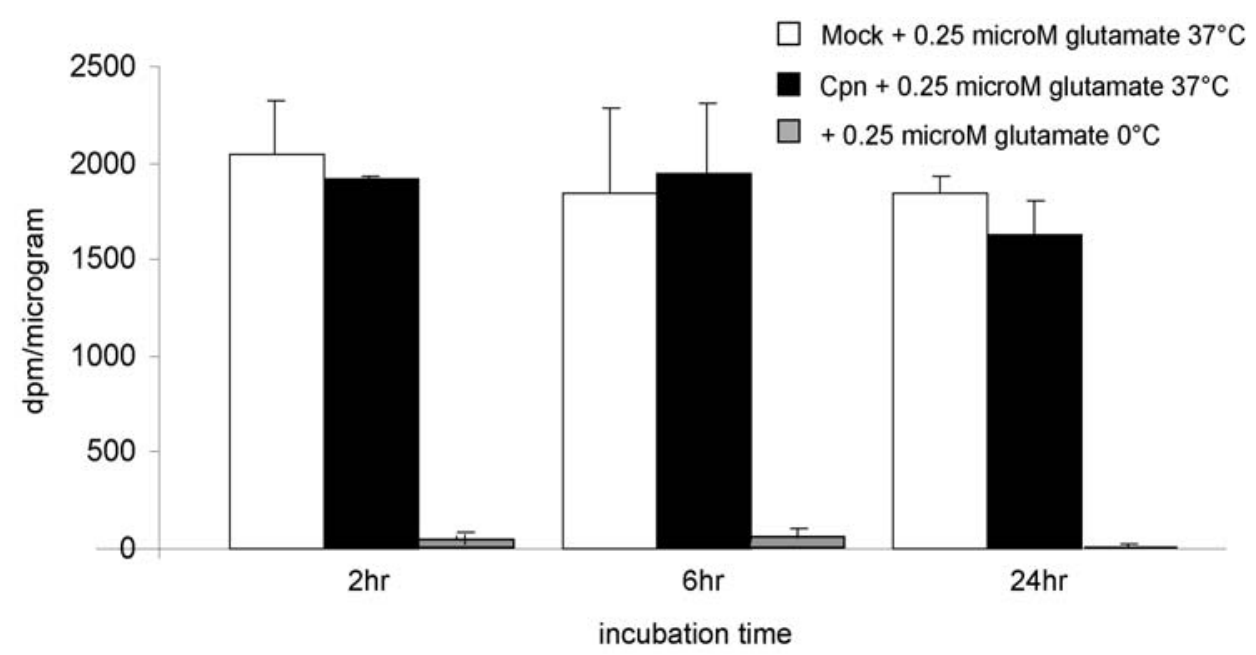

Figure 4. Glutamate uptake in astrocytes, after 2, 6 or $24 \mathrm{hr}$ treatment with supernatants of $\mathrm{Cpn} / \mathrm{mock}$ infected microglial cells. Values, displayed as the amount of disintegrations per minute $(\mathrm{dpm})$ per microgram $(\mu \mathrm{g})$ for the different conditions, are expressed as the mean \pm SEM of three independent experiments. As a control, glutamate uptake was performed at $0^{\circ} \mathrm{C}$ in astrocytes, treated with supernatant of $\mathrm{Cpn} /$ mock (not shown) infected MMC. Error bars: SEM. 


\section{Discussion}

Among the various neurotransmitters in the central nervous system, glutamate is the most significant one ${ }^{1}$. On the other hand, high extracellular glutamate concentrations are toxic and result in neuronal death. To prevent extracellular glutamate concentrations becoming toxic, glutamate is removed from the extracellular space through various $\mathrm{Na}^{+}$-dependent transporters ${ }^{3}$. Most of these transporters are present on astrocytes, which makes them key players, being accountable for the majority of glutamate uptake in the brain, predominantly by the GLT-1 transporter ${ }^{4}$. Nonetheless, there is evidence that infectious agents, like $\mathrm{HIV}^{6}$, or elevated concentrations of inflammatory mediators factors, as TNF$\alpha^{8}$, may affect glutamate removal, which may ultimately result in neuronal death. This may provide a pathway to explain the suggested association between infections and inflammation, which have progressively been linked to neurodegenerative processes in general ${ }^{9,11,12,16}$. Lately, Chlamydia pneumoniae has also been related to these disorders ${ }^{17,22}$, a hypothesis that was supported by recent data from our lab ${ }^{26,27}$. In the present study, we investigated whether inflammatory mediators, generated by $\mathrm{Cpn}$ infected microglial cells, affect glutamate uptake by astrocytes, which may provide an additional pathway in Cpn-induced neurodegeneration apart from the direct effects of Cpn on brain cells ${ }^{26}$ or the neurotoxic effect of the cytokines released by infected microglial cells $^{27}$. Indeed, we were able to demonstrate high levels of necrosis in neuronal cells, treated with glutamate-conditioned media of astrocytes, which were pretreated with supernatants of $\mathrm{Cpn}$ infected MMC. This percentage of necrotic neurons was significantly higher compared to the percentage dead neurons after incubation with glutamate-conditioned medium of astrocytes, pre-treated with supernatants of mock infected MMC. Moreover, when glutamate was not added to the astrocyte medium, only basal levels of neuronal necrosis could be detected, irrespective of the pre-treatment of the astrocytes. Taken together, these data suggest that astrocytes, pretreated with supernatant derived from Cpn infected MMC, are no longer capable of removing the high concentrations of glutamate from their culture medium. These high levels of glutamate are then responsible for the observed neuronal cell death once the glutamate containing medium is transferred to a neuronal cell culture. This observation suggests that inflammatory compounds, produced by MMC post Cpn infection, affect astrocytic glutamate uptake.

To further unravel this hypothesis, the mRNA expression of the GLT-1 transporter in astrocytes was investigated following incubation of the cells with conditioned medium from $\mathrm{Cpn}$ or mock infected MMC. We decided to examine possible variations only in the expression of this transporter because this 
transporter accounts for the majority of astroctytic glutamate clearance ${ }^{4}$ and moreover, it has previously been shown that its expression is sensitive to infection $^{6}$. Yet, in contrast to our expectations, no effect of pretreatment with conditioned medium from Cpn infected MMC on transporter mRNA levels was detected. Also our data are in contrast with previous findings concerning HIV infection ${ }^{6}$. Nonetheless, it should be noted that major differences exist between this study and the present one. First, in the study by Wang and colleagues human primary astrocyte cultures were used which may differ substantially from the murine cell line used in the present study. Second, these authors determined GLT1 mRNA levels in astrocytes following HIV infection of these cells. We, on the other hand, examined GLT1 mRNA expression by astrocytes following exposure to conditioned medium from $\mathrm{Cpn}$ infected MMC. It remains to be determined whether direct Cpn infection of astrocytes might alter the GLT1 mRNA expression levels.

Alternatively, it can be postulated that these unchanged GLT1 mRNA levels do not automatically indicate normal functioning of the GLT-1 transporter. It is well recognized that the ability of some glutamate transporters to travel from the intracellular compartment to the cell membrane is influenced by the existence of factors inhibiting this process ${ }^{36}$. Secondly, it was shown in several reports that the GLT-1 mRNA levels do not necessary reflect the amount of functional glutamate transporter ${ }^{37}$. Therefore, we determined the uptake of radiolabelled glutamate to determine functionality of the receptor, while immunohistochemical techniques were used to reveal the presence of the receptor on the astrocytes used in the present study.

First, an uptake assay was performed applying $\mathrm{L}-\left[3,4-{ }^{3} \mathrm{H}\right]$-glutamate to the astrocyte cell culture medium. When cells were incubated at $37^{\circ} \mathrm{C}$ for $15 \mathrm{~min}$, high amounts of radiolabelled glutamate could be detected in the astrocytes, suggesting uptake indeed occurs. To exclude that the detected glutamate was solely the result of sticking of the amino acid to the cell membrane or unrelated receptors, like the NMDA-receptor ${ }^{38}$, a similar experiment was performed at $0^{\circ} \mathrm{C}$. Under these conditions, only low basal levels of radioactivity were determined inside the cells. This strongly suggests that the measured glutamate uptake at $37^{\circ} \mathrm{C}$ was predominantly caused by $\mathrm{Na}^{+}$-dependent transport rather than sticking of glutamate to the cell membrane. However, when the outcomes for the various conditions were compared, no significant differences in astrocytic glutamate uptake after incubation with either medium of Cpn or mock infected microglial cells were observed. Previously it has been shown that TNF- $\alpha$ inhibits glutamate uptake ${ }^{8}$. Based on one of our earlier studies ${ }^{27}$, in which we demonstrated that the conditioned medium of Cpn infected MMC contains high levels of TNF- $\alpha$, it was expected that incubation of astrocytes with the 
conditioned medium would affect the uptake of glutamate by the astrocytes. The reason for this lack of effect is unclear. One possible explanation could be related to the origin of the astrocytes used in the present study and the ones used by Fine and colleagues. They applied a primary cell culture, isolated from human foetal brain material while a commercially available astrocyte cell line (C8D1A; ATCC CRL-2541) was utilized in the present study. In this respect it might be noteworthy to reveal whether the concentration of TNF- $\alpha$ present in the conditioned medium of $\mathrm{Cpn}$ infected MMC is sufficient to affect glutamate uptake in the astrocyte cell line used in the present study. Alternatively, the mixture of inflammatory, but also anti-inflammatory mediators released by infected MMC may have a different effect on glutamate uptake than the application of a single pro-inflammatory cytokine like TNF- $\alpha$.

We also used immunohistochemical techniques to study the potential downregulation of the receptor at the protein level. However, even under normal conditions, this transporter could not be detected in our cell line (Figure 3). This is in accordance with the results from Swanson et al., who were also unable to detect the GLT-1 transporter in astrocytic monocultures ${ }^{39}$. Furthermore, they showed that the expression of the receptor depends on neuronal influences as it was expressed in co-cultures of neurons and astrocytes. As we also used a monoculture in our experiments, it opens the question which receptor is responsible for the uptake of glutamate as was detected in the uptake experiments. Therefore, we also examined the expression of the other astrocyte glutamate transporter, EAAT1. Surprisingly, this receptor was abundantly expressed on our astrocyte cell line as shown in Figure 2. Therefore, additional experiments are required to determine whether the observed impairment in glutamate uptake following incubation with conditioned medium from $\mathrm{Cpn}$ infected MMC results from alterations in EAAT2 expression.

Summarizing the present study we evaluated a potential new pathway by which infections, and Chlamydia pneumoniae in particular, may contribute to neurodegeneration. Our main finding is that $\mathrm{Cpn}$ infected microglial cells may release a large variety of compounds that affect astrocytes in a way that makes them respond differently when exposed to glutamate. This altered astrocytic response may trigger a cascade of events that ultimately creates a neurotoxic milieu followed by the death of surrounding neurons. It seems unlikely that this is due to an altered uptake of the potentially neurotoxic compound glutamate, as its uptake was not affected in astrocytes pre-treated with supernatants derived from Cpn infected microglial cells. Furthermore, GLT1 mRNA expression or the immunopositive signals were not affected under these conditions, providing further evidence for alternative pathways. Nonetheless, as the other glutamate transporter (GLAST) might be more important for glutamate uptake in these cells, it should be determined whether the expression of this 
receptor might be affected by the treatment. Now taken all together, our data suggest that astrocytes, previously primed by inflammatory compounds, react to high levels of glutamate by secreting some potentially neuron-harmful components. To elucidate this hypothesis and determine these factors, future experiments are necessary.

\section{Acknowledgements}

This work was supported by the International Alzheimer's Research Foundation (ISAO; The Netherlands). We would like to thank Govert Hoogland, Erik Beuken, Marjanne Markerink and the students for their (technical) assistance.

\section{References}

1. Fonnum, F., Glutamate: a neurotransmitter in mammalian brain. J Neurochem, 1984. 42(1): p. 1-11.

2. Danbolt, N.C., Glutamate uptake. Prog Neurobiol, 2001. 65(1): p. 1-105.

3. Amara, S.G. and A.C. Fontana, Excitatory amino acid transporters: keeping up with glutamate. Neurochem Int, 2002. 41(5): p. 313-8.

4. Anderson, C.M. and R.A. Swanson, Astrocyte glutamate transport: review of properties, regulation, and physiological functions. Glia, 2000. 32(1): p. 1-14.

5. Belin, M.F., et al., Changes in astrocytic glutamate catabolism enzymes following neuronal degeneration or viral infection. Glia, 1997. 21(1): p. 154-61.

6. Wang, Z., et al., Reduced expression of glutamate transporter EAAT2 and impaired glutamate transport in human primary astrocytes exposed to HIV-1 or gp120. Virology, 2003. 312(1): p. 60-73.

7. Wang, Z., et al., Effects of human immunodeficiency virus type 1 on astrocyte gene expression and function: potential role in neuropathogenesis. J Neurovirol, 2004. 10 Suppl 1: p. 25-32.

8. Fine, S.M., et al., Tumor necrosis factor alpha inhibits glutamate uptake by primary human astrocytes. Implications for pathogenesis of HIV-1 dementia. J Biol Chem, 1996. 271(26): p. 15303-6.

9. Akiyama, H., et al., Inflammation and Alzheimer's disease. Neurobiol Aging, 2000. 21(3): p. 383-421.

10. Hald, A. and J. Lotharius, Oxidative stress and inflammation in Parkinson's disease: is there a causal link? Exp Neurol, 2005. 193(2): p. 279-90.

11. Perry, V.H., The influence of systemic inflammation on inflammation in the brain: implications for chronic neurodegenerative disease. Brain Behav Immun, 2004. 18(5): p. 407-13.

12. Weiner, H.L. and D.J. Selkoe, Inflammation and therapeutic vaccination in CNS diseases. Nature, 2002. 420(6917): p. 879-84.

13. Balin, B.J. and D.M. Appelt, Role of infection in Alzheimer's disease. J Am Osteopath Assoc, 2001. 101(12 Suppl Pt 1): p. S1-6.

14. Hemling, N., et al., Herpesviruses in brains in Alzheimer's and Parkinson's diseases. Ann Neurol, 2003. 54(2): p. 267-71.

15. Kolson, D.L. and F. Gonzalez-Scarano, HIV and HIV dementia. J Clin Invest, 2000. 106(1): p. 11-3. 
16. Wucherpfennig, K.W., Infectious triggers for inflammatory neurological diseases. Nat Med, 2002. 8(5): p. 455-7.

17. Stratton, C.W. and S. Sriram, Association of Chlamydia pneumoniae with central nervous system disease. Microbes Infect, 2003. 5(13): p. 1249-53.

18. Kuo, C.C., et al., Chlamydia pneumoniae (TWAR). Clin Microbiol Rev, 1995. 8(4): p. 451-61.

19. Grayston, J.T., et al., A new respiratory tract pathogen: Chlamydia pneumoniae strain TWAR. J Infect Dis, 1990. 161(4): p. 618-25.

20. Grayston, J.T., et al., Evidence that Chlamydia pneumoniae causes pneumonia and bronchitis. J Infect Dis, 1993. 168(5): p. 1231-5.

21. Weinberger, M., Respiratory infections and asthma: current treatment strategies. Drug Discov Today, 2004. 9(19): p. 831-7.

22. Yucesan, C. and S. Sriram, Chlamydia pneumoniae infection of the central nervous system. Curr Opin Neurol, 2001. 14(3): p. 355-9.

23. Gieffers, J., et al., Failure to detect Chlamydia pneumoniae in brain sections of Alzheimer's disease patients. J Clin Microbiol, 2000. 38(2): p. 881-2.

24. Nochlin, D., et al., Failure to detect Chlamydia pneumoniae in brain tissues of Alzheimer's disease. Neurology, 1999. 53(8): p. 1888.

25. Ring, R.H. and J.M. Lyons, Failure to detect Chlamydia pneumoniae in the late-onset Alzheimer's brain. J Clin Microbiol, 2000. 38(7): p. 2591-4.

26. Boelen, E., et al., Chlamydia pneumoniae infection of brain cells: an in vitro study. Neurobiol Aging, 2007. 28(4): p. 524-32.

27. Boelen, E., et al., Inflammatory responses following Chlamydia pneumoniae infection of glial cells. Eur J Neurosci, 2007. 25(3): p. 753-60.

28. Roblin, P.M., W. Dumornay, and M.R. Hammerschlag, Use of HEp-2 cells for improved isolation and passage of Chlamydia pneumoniae. J Clin Microbiol, 1992. 30(8): p. 1968-71.

29. Ezzahiri, R., et al., Chlamydia pneumoniae infection induces an unstable atherosclerotic plaque phenotype in LDL-receptor, ApoE double knockout mice. Eur J Vasc Endovasc Surg, 2003. 26(1): p. 88-95.

30. Blasi, E., et al., Immortalization of murine microglial cells by a $v$-raf/v-myc carrying retrovirus. J Neuroimmunol, 1990. 27(2-3): p. 229-37.

31. Kuo, C.C. and J.T. Grayston, A sensitive cell line, $H L$ cells, for isolation and propagation of Chlamydia pneumoniae strain TWAR. J Infect Dis, 1990. 162(3): p. 755-8.

32. Mazzini, G., C. Ferrari, and E. Erba, Dual excitation multi- fluorescence flow cytometry for detailed analyses of viability and apoptotic cell transition. Eur J Histochem, 2003. 47(4): p. 289-98.

33. Hatton, G.I. and V. Parpura, Glial vs Neuronal Signaling. Vol. 1. 2004, Boston: Kluwer Academic Publishers. 411.

34. Pfaffl, M.W., A new mathematical model for relative quantification in real-time RT-PCR. Nucleic Acids Res, 2001. 29(9): p. e45.

35. Yao, H.H., et al., Inhibitory effects of 1-methyl-4-phenylpyridinium on glutamate uptake into cultured C6 glioma cells. Acta Pharmacol Sin, 2004. 25(7): p. 855-60.

36. Duan, S., et al., Glutamate induces rapid upregulation of astrocyte glutamate transport and cell-surface expression of GLAST. J Neurosci, 1999. 19(23): p. 10193-200.

37. Gegelashvili, G. and A. Schousboe, High affinity glutamate transporters: regulation of expression and activity. Mol Pharmacol, 1997. 52(1): p. 6-15.

38. Hansson, E., et al., Astroglia and glutamate in physiology and pathology: aspects on glutamate transport, glutamate-induced cell swelling and gap-junction communication. Neurochem Int, 2000. 37(2-3): p. 317-29.

39. Swanson, R.A., et al., Neuronal regulation of glutamate transporter subtype expression in astrocytes. J Neurosci, 1997. 17(3): p. 932-40. 



\section{Chapt er}

\section{Detection of amyloid beta aggregates in the brain of $\mathrm{BALB} / \mathrm{c}$ mice after Chlamydia pneumoniae infection}

Ellen Boelen, Frank RM Stassen, Marijke AM Lemmens, Hellen PJ Steinbusch, Cathrien A Bruggeman, Christoph Schmitz, Harry WM Steinbusch Accepted for publication in Acta Neuropathologica 


\section{Abstract}

Cerebral infection and subsequent neuroinflammation as an etiological factor in neurodegenerative diseases, such as Alzheimer's disease (AD), has gained considerable interest over the past few years. We investigated whether Chlamydia pneumoniae (Cpn) infection results in extracellular aggregation of amyloid beta $(A \beta)$ in normal BALB/c mice. At 1 week post intranasal infection (p.i.), Cpn DNA was predominantly detected in the olfactory bulbs by PCR, whereas brains at 1 and 3 months p.i. remained negative. At 1 and 3 months p.i., extracellular $A \beta$ immunoreactivity was detected in the brain of $\mathrm{Cpn}$ infected mice, but also in the brain of mock infected mice and mice that were neither $C p n$ infected nor mock infected. However, these extracellular $A \beta$ aggregates showed morphological differences compared to extracellular $A \beta$ aggregates detected in the brain of APP $751^{\mathrm{SL}} / \mathrm{PS} 1^{\mathrm{M} 146 \mathrm{~L}}$ mice. These data do not support the hypothesis that $\mathrm{Cpn}$ infection induces the formation of $A D$-like $A \beta$ plaques in the brain of BALB/c mice. Accordingly, future studies are required to investigate whether $\mathrm{Cpn}$ is indeed an etiological factor in AD pathogenesis. 


\section{Introduction}

The most common cause of dementia is Alzheimer's disease (AD), which manifests in a familial and a sporadic form. The neuropathology in both conditions is characterized by neuritic or senile plaques, consisting mainly of amyloid beta protein $(A \beta)$, and neurofibrillary tangles with modified tau protein as its key component. Mutations in the amyloid precursor protein (APP), presenilin-1 (PS-1) or -2 (PS-2) genes have been associated with the familial form of $A D^{1}$. However, the most common type of this disease, sporadic $A D$, is not due to these mutations, and although risk factors have been identified, the initiating trigger is still unknown ${ }^{2}$. The potential importance of infections in the development of sporadic $A D$ has been recently recognized ${ }^{3-5}$. Specifically, various viruses like human immunodeficiency virus (HIV), herpes simplex virus and cytomegalovirus have been linked to the process of neurodegeneration ${ }^{6-9}$. Some data also suggest that Chlamydia pneumoniae (Cpn) should be added to the list of pathogens possibly involved in the pathogenesis of AD. Cpn is a widespread, obligatory intracellular pathogen, often causing acute respiratory infections, including pneumonia, sinusitis and bronchitis ${ }^{10-12}$. This microorganism has also been implicated in a variety of severe, chronic diseases, including some disorders of the central nervous system ${ }^{13-16}$. In an initial study, Balin and coworkers demonstrated the presence of $\mathrm{Cpn}$ in the brains of 17 out of 19 patients with sporadic $A D$ using a variety of techniques, including PCR, electron microscopy and immunohistochemistry, while the pathogen could only be demonstrated in 1 out of 19 controls $^{17}$. The presence of Cpn was demonstrated in various cell types, like microglia, astrocytes, perivascular macrophages and monocytes, and predominantly in brain areas linked with $A D$ pathology. However, others were unable to detect $C p n$ in $A D$ patient tissues ${ }^{18-21}$. The only animal study so far supporting a role of this pathogen in AD demonstrated an AD-like pathology in the brain of BALB/C mice post $\mathrm{Cpn}$ infection ${ }^{22}$. Three-month-old mice were inoculated intranasally with Cpn and the authors claimed that this resulted in the deposition of $A \beta$ in the brain up to 3 months post infection with increasing pathology as the infection progressed. Based on these results it was concluded that in naïve BALB/c mice, AD-like pathology can be induced by $\mathrm{Cpn}$ infection. In spite of these results, doubts subsist concerning the amyloid-like plaques as being only unrelated elevations in amyloid $^{23}$. Because of the possible implications of this study and the need for confirmation, it was our aim to repeat these experiments under quite corresponding conditions. Moreover, we compared our findings with the pathology found in a transgenic mouse model of $A D$. 


\section{Material and methods}

\subsection{Chlamydia pneumoniae (Cpn)}

The Cpn strain, TWAR 2043 (ATCC) was cultured and continuously propagated on Hep2 cells as previously described ${ }^{24}$. Bacterial titres were determined by titration in Hep2 cells ${ }^{15}$ and stained with a monoclonal Chlamydia LPS-specific antibody followed by a FITC-conjugated secondary antibody (RR-402; DAKO, Glostrup, Denmark). Titres were expressed as the number of inclusion forming units (IFU) per ml.

\subsection{Animals and infection protocol}

A total of 43 female, specific pathogen-free inbred BALB/c mice were obtained from Charles River (Someren, The Netherlands). The animals were kept under standard housing and care conditions at the Central Animal Facilities of Maastricht University (Maastricht, The Netherlands). All experimental procedures were approved by the Ethical Committee for the Use of Experimental Animals of Maastricht University.

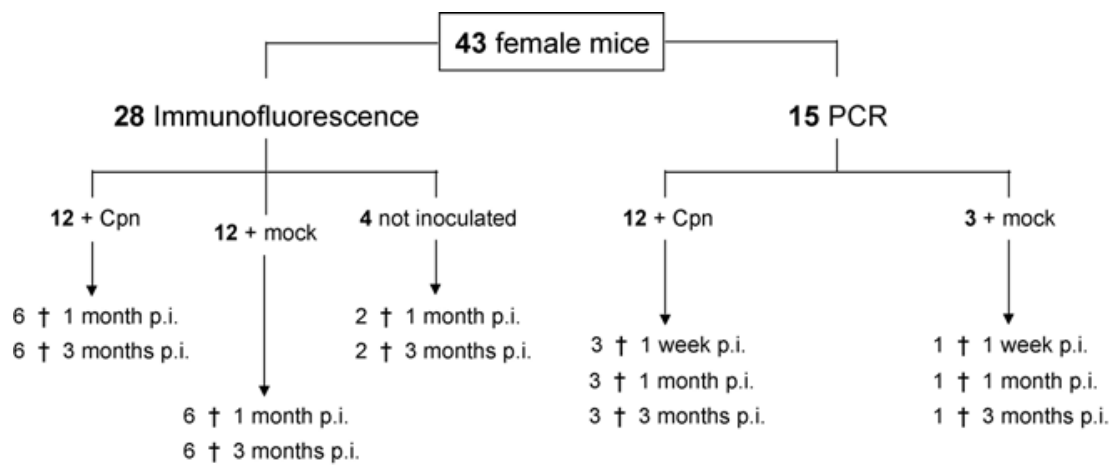

Figure 1. Schematic overview of the number of animals applied in the various experiments. $\dagger$ : sacrificed.

As indicated in Figure 1, twelve mice were inoculated intranasally with $10^{7} \mathrm{IFU}$ Cpn in $10 \mu \mathrm{l}(5 \mu \mathrm{l}$ per nostril) at the age of three months while the same number of animals was mock infected with a sucrose-phosphate-glucose solution (SPG, solution for storage of $\mathrm{Cpn}$ ). Half of the mice in each group were killed at 1 month post infection (p.i.), while the remaining animals were killed at 3 months p.i.. Four non-treated mice were processed in the same manner. For PCR analysis, 12 extra animals were infected with $\mathrm{Cpn}$ as described above and an 
equal number of animals was killed at 1 week, 1 and 3 months p.i.. Three mock infected mice were included and treated under identical conditions.

In addition, a 17-month-old transgenic mouse expressing human mutant APP751 (carrying the Swedish and London mutations KM670/671 NL and V717I, under the Thy1 promoter) and human mutant presenilin-1 (PS-1 M146L, under the HMG promoter) was used (APP751 ${ }^{\mathrm{SL}} / \mathrm{PS} 1^{\mathrm{M} 146 \mathrm{~L}}$ mouse; for a detailed description see references 3 and 22). This APP751 $1^{\mathrm{SL}} / \mathrm{PS} 1^{\mathrm{M} 146 \mathrm{~L}}$ mouse was bred on a CBA $(12.5 \%) \times$ C57BI6 (87.5\%) background.

\subsection{Tissue processing}

Prior to sacrifice, a weight-adjusted dose of pentobarbital (Nembutal; Sanofi Sante B.V., Maassluis, The Netherlands) was given to the BALB/c mice. In case of the APP751 $1^{\mathrm{SL}} / \mathrm{PS} 1^{\mathrm{M} 146 \mathrm{~L}}$ mouse, anaesthesia was performed with chloral hydrate ( $10 \%$ aqueous solution, $0.005 \mathrm{ml} / \mathrm{g}$ body weight, intraperitoneal).

\section{Immunofluorescence}

Twelve Cpn infected, 12 mock infected and 4 non-treated BALB/c mice, as well as the APP751 ${ }^{\mathrm{SL}} / \mathrm{PS} 1^{\mathrm{M} 146 \mathrm{~L}}$ mouse underwent intracardial perfusion fixation with tyrode followed by $4 \%$ paraformaldehyde, $15 \%$ picric acid and $0.05 \%$ glutaraldehyde in phosphate buffer, as previously described ${ }^{25}$. Brains were removed rapidly and post-fixed for 2 hours at $4^{\circ} \mathrm{C}$ in the same fixative, omitting the glutaraldehyde. In case of the APP $751^{\mathrm{SL}} / \mathrm{PS} 1^{\mathrm{M} 146 \mathrm{~L}}$ mouse, the brains were halved in the midsagittal line. Brain tissues were then cryoprotected by immersion in $30 \%$ sucrose in Tris-buffered saline at $4^{\circ} \mathrm{C}$ overnight. Afterwards, brains (or brain halves, respectively) were quickly frozen and stored at $-80^{\circ} \mathrm{C}$ until further processing. For immunohistochemical analysis, the entire brains (or, in case of the APP $751^{\mathrm{SL}} / \mathrm{PS} 1^{\mathrm{M} 146 \mathrm{~L}}$ mouse, the right brain half) were cut into entire series of $30 \mu \mathrm{m}$ thick frontal sections on a cryostat (Leica CM $3050 \mathrm{~S}$; Leica, Nussloch, Germany).

\section{PCR}

Subsequently, to detect Cpn DNA by PCR in the brains of infected animals, 15 $B A L B / c$ mice were perfused with sterile phosphate buffered saline (PBS) and their brains were dissected into five different regions: the olfactory bulbs (OB), the cerebellum, the hippocampus, the subventricular zone and the neocortex. The isolated regions were then snap-frozen in liquid nitrogen and stored at $80^{\circ} \mathrm{C}$ until further processing. 


\subsection{Cpn real-time PCR}

DNA was isolated from brain material using methods previously described ${ }^{26}$. The Nanodrop ${ }^{\circledR}$ ND-1000, a full-spectrum spectrophotometer $(220-750 \mathrm{~nm})$ was used to calculate the DNA content of each sample. Finally, the Cpn DNA copy number/ $\mu \mathrm{g}$ DNA in the collected brains was investigated by real-time PCR ( $A B I$ Prism 7000; Applied Biosystems, Foster City, CA) using the following primers and probe; forward (5'TCCGCATTGCTCAGCC3'), reverse (5'AACAATTTGCATGAAGTCTGAGAA3') and probe (5'-FAMTAAACTTAACTGCATGGAACCCTTCTTTACTAGG3'-TAMRA), as previously described $^{26,27}$.

\subsection{Immunohistochemical detection of $A \beta$ and GFAP}

Immediately after recovery from the $-80^{\circ} \mathrm{C}$ freezer and between every incubation step, sections were rinsed sequentially with Tris-buffered Saline (TBS) and TBS-Triton (TBS-T). After washing, the brain slides were incubated overnight at $4^{\circ} \mathrm{C}$ with the first layer consisting of a combination of mouse antihuman amyloid 17-24 (4G8 clone; 1:1,200 in TBS-T; Sigma-Aldrich, St. Louis, USA $)^{28-30}$ and polyclonal rabbit anti-mouse GFAP $(1: 1,600$ in TBS-T; DAKO, Glostrup, Denmark). Subsequently, slides were successively incubated with the secondary antibodies, a donkey anti-mouse Alexa 488 (1:100 in TBS-T; Molecular Probes, Oregon, USA), and a donkey anti-rabbit Alexa 594 (1:100 in TBS-T; Molecular Probes, Oregon, USA), each for 2 hours at room temperature. Finally, counterstaining was performed by incubation with Hoechst (1:500 in TBS; Sigma, St. Louis, USA) for 30 minutes at room temperature. The stained sections were mounted on gelatine coated glasses, dried and fixed with $80 \%$ glycerol in TBS. As a negative control, sections were only incubated with the secondary antibodies.

\subsection{Staining of extracellular $A \beta$ agregates with thioflavin-S}

For the detection of extracellular, fibrillary $A \beta$, a thioflavin-S staining was performed. Sections were rinsed twice in TBS followed by an $70 \%$ ethanol washing step. For the next 15 minutes, the slides were incubated with $1.5 \%$ thioflavin-S (Sigma, St. Louis, USA) in $70 \%$ ethanol at room temperature. Finally, the sections were counterstained with Hoechst and mounted, as described above. 


\subsection{Microscopy and photography}

Microscopic inspection of sections was performed with a MBF Bioscience Stereo Investigator Confocal Spinning Disk (SI-SD) system (MBF Bioscience; Williston, VT), consisting of a modified Olympus BX51 fluorescence microscope (Olympus, Tokyo, Japan) with UPlanSApo objectives $10 \times$ (N.A. $=0.4$ ), 40× (N.A $=0.9$ ) and $100 \times$ (oil; N.A = 1.4); Olympus), customized spinning disk unit (DSU; Olympus), computer-controlled excitation and emission filter wheels (Olympus), three-axis high-accuracy computer-controlled stepping motor specimen stage (4x4 Grid Encoded Stage; Ludl Electronic Products, Hawthorne, NY), linear Zaxis position encoder (Ludl), ultra-high sensitivity monochrome electron multiplier CCD camera $(1,000 \times 1,000$ pixels, C9100-02; Hamamatsu Photonics, Hamamatsu City, Japan) and controlling software (MBF Bioscience, Williston, USA). In case of sections, processed for the detection of $A \beta$ and GFAP, digital RGB image stacks, showing the same microscopic field in 50 consecutive focal planes with a distance of $0.5 \mu \mathrm{m}$ between the focal planes, were generated with the $40 x$ objective. In the case of sections stained with thioflavin-S, digital image stacks showing the same microscopic field at 150 consecutive RGB focal planes with a distance of $0.2 \mu \mathrm{m}$ between the focal planes were generated with the $100 x$ objective. From these image stacks threedimensional reconstructions (maximum intensity projections) were produced with Imaris software (Version 4.0; Bitplane, Zurich, Switzerland). In addition, low-power photomicrographs (10x) were taken from sections stained with thioflavin-S. Final figures were constructed using Corel Photo-Paint v.11 and Corel Draw v.11 (Corel, Ottawa, Canada). Only minor adjustments of contrast and brightness were made, without altering the appearance of the original materials. No deconvolution was performed on images obtained by confocal microscopy.

\subsection{Statistics}

For each of the three groups of BALB/c mice infected with Cpn and analysed with real-time PCR (analysis one week, one month or three months p.i.) the mean and standard error of the mean (SEM) of the Cpn DNA copy number/ $\mu \mathrm{g}$ DNA were calculated. Comparison between groups was performed with threeway ANOVA with Treatment, Time-point of analysis and Brain region as fixed factors. $P$ values smaller than 0.05 were considered statistically significant. Calculations were performed with SPSS v. 12.0.1 for Windows (SPSS, Chicago, $\mathrm{IL})$. 


\section{Results}

\subsection{Presence of Cpn in the brain of BALB/C mice infected with Cpn}

One week post infection with Cpn, the mean Cpn DNA copy number per $\mu \mathrm{g}$ DNA was $310.97 \pm 61.6$ (mean \pm SEM) in the olfactory bulbs, $2.6 \pm 0.8$ in the cerebellum, and $7.9 \pm 0.8$ in the hippocampus, while no Cpn DNA was detected in the subventricular zone and the neocortex. No Cpn DNA was detected in any brain region of the Cpn infected mice at one and three months p.i.. Cpn DNA was not detected in the brain of mock infected and non-treated BALB/c mice at any time point. Statistical analysis revealed significant differences among the groups of mice with respect to Treatment $(T)(p=0.024)$, Time point of analysis (Tpoa) $(p=0.008)$, Brain region $(\mathrm{Br})(p=0.002)$ as well as with respect to the combinations T-Tpoa $(p=0.008)$, T-Br $(p=0.002)$, Tpoa-Br $(p<0.001)$ and T$\operatorname{Tpoa-Br}(p<0.001)$.

\subsection{Detection of $A \beta$ and GFAP in the brain of BALB/C and APP751 ${ }^{\text {SL }}$ /PS1 ${ }^{\mathrm{M} 146 \mathrm{~L}}$ mice}

$A \beta$ immunoreactivity was found in the brains of all investigated mice, i.e., in Cpn infected BALB/c mice both 1 and 3 months p.i. (Figure 2A), mock infected $B A L B / c$ mice both 1 and 3 months after mock infection (Figure 2B), non-treated $\mathrm{BALB} / \mathrm{C}$ mice (Figure $2 \mathrm{C}$ ) and in $\mathrm{APP} 751^{\mathrm{SL}} / \mathrm{PS} 1^{\mathrm{M} 146 \mathrm{~L}}$ mice (Figure 2D). However, such $A \beta$-immunopositive aggregates were found only occasionally in the brains of the BALB/c mice (on average one to two aggregates per section without a preference for a given brain region), whereas they were found very frequently in the hippocampus and neocortex of $\mathrm{APP} 751^{\mathrm{SL}} / \mathrm{PS} 1^{\mathrm{M} 146 \mathrm{~L}}$ mice (see also Figure $2 \mathrm{H}$ in reference 22). Furthermore, there were several qualitative differences between the APP $751^{\mathrm{SL}} / \mathrm{PS} 1^{\mathrm{M} 146 \mathrm{~L}}$ and the BALB/C mice. First, in the brain of $\mathrm{APP} 751^{\mathrm{SL}} / \mathrm{PS} 1^{\mathrm{M} 146 \mathrm{~L}}$ mice, the materials immunopositive for $\mathrm{A} \beta$ formed $a$ dense core devoid of Hoechst-positive structures (i.e., cell nuclei). In contrast, the materials immunopositive for $A \beta$ in the brain of all BALB/c mice did not show a dense core and Hoechst-positive structures were scattered within these materials. Second, the astrocytic reaction in the brain of $\mathrm{APP} 751^{\mathrm{SL}} / \mathrm{PS} 1^{\mathrm{M} 146 \mathrm{~L}}$ mice surrounding the $A \beta$-immunopositive materials was much stronger than in the brain of BALB/C mice (arrowheads in Figure 1A-D). Third, in the brain of $\mathrm{APP} 751^{\mathrm{SL}} / \mathrm{PS} 1^{\mathrm{M} 146 \mathrm{~L}}$ mice, cells with intracellular deposits of $A \beta$ were found 
(asterisk in Figure 1D), which was not observed in the brains of BALB/c mice, irrespective of treatment.
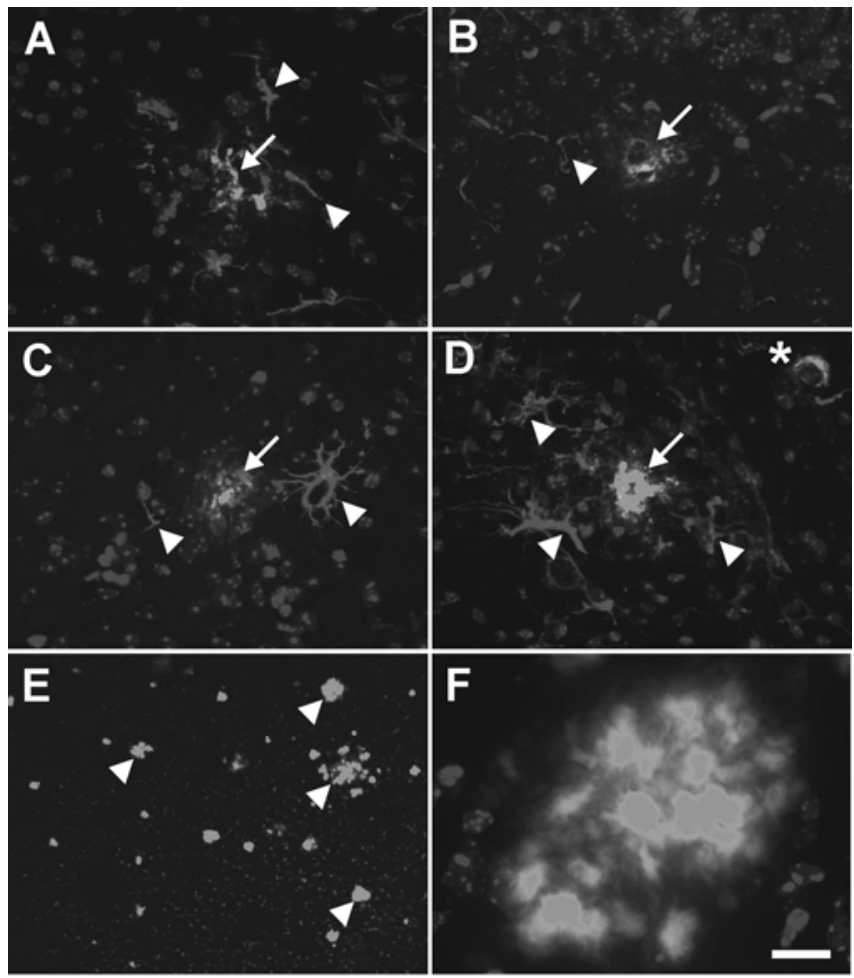

Figure 2. Immunohistochemical detection of $A \beta$ (green) and GFAP (red) in $30 \mu m$-thick cryostat sections, counterstained with Hoechst (blue), from the brain of a 6-month-old Cpn infected BALB/c mouse 3 months post infection (A), a 6-month-old mock infected BALB/c mouse 3 months after mock infection (B), a 6-month-old BALB/c mouse neither infected with $\mathrm{Cpn}$ nor mock infected $(C)$ and a 17 -month-old $A P P 751^{\mathrm{SL}} / \mathrm{PS} 1^{\mathrm{M} 146 \mathrm{~L}}$ transgenic mouse (D). Note that material immunopositive for $A \beta$ was found in the brain of all mice (arrows). However, there were differences between the APP $751^{\mathrm{SL}} / \mathrm{PS} 1^{\mathrm{M} 146 \mathrm{~L}}$ mouse and the BALB/C mice: (i) in the brain of the APP751 $1 \mathrm{LL} / \mathrm{PS} 1^{\mathrm{M} 146 \mathrm{~L}}$ mouse the material immunopositive for $A \beta$ formed a dense core devoid of Hoechst-positive structures (i.e., cell nuclei). In contrast, the material immunopositive for $A \beta$ in the brain of the BALB/c mice did not show a dense core, and Hoechst-positive structures were scattered within it. (ii) The astrocytic reaction in the brain of the APP $751^{\mathrm{SL}} / \mathrm{PS} 1^{\mathrm{M} 146 \mathrm{~L}}$ mouse surrounding the material immunopositive for $A \beta$, was much stronger than in the brain of the BALB/c mice (arrowheads). (iii) In the brain of the APP $751^{\mathrm{SL}} / \mathrm{PS} 1^{\mathrm{M} 146 \mathrm{~L}}$ mouse cells with intracellular deposits of material immunopositive for $A \beta$ were found (asterisk in D). This was not observed in the brain of the BALB/c mice. Furthermore, extracellular thioflavin-S-positive structures in the brain of the 17 -month-old APP $751^{\mathrm{SL}} / \mathrm{PS} 1^{\mathrm{M} 146 \mathrm{~L}}$ mouse are shown ( $E$ [arrowheads] and $F$, resembling fibrillary $A \beta$ deposits. Scale bar $=$ $25 \mu \mathrm{m}$ in $\mathrm{A}$ to $\mathrm{D}, 100 \mu \mathrm{m}$ in $\mathrm{E}$ and $10 \mu \mathrm{m}$ in $\mathrm{F}$. (See coloured illustration inserted at the back of this thesis). 


\subsection{Detection of thioflavin-S-positive structures in the brain of $A P P 751^{\text {SL }} / P S 1^{M 146 L}$ but not in the brain of BALB/C mice}

In the brain of $\mathrm{APP} 751^{\mathrm{SL}} / \mathrm{PS} 1^{\mathrm{M} 146 \mathrm{~L}}$ mice, extracellular thioflavin-S-positive structures were found (Figure $2 E$ and $F$ ), as previously reported ${ }^{25,31}$, resembling fibrillary $A \beta$ deposits. Such extracellular thioflavin-S-positive structures were not found in the brains of the BALB/c mice.

\section{Discussion}

The role of inflammatory factors in the initiation or acceleration of neurodegenerative diseases is increasingly recognized. In most of the cases, these inflammatory factors are caused by infections. Several viruses have already been associated with central nervous system disorders ${ }^{6-9}$. The obligatory intracellular bacterium $\mathrm{Cpn}$ has also been linked to a variety of neurodegenerative diseases including AD. In 1998, the presence of this pathogen was described in postmortem brains from patients with $A D^{17}$, and significant amounts of Cpn were found in various cerebral cell types. That Cpn may contribute to neurodegenerative processes was recently supported by data from our laboratory, as we demonstrated that Cpn is able to infect neurons, ultimately resulting in neuronal cell death in vitro ${ }^{26}$. However, to the best of our knowledge, only one experimental in vivo study has been published so far supporting a role for $\mathrm{Cpn}$ in $A D^{22}$. In this study, naïve $B A L B / c$ mice were inoculated intranasally with $\mathrm{Cpn}$ at an age of 3 months. Brains were recovered at 1-3 months p.i. revealing the presence of amyloid-like plaques and astrocyte reactivity. Due to the possible impact of this study, it was our goal to confirm these data by repeating these experiments. Focusing on our results of Cpn inoculated mice at 3 months p.i., $A \beta$-immunopositive areas were indeed detected in those brains. Accordingly, at first glance, our results are in accordance with the study of Little and colleagues ${ }^{22}$. Comparing the morphological appearance of this material, immunopositive for $A \beta$, with corresponding material in the brain of $\mathrm{APP} 751^{\mathrm{SL}} / \mathrm{PS} 1^{\mathrm{M} 146 \mathrm{~L}}$ mice, however, revealed some significant and important differences. First, one characteristic of neuritic plaques, as described in $A D$, is the presence of filamentous, starshaped aggregates of $A \beta$ fibrils with a thioflavin-S-positive dense core. However, neither such star-shaped aggregates of $A \beta$ fibrils nor extracellular thioflavin-S-positive structures were found in any of the brains of Cpn infected or mock infected mice, whereas both lesions were abundant in the brain of 
APP751 1 LL $/ P S 1^{\mathrm{M} 146 \mathrm{~L}}$ mice. Second, no damage was found in the tissue surrounding the $A \beta$-immunopositive areas. Also, Hoechst-positive structures (i.e., cell nuclei) could be detected within the $A \beta$-immunopositive parts, a feature that was not seen in the brain of the APP751 ${ }^{\mathrm{SL}} / \mathrm{PS} 1^{\mathrm{M} 146 \mathrm{~L}}$ mice. Finally, although astrocytes were found in the vicinity of the $A \beta$-immunopositive areas in the brain of $\mathrm{Cpn}$ infected or mock infected mice, they were not intimately associated with the $A \beta$ immunoreactivity, as seen in the brain of the APP751 ${ }^{\mathrm{SL}} / \mathrm{PS} 1^{\mathrm{M} 146 \mathrm{~L}}$ mice. In summary, our data suggest that 3 months after $C p n$ infection, $A \beta$ plaques could not be reliably detected in 12 months old naïve, non-transgenic mice, whereas these characteristic features of $A D$ pathology were prominent in the brain of APP $751^{\mathrm{SL}} / \mathrm{PS}^{\mathrm{M} 146 \mathrm{~L}}$ mice. It may still be argued that the $\mathrm{A} \beta$-immunopositive parts, found in the brain of the Cpn infected mice, represented early precursors of neuritic plaques. To our surprise, however, nearly identical patterns of $A \beta$ immunoreactivity were detected in mock infected mice, as well as in mice neither $\mathrm{Cpn}$ infected, nor mock infected. This suggests that the observed immunoreactivity for $A \beta$ in the brain of the BALB/c mice does not directly result from $C p n$ infection, but represents unrelated elevations in amyloid. Positive staining for $A \beta$ in the brain of mock infected mice was also observed by Little and colleagues $^{22}$, who found that the amyloid deposition load and size were significantly enhanced in Cpn infected mice compared to mock infected mice, in contrast to the present study. The reason for this disparity is unknown, although it should be noted that Little and colleagues $^{22}$ used a Cpn strain (C. pneumoniae, 96-41, isolated from the postmortem brain of an AD patient) that was rather different from the $\mathrm{Cpn}$ strain that was used in the present study (TWAR 2043, ATCC). Notably, Little and colleagues were able to detect Cpn in olfactory tissues of infected mice up to 3 months p.i., by both light as electron microscopy. In the present study, however, we were only able to detect Cpn DNA in this tissue at 1 week p.i., but not at 1 or 3 months p.i., despite the use of a more sensitive detection method (real-time PCR). As it is well established that the clinical isolates of pathogens are often more infectious than their laboratory counterparts, this could also explain the discrepancy between both studies. Furthermore, it cannot be excluded that differences in solutions, used for mock infection (Hanks balanced salt solution in the study by Little and colleagues ${ }^{22}$ vs. sucrose-phosphate-glucose solution in the present study), may have affected the final outcome. Yet, although some areas immunopositive for $A \beta$ were also detected in brains of the mice neither $\mathrm{Cpn}$ infected nor mock infected, the immunosignal in these mice appeared somewhat less strong than in the brain of the mice that were either Cpn infected or mock infected (a detailed quantitative analysis was not performed). This suggests that intranasal application of $\mathrm{Cpn}$ or other infectious agents may trigger the production and 
deposition of $A \beta$ in the brain of BALB/c mice. For the time being, however, the impact of this remains unclear.

In conclusion, our data do not unequivocally support the hypothesis that Cpn infection induces the formation of $A D$ like $A \beta$ plaques in the brain of BALB/C mice, as suggested by Little and colleagues ${ }^{22}$. Accordingly, future studies are required to investigate whether $C p n$ infections may aggravate $A D$ pathology by stimulating the formation of $A \beta$ plaques as has been suggested in atherosclerosis, a disease that is also characterized by pronounced local inflammation.

\section{Acknowledgements}

We thank Sofie Lemmens for excellent technical assistance. This study was supported by grants from the International Alzheimer's Research Foundation (ISAO; The Netherlands) and The Netherlands Organization for Scientific Research (NWO; The Netherlands).

\section{References}

1. Tanzi, R.E., et al., The gene defects responsible for familial Alzheimer's disease. Neurobiol Dis, 1996. 3(3): p. 159-68.

2. Lippa, C.F., et al., Familial and sporadic Alzheimer's disease: neuropathology cannot exclude a final common pathway. Neurology, 1996. 46(2): p. 406-12.

3. Wucherpfennig, K.W., Infectious triggers for inflammatory neurological diseases. Nat Med, 2002. 8(5): p. 455-7.

4. Mattson, M.P., Infectious agents and age-related neurodegenerative disorders. Ageing Res Rev, 2004. 3(1): p. 105-20.

5. Balin, B.J. and D.M. Appelt, Role of infection in Alzheimer's disease. J Am Osteopath Assoc, 2001. 101(12 Suppl Pt 1): p. S1-6.

6. Dobson, C.B. and R.F. Itzhaki, Herpes simplex virus type 1 and Alzheimer's disease. Neurobiol Aging, 1999. 20(4): p. 457-65.

7. Lin, W.R., et al., Herpesviruses in brain and Alzheimer's disease. J Pathol, 2002. 197(3): p. 395-402.

8. Hemling, N., et al., Herpesviruses in brains in Alzheimer's and Parkinson's diseases. Ann Neurol, 2003. 54(2): p. 267-71.

9. Kolson, D.L. and F. Gonzalez-Scarano, HIV and HIV dementia. J Clin Invest, 2000. 106(1): p. 11-3.

10. Kuo, C.C., et al., Chlamydia pneumoniae (TWAR). Clin Microbiol Rev, 1995. 8(4): p. 451-61.

11. Grayston, J.T., et al., A new respiratory tract pathogen: Chlamydia pneumoniae strain TWAR. J Infect Dis, 1990. 161(4): p. 618-25.

12. Grayston, J.T., et al., Evidence that Chlamydia pneumoniae causes pneumonia and bronchitis. J Infect Dis, 1993. 168(5): p. 1231-5.

13. Weinberger, M., Respiratory infections and asthma: current treatment strategies. Drug Discov Today, 2004. 9(19): p. 831-7. 
14. Kuo, C.C., et al., Chlamydia pneumoniae (TWAR) in coronary arteries of young adults (15-34 years old). Proc Natl Acad Sci U S A, 1995. 92(15): p. 6911-4.

15. Ezzahiri, R., et al., Chlamydia pneumoniae infection induces an unstable atherosclerotic plaque phenotype in LDL-receptor, ApoE double knockout mice. Eur J Vasc Endovasc Surg, 2003. 26(1): p. 88-95.

16. Yucesan, C. and S. Sriram, Chlamydia pneumoniae infection of the central nervous system. Curr Opin Neurol, 2001. 14(3): p. 355-9.

17. Balin, B.J., et al., Identification and localization of Chlamydia pneumoniae in the Alzheimer's brain. Med Microbiol Immunol (Berl), 1998. 187(1): p. 23-42.

18. Gieffers, J., et al., Failure to detect Chlamydia pneumoniae in brain sections of Alzheimer's disease patients. J Clin Microbiol, 2000. 38(2): p. 881-2.

19. Nochlin, D., et al., Failure to detect Chlamydia pneumoniae in brain tissues of Alzheimer's disease. Neurology, 1999. 53(8): p. 1888.

20. Ring, R.H. and J.M. Lyons, Failure to detect Chlamydia pneumoniae in the late-onset Alzheimer's brain. J Clin Microbiol, 2000. 38(7): p. 2591-4.

21. Taylor, G.S., et al., Failure to correlate C. pneumoniae with late onset Alzheimer's disease. Neurology, 2002. 59(1): p. 142-3.

22. Little, C.S., et al., Chlamydia pneumoniae induces Alzheimer-like amyloid plaques in brains of $B A L B / c$ mice. Neurobiol Aging, 2004. 25(4): p. 419-29.

23. Robertson, M., Is Chlamydia associated with Alzheimer's? Drug Discov Today, 2004. 9(11): p. 469.

24. Roblin, P.M., W. Dumornay, and M.R. Hammerschlag, Use of HEp-2 cells for improved isolation and passage of Chlamydia pneumoniae. J Clin Microbiol, 1992. 30(8): p. 1968-71.

25. Schmitz, C., et al., Hippocampal neuron loss exceeds amyloid plaque load in a transgenic mouse model of Alzheimer's disease. Am J Pathol, 2004. 164(4): p. 1495-502.

26. Boelen, E., et al., Chlamydia pneumoniae infection of brain cells: an in vitro study. Neurobiol Aging, 2007. 28(4): p. 524-32.

27. Tondella, M.L., et al., Development and evaluation of real-time PCR-based fluorescence assays for detection of Chlamydia pneumoniae. J Clin Microbiol, 2002. 40(2): p. 575-83.

28. Law, A., S. Gauthier, and R. Quirion, Say NO to Alzheimer's disease: the putative links between nitric oxide and dementia of the Alzheimer's type. Brain Res Brain Res Rev, 2001. 35(1): p. 73-96.

29. Zhu, Y.J., H. Lin, and R. Lal, Fresh and nonfibrillar amyloid beta protein(1-40) induces rapid cellular degeneration in aged human fibroblasts: evidence for AbetaP-channel-mediated cellular toxicity. Faseb J, 2000. 14(9): p. 1244-54.

30. Bhatia, R., H. Lin, and R. Lal, Fresh and globular amyloid beta protein (1-42) induces rapid cellular degeneration: evidence for AbetaP channel-mediated cellular toxicity. Faseb J, 2000. 14(9): p. 1233-43.

31. Blanchard, V., et al., Time sequence of maturation of dystrophic neurites associated with Abeta deposits in APP/PS1 transgenic mice. Exp Neurol, 2003. 184(1): p. 247-63. 



\section{Chapt er}

General Discussion \& Summary 

Because of an improved life expectancy in our Western society, neurodegenerative disorders of the elderly, like Alzheimer's disease (AD), are becoming an increasing health problem ${ }^{1,2}$. Apart from the socio-economic burden on the society, these diseases have been shown to be more and more an important cause of mortality and therefore, we should expand our knowledge concerning risk factors and underlying events, resulting in disease pathology. Although several risk factors have already been identified, the cause and cure for most of these disorders are still lacking. Nowadays, although occasionally described as a secondary mechanism in disease progression, (neuro)inflammation is increasingly being appreciated as an etiological factor in neurodegenerative diseases ${ }^{3}$. Infectious agents like human immunodeficiency virus (HIV) $)^{4}$, herpes simplex virus ${ }^{5,6}$ or cytomegalovirus ${ }^{7}$ have been shown to stimulate these inflammatory responses, and may as such contribute to the process of neurodegeneration. More recently, data have been published suggesting that the respiratory, obligate intracellular bacterium, Chlamydia pneunoniae ( $\mathrm{Cpn}$ ), previously linked to chronic inflammatory diseases like atherosclerosis ${ }^{8,9,10,11,12}$, might be another pathogen associated with several neurodegenerative diseases ${ }^{13,14}$. More precisely, the prominent presence of the pathogen in brains from $A D$ patients, compared to the relative lack in patients who died of other causes, launched the hypothesis that $\mathrm{Cpn}$ could be a prominent player in the aetiology of the disease ${ }^{15,16}$. Although it is well defined that Cpn can traffic towards the nervous system ${ }^{13}$, at the time the studies described in the present thesis were initiated, it was unclear whether or not the bacterium really contributes to disease pathology and by which mechanisms it does so. Therefore, various in vitro studies as well as an in vivo study were conducted to gain further insight in these questions.

\section{In vitro studies}

Initially, we used cell cultures in an attempt to establish whether $\mathrm{Cpn}$ is able to trigger (neuro)degeneration and whether this is due either to a direct effect of the pathogen on (neuronal) cells, or merely results from chronic cerebral inflammation, caused by the pathogen (Chapter 2, 3, 5).

Although it has been shown that $\mathrm{Cpn}$ is capable to infect a large variety of cells ${ }^{17}$, it was unclear whether brain cells are susceptible to the pathogen. Therefore, we first investigated Cpn tropism in vitro in brain cell lines: a microglial cell line (MMC), a neuronal cell line (NB) and an astrocyte cell line (C8D1A), while a human epithelial cell line (Hep2) was used as a reference cell 
line (Chapter 2). Furthermore, we determined whether Cpn infection directly results in cell death, and if it did, whether this was due to apoptosis or necrosis. Microscopic results of our reference cell line, Hep2, showing the various stages of the developmental cycle, were in accordance with earlier data ${ }^{18}$. Small inclusion bodies were demonstrated at the early time points p.i. in almost all Hep2 cells. Then, starting from $24 \mathrm{hr}$ p.i., inclusion body size started to increase until maximal sizes were detected at 48 and $72 \mathrm{hr}$ p.i.. At these later time points, not all cells showed positive signal, but the majority still seemed to be infected. One and two weeks post infection, the Hep2 cells display a large variety in Cpn inclusion body sizes. With respect to the brain cells, the neuronal cell line showed identical infection patterns to the Hep2 cell line, displaying high sensitivity to $\mathrm{Cpn}$. Also viable progeny was found and most importantly, these cells were prone to die post infection by necrosis. Cpn tropism was quite similar in the astrocyte cell line, except for the higher production of infectious Cpn, as shown by the transfer experiments.

Yet, observations in the microglial cell line (MMC) were markedly different. The MMC seemed highly resistant to Cpn, as no positive immunohistochemical staining was observed, in particular at later time points. Furthermore, hardly any viable progeny or necrotic microglial cells were observed. Nevertheless, significant Cpn DNA amounts could be detected, suggesting Cpn persistence, as demonstrated in monocytes even in the presence of macrolides ${ }^{19}$. Moreover, as Cpn protein expression patterns could potentially change during persistent infection $^{20}$, it was suggested that the lack of immunofluorescence in MMC is probably due to such altered protein expression profiles. Therefore, it is hypothesized that microglial cells serve as an anatomical and functional filter to protect more permissive cell types like neuronal cells, as already described for Chlamydia trachomatis ${ }^{21}$. Comparing our observations in MMC, the macrophage equivalent of the $\mathrm{CNS}^{22}$, with infections patterns in various tissue macrophages, revealed similar outcomes ${ }^{23,17,24}$. Moreover, it was reported by Rothfuchs et al. that INF- $\gamma$ and nitric oxide could be responsible for controlling intracellular $\mathrm{Cpn}$ infection in bone marrow-derived macrophages ${ }^{25}$. Thereupon, it was investigated if similar mechanisms could be responsible for the aberrant course of Cpn infection in microglial cells (Chapter 4). However, neither inhibiting NO production nor neutralizing INF- $\gamma$ resulted in a higher infectivity of our microglial cells. Moreover, cytokine measurements post $\mathrm{Cpn}$ infection did not show any detectable INF- $\gamma$ levels at any time point. On the contrary, IL-6 and TNF- $\alpha$ were prominently released by Cpn infected microglial cells. As the latter has been shown previously to be involved in restraining the growth of Chlamydia $^{26,27}$, these compounds were neutralized from the culture medium. Nonetheless, this treatment also did not change the susceptibility of our 
microglial cell line to $\mathrm{Cpn}$. Taken together, these results suggest that neither INF- $\gamma$, TNF- $\alpha$, IL-6 nor nitric oxide play a considerable role in controlling $\mathrm{Cpn}$ infection by MMC.

In summary, most importantly, we could show that neurons as well as astrocytes are highly susceptible to $\mathrm{Cpn}$ and die, once infected by the bacterium. MMC, on the other hand, are well able to control intracellular growth of $\mathrm{Cpn}$ by yet unknown mechanisms and display persistence, thereby possibly protecting neurons.

Apart from direct effects of $\mathrm{Cpn}$ on neurodegeneration, it was hypothesized that in response to Cpn infection, glial cells may release excessive amounts of proinflammatory cytokines, which may ultimately result in neuro-inflammation and subsequent neurotoxicity. This indirect pathway is probably more common as in vivo, neurons are morphologically protected by glial cells. Once a pathogen invades the brain, it will directly come into contact with astrocytes, a major component of the blood-brain barrier and moreover, neurons are densely surrounded by this cell type. Additionally, microglial cells, the immune cells of the CNS, will respond immediately to infection and migrate to the place of danger $^{22}$, thereby protecting neurons. To investigate this pathway, various chemo- and cytokines levels were determined in the culture supernatant of MMC and astrocytes, at various time points following Cpn infection (Chapter 3). Significant higher levels of MCP-1, IL-6, TNF- $\alpha$ and IL-1 $\beta$ were produced by infected MMC compared to controls, with maximal values detected at $24 \mathrm{hr}$ p.i.. In contrast, only MCP-1 and IL-6 levels were significantly increased following infection of astrocytes, predominantly at 1 week p.i., compared to controls. Moreover, when neurons were exposed to conditioned supernatants from infected MMC (but not astrocytes), a significant increase in cell death, predominantly caused by IL- 6 and TNF- $\alpha$, was observed compared to mock infection. Likewise, in $A D$, it has already been shown that activated glial cells produce numerous compounds, like IL-6, IL-1 and TNF- $\alpha$, that contribute to neurodegeneration and cell death ${ }^{3,28,29}$. Several theories exist concerning the origin of this inflammatory response $\mathrm{e}^{3,30}$ and among those, several pathogens, like for instance HIV-1, were found able to trigger these processes ${ }^{31,32}$. Here, we demonstrated that $\mathrm{Cpn}$ can also induce the release of such neurotoxic compounds, predominantly by microglial cells. In contrast, astrocytes produced only IL- 6 and MCP-1 and these amounts were also significantly lower as those released by MMC. The latter are the cerebral equivalent of tissue macrophages in which activation by LPS results in the production of pro-inflammatory cytokines, like TNF- $\alpha$, IL- 6 or IL- $1 \alpha / \beta^{33}$, comparable with our data on Cpn infection of microglial cells. Likewise, identical cytokine profiles were shown 
following Cpn infection of primary bone marrow-derived macrophages or alveolar macrophages ${ }^{23,34,35}$. Based on these similarities, it can be speculated that the classical LPS receptor, Toll-like receptor 4 (TLR4), may play a prominent role in mediating the inflammatory responses to $\mathrm{Cpn}$ by glial cells. Activation of this receptor by LPS, a major compound on the cell surface of Gram-negative bacteria like $\mathrm{Cpn}^{36}$, will result in the profound release of various cyto- and chemokines ${ }^{37,38}$. Moreover, it is generally accepted that this receptor is present on microglial cells ${ }^{39,40,41}$. However, the presence of this receptor on astrocytes is more controversial ${ }^{40,41,42,43}$. To elucidate that aspect in our setting, nitric oxide (NO) production was measured after stimulation with various concentrations of LPS. While high amounts were detected in the supernatants of microglial cells, astrocytes were unable to produce measurable amounts of NO (unpublished data). This suggests that TLR4 stimulation may be largely responsible for the majority of pro-inflammatory cytokines produced by MMC. Nonetheless, the release of IL- 6 and MCP- 1 by astrocytes suggests that there might also be a TLR4 independent pathway by which cytokines/chemokines can be produced.

Summarizing, we demonstrated that $\mathrm{Cpn}$ infection of glial cells, and microglial cells in particular, results in the release of various pro-inflammatory cytokines/chemokines in amounts that are sufficient to cause the death of neuronal cells. Whether such processes also take place in the intact brain and may as such provide a possible mechanism by which microbes and Cpn in particular may affect neurodegeneration, requires further examination.

Next, we suggested that these inflammatory compounds, produced predominantly by microglial cells following Cpn infection, may also result in neurodegeneration by impairing astrocyte glutamate transport (Chapter 5). This could finally result in neurotoxic concentrations of this neurotransmitter, as has previously been shown in amyotrophic lateral sclerosis (ALS) and Alzheimer's disease $(A D)^{44}$. Indeed, we observed a significant increase in neuronal cell death when these cells were incubated with glutamate-containing medium from astrocytes, which were exposed to medium from infected MMC earlier. In contrast, when neurons were incubated with glutamate-containing medium from astrocytes, exposed to medium derived from non-infected MMC, neuronal cell death was significantly lower. These findings suggested that glutamate uptake by astrocytes might be severely impaired once these cells are exposed to inflammatory cytokines, released by infected MMC. Subsequently, this will result in augmented levels of glutamate in the extracellulair milieu, toxic effects on neurons and ultimately neurodegeneration. However, and to our surprise, neither glutamate uptake nor the expression of the most important astrocytic glutamate transporter, GLT-1 (EAAT2) ${ }^{44}$, were disturbed in treated astrocytes, 
which questions our conclusion that the observed neuronal cell death was due to neurotoxic levels of glutamate. This is also in contrast with data from Wang and colleagues, who demonstrated in vitro that infection of astrocytes by another human pathogen (HIV) resulted in deficits in glutamate uptake, possibly caused by impairments in the transcription of EAAT2 ${ }^{45}$. However, in these experiments, astrocytes were directly infected with the virus, while in our case, astrocytes were incubated with conditioned medium from $\mathrm{Cpn}$ infected microglial cells, which may explain the difference. Furthermore, the different origin of their astrocyte culture and pathogen may explain these discrepancies. On the other hand, also indirect causes of (HIV) infection, and in particular the release of TNF- $\alpha$, have been linked with a decreased astrocytic glutamate uptake ${ }^{47}$. However, in our setting, incubation of astrocytes with conditioned medium from $\mathrm{Cpn}$ infected MMC, which contains high levels of predominantly IL-6 and TNF- $\alpha$ (Chapter 3), did not affect glutamate transport whatsoever. This makes it unlikely that these compounds are responsible for triggering the processes that ultimately resulted in neuronal cell death. Furthermore, immunohistochemical staining revealed that the major glutamate transporter, GLT-1, was expressed only at very low levels in our astrocyte cell line while GLAST was abundantly expressed. This is in accordance with earlier data which demonstrated that GLT-1 is only expressed by astrocytes when cocultured with neurons but not in monocultures ${ }^{48}$. As we used an astrocyte monoculture, this is probably why this transporter could not be detected. Nevertheless, this does not answer the question why neurons are more prone to die when incubated with glutamate-containing medium from astrocytes, which were previously exposed to medium derived from $\mathrm{Cpn}$ infected microglial cells. This suggests that astrocytes, previously primed by inflammatory compounds, react to high levels of glutamate by secreting some yet unknown neurotoxic compounds which may ultimately cause neurodegeneration. Further experiments are required to elucidate the various compounds produced by primed astrocytes following application of glutamate. In addition, the effect of neutralizing these factors on neurodegeneration should also be evaluated.

\section{An integrated model}

Taken together, these in vitro data inspired us to a unifying hypothesis regarding the pathways by which $\mathrm{Cpn}$ might contribute to neurodegenerative diseases like Alzheimer's disease.

First, as Chlamydia pneumoniae is assumed to travel from person to person via nasal droplets ${ }^{49}$, the primary site of infection will be the respiratory tract ${ }^{50}$. However, one can speculate that via this intranasal route, a certain amount of 
Cpn can directly enter the brain via the bulbi olfactorii ${ }^{51}$, thereby evading the blood-brain barrier (olfactory pathway). In this situation, Cpn might be able to approach and infect neurons directly. Here, we demonstrated that this cell type is highly susceptible to Cpn and supports the growth of the pathogen. Also, we showed that neurons degenerate following infection, thereby releasing newly formed infectious elementary bodies. These elementary bodies will subsequently infect neighbouring cells like astrocytes, microglial cells or other neurons. Infection of astrocytes, which densely surround neurons ${ }^{22}$, will result in a similar pattern characterized by a high level of infection and again the release of elementary bodies, that will further disseminate the infection to adjacent cells. Microglial cells, on the other hand, were rather resistant to the direct necrotizing effect of Cpn infection by yet unravelled mechanisms. Nevertheless, these cells highly responded to the pathogen. We established that $\mathrm{Cpn}$ infected microglial cells produced various inflammatory factors, predominantly IL- 6 and TNF- $\alpha$, in amounts that are sufficient to cause neuronal cell death, thereby providing an indirect way by which $\mathrm{Cpn}$ might contribute to neurodegeneration, next to its direct necrotic effects on brain cells.

Apart from entering the brain through the bulbi olfactorii, Cpn may enter the nervous system through other pathways. It is generally accepted that Cpn disseminates to other parts of the body, predominantly via infected monocytes ${ }^{52}$. Nowadays, various routes have been described how a systemic infection/inflammation can communicate with the central nervous system. One important circuit involves the circumventricular organs that lack a blood-brain barrier $^{53}$. At these particular locations, direct contact between the pathogen and neurons might result in the same consequences as described above. However, the major route will involve the blood-brain barrier. As Cpn is able to traffic systemically to distant sites, Cpn infected monocytes will invade the brain via the blood-brain barrier, whose permeability increases in response to a Cpn infection $^{54,55}$. The pathogen will initially encounter microglial cells ${ }^{56}$ and astrocytes ${ }^{57}$ before neurons will be reached. Astrocytes are demonstrated to be highly susceptible to $\mathrm{Cpn}$ and able to produce infectious Cpn elementary bodies, which will infect neighbouring neurons. Also, the release of inflammatory molecules by infected microglial cells, initially intended to control the infection, will create a neurotoxic milieu, thereby contributing further to neurodegeneration. Also other mechanisms, like an impairment of glutamate metabolism, might provide additional pathways by which pathogens can contribute to neurodegenerative diseases. Concluding from our in vitro data, there might be various pathways by which pathogens, and $\mathrm{Cpn}$ in particular, can have profound effects on neurodegeneration, even when there is no direct contact between the microbe and neurons. 


\section{An integrated model, involving the blood-brain barrier}

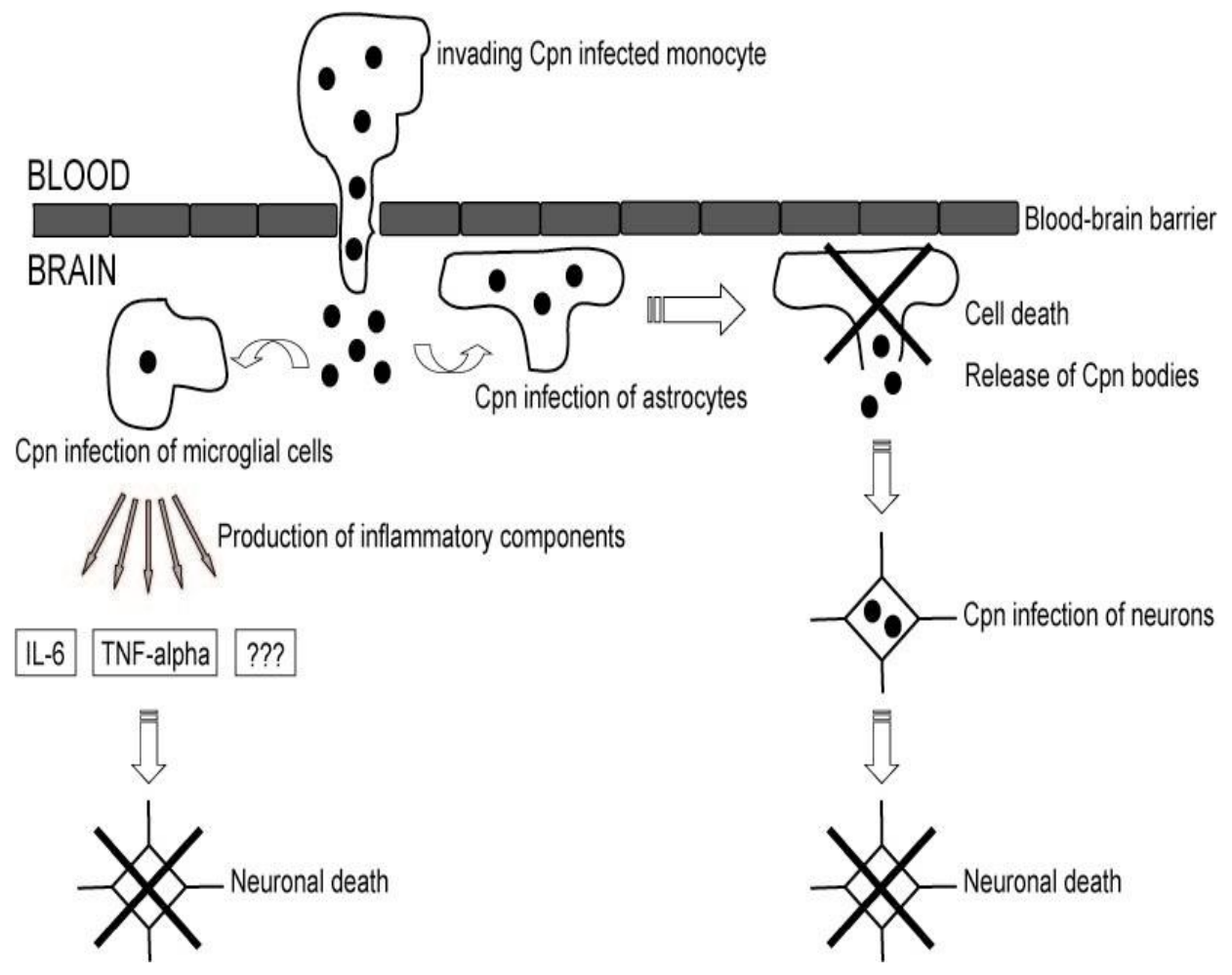

\section{In vivo experiments}

Next to our in vitro models, we also investigated the consequences of $\mathrm{Cpn}$ infection on the brain in an in vivo mouse model. Our major goal was to determine whether $\mathrm{Cpn}$ infection could initiate one of the hallmarks of Alzheimer's disease (AD), extracellular aggregation of amyloid beta $(A \beta)$, in normal BALB/c mice. Also, findings were compared with pathology identified in transgenic $A D$ mice (Chapter 6). Normal female mice were inoculated intranasally and at various time points p.i., we i) screened for the presence of $\mathrm{Cpn}$ in their brain and ii) analysed whether amyloid plaques could be detected at 1 and 3 months p.i.. Only at 1 week post infection, we were able to detect Cpn DNA in the brain, and predominantly in the bulbi olfactorii. Furthermore, extracellular $A \beta$ deposits could be detected in brains of $\mathrm{Cpn}$ infected mice at 1 and 3 months p.i., but similar observations were made in brains of mock 
infected suggesting Cpn-unrelated elevations in amyloid. Moreover, marked morphological differences were observed, when comparing these extracellular $\mathrm{A} \beta$ aggregates to those observed in brains of $\mathrm{APP} 751^{\mathrm{SL}} / \mathrm{PS} 1^{\mathrm{M} 146 \mathrm{~L}}$ mice. For example, no star-shaped aggregates of $A \beta$ fibrils with a thioflavin-S-positive dense core could be detected, tissue damage in the $A \beta$ positive areas was absent and no abundant astrocytes were found in the close vicinity of $A \beta$ positive areas. Yet, although we cannot exclude that the morphological features we observed might be initial stages of the disease, these finding suggest that a single $C p n$ infection may not result in the formation of advanced $A \beta$ plaques and profound $A D$, at least in normal mice. In contrast, others have claimed that $\mathrm{Cpn}$ infection is able to induce the formation of $A \beta$ plaques in normal mice ${ }^{51}$. Little and colleagues detected $\mathrm{Cpn}$ in the olfactory tissue even at 1 and 3 months post infection, by light and electron microscopy. Moreover, amyloid deposition load and size were significantly enhanced in Cpn infected mice compared to mock infected mice. These discrepancies could possibly be explained by the use of a different $\mathrm{Cpn}$ strain. Little et al. used a clinical Cpn strain, isolated from post-mortem AD brain material while a laboratory strain, TWAR 2043 (ATCC) was used in our study. As clinical isolates are usually more infectious than laboratory strains, this might, to some extent, explain the difference between their and our results. Additionally, also the mock solution varied between both studies (Hanks balanced salt solution vs. sucrose-phosphate-glucose solution) which may possibly affect the results. Finally, $A \beta$ positive areas were also detected in our non-treated mice. However, these deposits were less pronounced compared to the other two groups, suggesting that intranasal application of some solution may already trigger the deposition of $A \beta$. However, further studies are needed to elucidate this. To conclude, the hypothesis that $C p n$ infection induces the formation of $A D$ like $A \beta$ plaques in the brain of $\mathrm{BALB} / \mathrm{c}$ mice, as suggested before ${ }^{51}$, was not truly supported by our study.

\section{Conclusions and future perspectives}

In summary, although our in vivo data do not unequivocally support the hypothesis that $\mathrm{Cpn}$ causes $\mathrm{AD}$, it cannot be excluded that infections, and $\mathrm{Cpn}$ in particular, accelerate the progression of $A D$, either in a direct way by causing neurodegeneration or more indirectly as a result of a chronic cerebral inflammation with the profound production of inflammatory compounds, that ultimately result in neurodegenation. Interestingly, apart from chronic cerebral infection and inflammation, chronic systemic inflammation has also recently been suggested to contribute significantly to neurodegenerative diseases ${ }^{53,58,59}$. 
To elaborate this hypothesis further, studies in animal models of neurological diseases should be done in order to allow us to investigate the cellular and molecular events by which secretion of products of infected and activated microglia influence disease progression and neurological function. Additionally, future experiments should be conducted to investigate whether infections or inflammation in general are a possible trigger to switch from normal aging to neurodegenerative disorders. Accordingly, in a model with a brain already primed by disease (AD) or infection, the impact of a systemic infection on disease progression could be evaluated.

Overall, although the role of infections in neurodegenerative disorders has been increasingly appreciated, the field is still in its infancy. Therefore, future studies are required, both basic as well as clinical, to further unravel the impact of infections on these diseases before we can develop strategies to counteract the consequences of infection and inflammation on neuronal function in the aging population.

\section{References}

1. Brayne, C., et al., Dementia before death in ageing societies--the promise of prevention and the reality. PLoS Med, 2006. 3(10): p. e397.

2. Mayeux, R., Epidemiology of neurodegeneration. Annu Rev Neurosci, 2003. 26: p. 81-104.

3. Akiyama, H., et al., Inflammation and Alzheimer's disease. Neurobiol Aging, 2000. 21(3): p. 383-421.

4. Kolson, D.L. and F. Gonzalez-Scarano, HIV and HIV dementia. J Clin Invest, 2000. 106(1): p. 11-3.

5. Dobson, C.B. and R.F. Itzhaki, Herpes simplex virus type 1 and Alzheimer's disease. Neurobiol Aging, 1999. 20(4): p. 457-65.

6. Hemling, N., et al., Herpesviruses in brains in Alzheimer's and Parkinson's diseases. Ann Neurol, 2003. 54(2): p. 267-71.

7. Lin, W.R., et al., Cytomegalovirus is present in a very high proportion of brains from vascular dementia patients. Neurobiol Dis, 2002. 9(1): p. 82-7.

8. Grayston, J.T., Does Chlamydia pneumoniae cause atherosclerosis? Arch Surg, 1999. 134(9): p. 930-4.

9. Campbell, L.A., C.C. Kuo, and J.T. Grayston, Chlamydia pneumoniae and cardiovascular disease. Emerg Infect Dis, 1998. 4(4): p. 571-9.

10. Ong, G., et al., Detection and widespread distribution of Chlamydia pneumoniae in the vascular system and its possible implications. J Clin Pathol, 1996. 49(2): p. 102-6.

11. Ezzahiri, R., et al., Chlamydia pneumoniae infection induces an unstable atherosclerotic plaque phenotype in LDL-receptor, ApoE double knockout mice. Eur J Vasc Endovasc Surg, 2003. 26(1): p. 88-95.

12. Moazed, T.C., et al., Chlamydia pneumoniae infection accelerates the progression of atherosclerosis in apolipoprotein E-deficient mice. J Infect Dis, 1999. 180(1): p. 238-41.

13. Stratton, C.W. and S. Sriram, Association of Chlamydia pneumoniae with central nervous system disease. Microbes Infect, 2003. 5(13): p. 1249-53.

14. Yucesan, C. and S. Sriram, Chlamydia pneumoniae infection of the central nervous system. Curr Opin Neurol, 2001. 14(3): p. 355-9. 
15. Balin, B.J., et al., Identification and localization of Chlamydia pneumoniae in the Alzheimer's brain. Med Microbiol Immunol (Berl), 1998. 187(1): p. 23-42.

16. Gerard, H.C., et al., Chlamydophila (Chlamydia) pneumoniae in the Alzheimer's brain. FEMS Immunol Med Microbiol, 2006. 48(3): p. 355-66.

17. Gaydos, C.A., et al., Replication of Chlamydia pneumoniae in vitro in human macrophages, endothelial cells, and aortic artery smooth muscle cells. Infect Immun, 1996. 64(5): p. 161420.

18. Wolf, K., E. Fischer, and T. Hackstadt, Ultrastructural analysis of developmental events in Chlamydia pneumoniae-infected cells. Infect Immun, 2000. 68(4): p. 2379-85.

19. Gieffers, J., et al., Chlamydia pneumoniae infection in circulating human monocytes is refractory to antibiotic treatment. Circulation, 2001. 103(3): p. 351-6.

20. Molestina, R.E., et al., Proteomic analysis of differentially expressed Chlamydia pneumoniae genes during persistent infection of HEp-2 cells. Infect Immun, 2002. 70(6): p. 2976-81.

21. Levitt, D., R. Danen, and P. Levitt, Selective infection of astrocytes by Chlamydia trachomatis in primary mixed neuron-glial cell cultures. Infect Immun, 1986. 54(3): p. 913-6.

22. Squire, L.R., et al., Cellular and Molecular Neuroscience. 2 ed. Fundamental Neuroscience, ed. L.R. Squire, et al. 2003, California: Academic Press, Elsevier Science. 49-339.

23. Redecke, V., et al., Interaction of Chlamydia pneumoniae and human alveolar macrophages: infection and inflammatory response. Am J Respir Cell Mol Biol, 1998. 19(5): p. 721-7.

24. Haranaga, S., et al., Chlamydia pneumoniae infection of alveolar macrophages: a model. J Infect Dis, 2003. 187(7): p. 1107-15.

25. Rothfuchs, A.G., et al., IFN-alpha beta-dependent, IFN-gamma secretion by bone marrowderived macrophages controls an intracellular bacterial infection. J Immunol, 2001. 167(11): p. 6453-61.

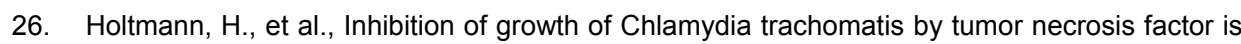
accompanied by increased prostaglandin synthesis. Infect Immun, 1990. 58(10): p. 3168-72.

27. Shemer-Avni, Y., D. Wallach, and I. Sarov, Reversion of the antichlamydial effect of tumor necrosis factor by tryptophan and antibodies to beta interferon. Infect Immun, 1989. 57(11): p. 3484-90.

28. Remarque, E.J., et al., Patients with Alzheimer's disease display a pro-inflammatory phenotype. Exp Gerontol, 2001. 36(1): p. 171-6.

29. Weiner, H.L. and D.J. Selkoe, Inflammation and therapeutic vaccination in CNS diseases. Nature, 2002. 420(6917): p. 879-84.

30. Cummings, J.L., Alzheimer's disease. N Engl J Med, 2004. 351(1): p. 56-67.

31. Epstein, L.G. and H.E. Gendelman, Human immunodeficiency virus type 1 infection of the nervous system: pathogenetic mechanisms. Ann Neurol, 1993. 33(5): p. 429-36.

32. Pulliam, L., et al., Human immunodeficiency virus-infected macrophages produce soluble factors that cause histological and neurochemical alterations in cultured human brains. $\mathrm{J}$ Clin Invest, 1991. 87(2): p. 503-12.

33. Nakamura, Y., Q.S. Si, and K. Kataoka, Lipopolysaccharide-induced microglial activation in culture: temporal profiles of morphological change and release of cytokines and nitric oxide. Neurosci Res, 1999. 35(2): p. 95-100.

34. Naiki, Y., et al., MyD88 is pivotal for the early inflammatory response and subsequent bacterial clearance and survival in a mouse model of Chlamydia pneumoniae pneumonia. $J$ Biol Chem, 2005. 280(32): p. 29242-9.

35. Quinn, T.C. and C.A. Gaydos, In vitro infection and pathogenesis of Chlamydia pneumoniae in endovascular cells. Am Heart J, 1999. 138(5 Pt 2): p. S507-11.

36. Bos, M.P. and J. Tommassen, Biogenesis of the Gram-negative bacterial outer membrane. Curr Opin Microbiol, 2004. 7(6): p. 610-6.

37. Ulevitch, R.J. and P.S. Tobias, Recognition of Gram-negative bacteria and endotoxin by the innate immune system. Curr Opin Immunol, 1999. 11(1): p. 19-22. 
38. Akira, S. and K. Takeda, Toll-like receptor signalling. Nat Rev Immunol, 2004. 4(7): p. 499511.

39. Bsibsi, M., et al., Broad expression of Toll-like receptors in the human central nervous system. J Neuropathol Exp Neurol, 2002. 61(11): p. 1013-21.

40. Laflamme, N. and S. Rivest, Toll-like receptor 4: the missing link of the cerebral innate immune response triggered by circulating Gram-negative bacterial cell wall components. Faseb J, 2001. 15(1): p. 155-163.

41. Lehnardt, S., et al., The toll-like receptor TLR4 is necessary for lipopolysaccharide-induced oligodendrocyte injury in the CNS. J Neurosci, 2002. 22(7): p. 2478-86.

42. Farina, C., et al., Preferential expression and function of Toll-like receptor 3 in human astrocytes. J Neuroimmunol, 2005. 159(1-2): p. 12-9.

43. Bowman, C.C., et al., Cultured astrocytes express toll-like receptors for bacterial products. Glia, 2003. 43(3): p. 281-91.

44. Anderson, C.M. and R.A. Swanson, Astrocyte glutamate transport: review of properties, regulation, and physiological functions. Glia, 2000. 32(1): p. 1-14.

45. Wang, Z., et al., Reduced expression of glutamate transporter EAAT2 and impaired glutamate transport in human primary astrocytes exposed to HIV-1 or gp120. Virology, 2003. 312(1): p. 60-73.

46. Speth, C., M.P. Dierich, and S. Sopper, HIV-infection of the central nervous system: the tightrope walk of innate immunity. Mol Immunol, 2005. 42(2): p. 213-28.

47. Fine, S.M., et al., Tumor necrosis factor alpha inhibits glutamate uptake by primary human astrocytes. Implications for pathogenesis of HIV-1 dementia. J Biol Chem, 1996. 271(26): p. 15303-6.

48. Swanson, R.A., et al., Neuronal regulation of glutamate transporter subtype expression in astrocytes. J Neurosci, 1997. 17(3): p. 932-40.

49. Kuo, C.C., et al., Chlamydia pneumoniae (TWAR). Clin Microbiol Rev, 1995. 8(4): p. 451-61.

50. Grayston, J.T., et al., A new respiratory tract pathogen: Chlamydia pneumoniae strain TWAR. J Infect Dis, 1990. 161(4): p. 618-25.

51. Little, C.S., et al., Chlamydia pneumoniae induces Alzheimer-like amyloid plaques in brains of BALB/c mice. Neurobiol Aging, 2004. 25(4): p. 419-29.

52. Airenne, S., et al., Chlamydia pneumoniae infection in human monocytes. Infect Immun, 1999. 67(3): p. 1445-9.

53. Perry, V.H., C. Cunningham, and C. Holmes, Systemic infections and inflammation affect chronic neurodegeneration. Nat Rev Immunol, 2007. 7(2): p. 161-7.

54. Maclntyre, A., et al., Chlamydia pneumoniae infection promotes the transmigration of monocytes through human brain endothelial cells. J Neurosci Res, 2003. 71(5): p. 740-50.

55. Maclntyre, A., et al., Chlamydia pneumoniae infection alters the junctional complex proteins of human brain microvascular endothelial cells. FEMS Microbiol Lett, 2002. 217(2): p. 167-72.

56. Kreutzberg, G.W., Microglia: a sensor for pathological events in the CNS. Trends Neurosci, 1996. 19(8): p. 312-8.

57. Saunders, N.R., G.W. Knott, and K.M. Dziegielewska, Barriers in the immature brain. Cell Mol Neurobiol, 2000. 20(1): p. 29-40.

58. Perry, V.H., The influence of systemic inflammation on inflammation in the brain: implications for chronic neurodegenerative disease. Brain Behav Immun, 2004. 18(5): p. 407-13.

59. Perry, V.H., T.A. Newman, and C. Cunningham, The impact of systemic infection on the progression of neurodegenerative disease. Nat Rev Neurosci, 2003. 4(2): p. 103-12. 

Samenvatting 

Door de vergrijzing in onze westerse maatschappij vormen neurodegeneratieve stoornissen bij ouderen, zoals de ziekte van Alzheimer, een toenemend gezondheidsprobleem dat gepaard gaat met een hoge morbiditeit en mortaliteit. Daarom is het belangrijk dat we onze kennis met betrekking tot risicofactoren en onderliggende mechanismen van deze ziekte uitbreiden. Hoewel verschillende risicofactoren reeds geïdentificeerd zijn, is er nog steeds geen duidelijke oorzaak voor deze aandoeningen bekend. Wel worden ontstekingen, waarvan reeds bekend is dat ze bijdragen aan het voortschrijden van neurodegeneratieve aandoeningen, meer en meer genoemd als mogelijke oorzaak. Verder is er geopperd dat diverse virussen, zoals het humaan immunodeficiëntie virus (HIV), het herpes simplex virus of het cytomegalovirus, deze ontstekingen kunnen veroorzaken of stimuleren en als zodanig kunnen bijdragen aan het neurodegeneratieve proces. Daarnaast zijn er recent ook onderzoeksresultaten gepubliceerd die suggereren dat de respiratoire, obligaat intracellulaire bacterie Chlamydia pneumoniae (Cpn), waarvan bekend is dat ze chronisch inflammatoire aandoeningen kan veroorzaken, ook een rol zou kunnen spelen bij de ontwikkeling van verschillende neurodegeneratieve stoornissen. Zo kon, in een studie uit Amerika in 1998, Cpn duidelijk aangetoond worden in de hersenen van Alzheimer patiënten terwijl deze bacterie vrijwel afwezig was in de hersenen van personen zonder Alzheimer. Deze bevindingen vormden de aanleiding voor de hypothese dat $\mathrm{Cpn}$ een rol speelt in het ontstaan van deze ziekte. Om deze hypothese nader te onderzoeken werden er verschillende in vitro en in vivo studies uitgevoerd ten einde een beter inzicht te krijgen of, en op welke wijze, Chlamydia pneumoniae kan bijdragen aan deze ernstige ziekte.

\section{In vitro studies}

In het eerste onderzoek werd met behulp van celkweek onderzocht of $\mathrm{Cpn}$ in staat is om neurodegeneratie te veroorzaken en of dit gemanifesteerd werd door directe infectie van neuronale cellen of door chronische cerebrale inflammatie, die veroorzaakt werd door de infectie.

Hoewel reeds bekend was dat $\mathrm{Cpn}$ verschillende celtypes kan infecteren, was het bij de start van de experimenten, die beschreven zijn in dit proefschrift, onduidelijk of hersencellen ook toegankelijk zijn voor deze bacterie. Daarom werd dit eerst in vitro onderzocht met behulp van verschillende hersencellijnen: microglia (MMC), neuronen (NB) en astrocyten (C8D1A). Een humane epitheelcellijn (Hep2) werd als referentie meegenomen (Hoofdstuk 2). Verder werd er bepaald of $\mathrm{Cpn}$ infectie rechtstreeks celdood kan veroorzaken, en zo ja, 
of dit gebeurt via apoptose of necrose. Immunohistochemische kleuringen van onze referentiecellijn (Hep2) toonden aan dat de ontwikkelingscyclus van $\mathrm{Cpn}$ volledig werd gevolgd. Op vroege tijdspunten na infectie werden kleine inclusielichaampjes gedetecteerd. Vervolgens was er vanaf 24 uur na infectie een duidelijke toename in grootte van deze inclusielichaampjes waarneembaar, met maximale afmetingen op 48 en 72 uur na infectie. Hoewel Cpn op deze tijdstippen niet meer in alle cellen gedetecteerd kon worden, bleek het merendeel toch geïnfecteerd te zijn. Inclusielichamen van verschillende afmetingen konden tenslotte worden aangetoond op zowel 1 als 2 weken na infectie. Identieke infectiepatronen werden aangetoond in onze neuronale cellijn, waarmee we konden aantonen dat deze cellen gemakkelijk door Cpn geïnfecteerd kunnen worden.Verder kon de productie van infectieuze partikels aangetoond worden en bleken de neuronen na Cpn infectie af te sterven door necrose. Een vergelijkbaar infectieverloop konden we aantonen in astroctyen, waarbij aangetekend dient te worden dat in deze cellen een lagere productie van infectieuze partikels werd gevonden.

Daarentegen waren de resultaten van de microgliacellen (de hersenequivalent van macrofagen in de rest van het lichaam) opvallend verschillend van de resultaten in de neuronen en de astrocyten. Er konden met behulp van immunohistochemische kleuringen vrijwel geen Cpn-positieve cellen worden aangetoond op late tijdstippen na infectie, wat suggereerde dat microgliacellen weinig permissief zijn voor Cpn. Bovendien konden er nauwelijks extracellulaire infectieuze Cpn partikels worden aangetoond en werd er geen Cpngerelateerde celdood gevonden. Niettemin werden significante hoeveelheden Cpn DNA gedetecteerd, waaruit geconcludeerd kan worden dat microgliacellen in staat zijn om de Cpn infectie onder controle te houden. Een interessant gegeven is dat monocyten, de equivalent van de microgliacellen in de rest van het lichaam, tot een soortgelijke controle van Cpn infectie in staat zijn. Verder heeft deze bevinding geleid tot de hypothese dat de microgliacellen een functionele en eventueel anatomische filter vormen (op basis van het feit dat microgliacellen onmiddellijk migreren naar de plaats van infectie) om meer gevoelige celtypes (neuronen) te beschermen tegen infecties.

Zoals reeds vermeld, suggereerden onze resultaten dat microgliacellen in staat zijn om een Cpn infectie onder controle te houden. Nu hebben eerdere studies in macrofagen reeds aangetoond dat interferon(INF)- $\gamma$ en stikstofmonoxide (NO) grotendeels verantwoordelijk zijn voor het controleren van een $\mathrm{Cpn}$ infectie. Op basis van deze gegevens werd besloten om te onderzoeken of vergelijkbare mechanismen verantwoordelijk zijn voor het controleren van de Cpn infectie door onze microgliacellijn (Hoofdstuk 4). Echter, noch het remmen van de NO productie, noch het neutraliseren van INF- $\gamma$ resulteerde in een hogere gevoeligheid van de microgliacellen voor Cpn. Dat INF- $\gamma$ inderdaad geen 
significante rol speelt bij het controleren van de infectie werd nog eens onderstreept door het feit dat dit cytokine op geen enkel tijdstip aangetoond kon worden in het medium van geïnfecteerde microgliacellen. Daarentegen werden interleukine(IL)- 6 en tumor necrose factor(TNF)- $\alpha$ wel in grote hoeveelheden geproduceerd door de microgliacellen na infectie. Echter, ook het neutraliseren van deze cytokines had geen effect op de gevoeligheid van microgliacellen voor Cpn. Deze resultaten suggereren dus dat geen van deze mediatoren (INF- $\gamma$, TNF- $\alpha$, IL-6 en NO) een rol speelt in het controleren van een Cpn infectie.

Naast de rechtstreekse gevolgen van $\mathrm{Cpn}$ op neurodegeneratie werd ook de hypothese onderzocht dat gliacellen tijdens een Cpn infectie grote hoeveelheden pro-inflammatoire cytokines produceren, wat uiteindelijk kan leiden tot neuroinflammatie en neurotoxiciteit. In vivo is dit mechanisme waarschijnlijk zelfs meer voor de hand liggend, aangezien neuronen in vivo morfologisch beschermd worden door gliacellen en neuronale celdood als gevolg van een directe infectie van neuronen door $\mathrm{Cpn}$ minder voor de hand ligt. Immers, als een micro-organisme de hersenen binnendringt, zal het eerst in contact komen met astrocyten, de belangrijkste component van de bloedhersen barrière. Dit celtype kan ook in grote getale teruggevonden worden rondom neuronen. Bovendien zullen microgliacellen, die beschouwd kunnen worden als de immuuncellen van het centrale zenuwstelsel, bij infectie onmiddellijk reageren en migreren naar de plek van gevaar, om zo neuronen te beschermen. Om dit indirect mechanisme van neuronale celdood als gevolg van de excessieve productie van pro-inflammatoire mediatoren door geïnfecteerde gliacellen te onderzoeken, werden verschillende cyto- en chemokines gemeten in het medium van Cpn-geïnfecteerde microgliacellen en astrocyten op verschillende tijdstippen na infectie (Hoofdstuk 3). Significant hogere hoeveelheden monocyt chemoattractant proteïne(MCP)-1, IL-6, TNF- $\alpha$ en IL-1 $\beta$ werden gemeten in het medium van geïnfecteerde MMC, in vergelijking met de controles. Bij astrocyten, daarentegen, konden alleen MCP1 en IL-6 gedetecteerd worden en dit voornamelijk 1 week na Cpn infectie. Verdere ondersteuning voor dit indirecte mechanisme kwam uit de observatie dat blootsteling van neuronen aan geconditioneerd medium van Cpn geïnfecteerde microgliacellen resulteerde in een significante hogere neuronale celdood in vergelijking met blootstelling aan medium van mock geïnfecteerde microgliacellen. Dit werd vooral veroorzaakt door IL- 6 en TNF- $\alpha$, zoals aangetoond in neutralisatie-experimenten. In ons onderzoek hebben wij aangetoond dat $\mathrm{Cpn}$ in staat is om met name microgliacellen aan te zetten tot de productie van deze potentieel neurotoxische stoffen. Deze bevinding vormt een verdere onderbouwing van de hypothese dat $\mathrm{Cpn}$ kan bijdragen aan het 
ontstaan dan wel het voortschrijden van de neurodegeneratieve processen zoals bij de ziekte van Alzheimer.

Vervolgens werd er onderzocht of deze ontstekingsfactoren ook de glutamaat opname door astrocyten kunnen beïnvloeden. Dit zou kunnen leiden tot neurotoxische concentraties van deze neurotransmitter, zoals het geval is bij onder andere de ziekte van Alzheimer. Inderdaad vonden we een significante stijging in neuronale celdood na behandeling van neuronen met glutamaat bevattend medium van astrocyten, welke eerder blootgesteld waren aan het supernatant van Cpn-geïnfecteerde microgliacellen (Hoofdstuk 4). Deze bevindingen suggereerden dat de opname van glutamaat door astrocyten verstoord is na incubatie met ontstekingsfactoren, geproduceerd door Cpngeïnfecteerde microgliacellen. Echter, nader onderzoek wees uit dat behandeling van astrocyten met ontstekingsmediatoren-bevattend medium geen verstoring van glutamaat opname tot gevolg had. Ook werden er geen veranderingen gevonden in de aanwezigheid van de belangrijkste glutamaat transporter in astrocyten, glutamaat transporter subtype(GLT)-1 (EAAT2). Op basis van deze resultaten moest geconcludeerd worden dat de gedetecteerde neuronale celdood waarschijnlijk niet veroorzaakt werd door neurotoxische hoeveelheden glutamaat. Dit doet vermoeden dat de blootstelling aan glutamaat er voor zorgt dat met ontstekingsfactoren voorbehandelde astrocyten een, voorlopig onbekende, factor gaan produceren die toxisch blijkt te zijn voor neuronen. Verdere experimenten zijn nodig om te onderzoeken welke stoffen geproduceerd worden door behandelde astrocyten na toevoeging van glutamaat.

\section{Een geïntegreerd model}

Op basis van deze data kan een hypothese geformuleerd worden over de mechanismen die Cpn gebruikt om het proces van neurodegeneratie te beïnvloeden.

Ten eerste, omdat men veronderstelt dat Cpn overgedragen wordt via de respiratoire route, zal de primaire plaats van infectie het luchtwegstelsel zijn. Via deze intranasale route zou echter een bepaalde hoeveelheid Cpn rechtstreeks de hersenen kunnen bereiken waardoor Cpn in staat zou zijn om direct in contact te komen met neuronen en deze te infecteren. We toonden aan dat dit celtype zeer gevoelig is voor Cpn en dat neuronen afsterven na infectie waarbij nieuw gevormde infectieuze Cpn lichaampjes vrijkomen. Deze 
elementaire lichaampjes kunnen vervolgens nabijgelegen cellen, zoals astrocyten, microgliacellen of andere neuronen infecteren. Infectie van astrocyten, de cellen die neuronen het meest omringen, resulteert in een gelijkaardig infectiepatroon, namelijk een hoge infectiegraad en de productie van elementaire $\mathrm{Cpn}$ lichaampjes die verder migreren naar aangrenzende cellen. Microgliacellen bleken eerder resistent voor $\mathrm{Cpn}$ infectie maar produceerden daarentegen verschillende inflammatoire stoffen, resulterend in neuronale celdood.

Naast deze intranasale route zou Cpn ook de hersenen kunnen binnendringen via andere wegen. Het is algemeen aanvaard dat $\mathrm{Cpn}$ voornamelijk via geïnfecteerde monocyten doorheen het lichaam migreert. Tegenwoordig zijn er verschillende routes beschreven over hoe een systemische infectie of inflammatie kan "communiceren" met het centrale zenuwstelsel. Het eerste belangrijke circuit impliceert de circumventriculaire organen, gekenmerkt door de afwezigheid van een bloed-hersen barrière. Op deze plaatsen, waar een direct contact mogelijk is tussen het micro-organisme en neuronen, zou neurodegeneratie kunnen optreden. Echter, de belangrijkste route van een micro-organisme om de hersenen te bereiken is via de bloed-hersen barrière.

Ook Cpn kan via deze barrière, waarvan de permeabiliteit stijgt na Cpn infectie, de hersenen binnendringen. Het micro-organisme zal op deze manier eerst microgliacellen en astrocyten bereiken. In onze studie werd aangetoond dat astrocyten zeer gevoelig zijn voor Cpn en in staat zijn om infectieuze Cpn deeltjes te produceren, waardoor nabij gelegen cellen geïnfecteerd kunnen worden. Daarnaast zal de productie van inflammatoire stoffen door Cpn geïnfecteerde microgliacellen een neurotoxisch milieu creëren waardoor er verder wordt bijgedragen aan het proces van neurodegeneratie. Additioneel zouden pathogenen via andere mechanismen, zoals het beïnvloeden van het glutamaat metabolisme, een effect kunnen hebben op neurodegeneratieve ziekten. Concluderend kan gesteld worden dat pathogenen, zoals Cpn, via verschillende mechanismen neurodegeneratieve processen kunnen beïnvloeden en dat dit kan plaatsvinden zonder direct contact tussen het microorganisme en de neuronen.

\section{In vivo experimenten}

Naast de in vitro modellen, werden de gevolgen van een Cpn infectie op de hersenen ook in een muismodel onderzocht. Het belangrijkste doel van ons onderzoek was om te bepalen of een Cpn infectie de extracellulaire aggregatie van amyloïd beta $(A \beta)$, een van de belangrijkste kenmerken van de ziekte van Alzheimer, kan initiëren in normale muizen. Voor dit onderzoek werden 
vrouwelijke muizen intranasaal geïnfecteerd met Cpn. Vervolgens werden de hersenen op verschillende tijdstippen na infectie enerzijds gecontroleerd op de aanwezigheid van $\mathrm{Cpn}$ en anderzijds op amyloid plaques. Alhoewel $\mathrm{Cpn}$ alleen op 1 week na infectie in de hersenen gedetecteerd kon worden, werden extracellulaire amyloïd afzettingen aangetoond op zowel 1 en 3 maanden na infectie. Een vergelijkbaar resultaat werd echter ook gevonden in de mock geïnfecteerde muizen. Dit alles doet vermoeden dat de gevonden amyloïd afzettingen niet gerelateerd kunnen worden aan Cpn infectie. Ook werden er opvallende verschillen gevonden in de morfologie van de extracellulaire $A \beta$ afzettingen in vergelijking met de afzettingen die gevonden worden in een transgeen muismodel voor de ziekte van Alzheimer. Zo werden er bijvoorbeeld geen stervormige aggregaten van $A \beta$ met een thioflavine-S-positieve en dichte kern gedetecteerd, weefselbeschadiging in de $A \beta$ positieve gebieden was afwezig en astrocyten werden niet in grote getale in de nabije buurt van $A \beta$ gevonden. Hoewel niet kan worden uitgesloten dat de morfologische kenmerken die wij observeerden duiden op de initiële stadia van de ziekte, suggereren deze resultaten in elk geval dat één enkele Cpn infectie niet zal leiden tot de vorming van gevorderde $A \beta$ plaques.

\section{Conclusie}

Uit onze in vivo modellen kunnen we niet concluderen dat een Cpn infectie de ziekte van Alzheimer veroorzaakt. Echter, op basis van onze in vitro data en recente aanwijzingen in de literatuur, kan gesuggereerd worden dat infecties, en $\mathrm{Cpn}$ in het bijzonder, kunnen bijdragen aan de progressie van de ziekte van Alzheimer. Dit zou bereikt kunnen worden via een directe weg waardoor neurodegeneratie optreedt ten gevolge van $\mathrm{Cpn}$ infectie of eerder indirect via een chronische cerebrale ontsteking met als gevolg de productie van inflammatoire stoffen, resulterend in neurodegeneratie. Hoewel er een toenemende aandacht is voor de rol van infecties in het ontstaan en de voortgang van neurodegeneratieve ziekten, is nog veel onderzoek noodzakelijk en dit zowel op basaal/experimenteel als op klinisch niveau, om de rol van infecties op deze aandoeningen verder te ontrafelen. 




\section{Dankwoord}



Dit alles was nooit gelukt zonder de hulp en steun van velen, daarom wil ik dit laatste stukje van mijn proefschrift aan hen wijden.

Allereerst zou ik mijn promotie-team: Cathrien Bruggeman, Harry Steinbusch, Frank Stassen en André van der Ven willen bedanken voor hun onmisbare bijdrage aan dit proefschrift. Cathrien, allereerst wil ik je bedanken voor de kans die je me gaf om te promoveren op jouw afdeling. Al vanaf het begin heb ik een grote bewondering en respect voor jou. Bedankt dat je ondanks je drukke agenda altijd tijd voor me maakte en zo nauw betrokken was met mijn onderzoek. Jouw positieve ingesteldheid en vertrouwen in mij hebben me vaak een enorme stimulans gegeven. Bedankt voor al je goede begeleiding! Harry Steinbusch wil ik graag bedanken voor de mogelijkheid om onderzoek uit te voeren op de afdeling Cellulaire Neurowetenschappen en voor de vrijheid die ik al die jaren kreeg om nieuwe ideeën uit te voeren. Frank, als co-promotor heb jij de belangrijkste rol gespeeld in mijn "wetenschappelijke ontwikkeling". Ik heb veel geleerd van onze brainstormsessies die vaak uren duurden en nog meer uren aan werk opleverden maar waaruit het grootste deel van dit boekje is ontstaan. Daarnaast leerde je me geduld te hebben en te relativeren, ook al lukt dat nog niet altijd even goed maar we komen er wel... Bedankt! André, jij stond mede aan de wieg van dit onderzoek. Ondanks de afstand, ben je mijn onderzoek met grote interesse en betrokkenheid blijven volgen en had je er het volste vertrouwen in. Bedankt hiervoor!

Natuurlijk mag een woord van dank aan mijn paranimfen Gert en Hilde niet ontbreken. Gertje, toen ik hier pas als beginnend AIO'ke terecht kwam werd ik meteen (en gelukkig maar) door jou opgevangen. Je leerde me de kneepkes van het vak en het bleek dat al snel dat we goed met elkaar konden opschieten, ondanks het "kleine" leeftijdsverschil. Kan me nog levendig herinneren dat we samen aan de microscoop zaten te "stichelen" over mijn resultaten om enkele minuten later in lachen uit te barsten. Ik heb er echt van genoten om al die jaren, al werden deze onderbroken door spectaculaire fietsongevallen, met jou samen te werken en hopelijk kan dit ook nog in de toekomst. Bedankt dat je altijd voor me klaarstond met raad en daad. Ik waardeer jouw steun op werkgebied maar ook daarbuiten enorm. Fijn dat je ook nu weer aan mijn zijde wilt staan. Hildeke, toen je bij ons op de afdeling kwam werd het al heel snel duidelijk dat het klikte tussen ons. We moesten vaak gewoon maar naar elkaar kijken en dan wisten we meteen wat de ander bedoelde. Heb enorm genoten van die (te korte) tijd samen in Maastricht en mis dat nog steeds maar gelukkig komen we elkaar nog wel eens "toevallig" tegen op congres, feestjes,... Door drukke, nog drukkere en ongeloofelijk drukke agenda's hebben we elkaar de 
laatste tijd weinig gezien maar desondanks blijft onze vriendschap behouden. Bedankt voor al je steun en ben echt blij dat je straks naast me wilt gaan staan.

Alle collega's bij Cellulaire Neurowetenschappen wil ik bedanken voor de aangename samenwerking. Marjanne en Hellen, bedankt dat jullie deur altijd voor me openstond en ik er altijd terecht kon voor raad en steun. Hellen, vond het altijd heel gezellig en leerrijk om samen met jou perfusies en kleuringen uit te voeren. Verder zou ik graag Nicole en de dames van het secretariaat (Akke en Mirèse) bedanken voor al hun hulp. Ook bedankt aan Christoph Schmitz en Govert Hoogland voor hun wetenschappelijke inbreng.

Medische Microbiologie. Ik heb me hier vanaf het eerste moment thuis gevoeld en doorheen de jaren zijn er mooie vriendschappen ontstaan, bedankt hiervoor! Allereerst zou ik graag de mensen van Gerts, alias het "voorste" lab; Dionne, Geoffrey, Inge, Laura, Manuela, Rajaa, Rick, Tanja, Tryfon en Xavier bedanken voor de fijne samenwerking en de leuke sfeer. Gelukkig waren er in de superdrukke tijden mensen op wiens hulp ik kon rekenen. Dionne, Gert, Sylvie en al mijn studenten van de afgelopen jaren, bedankt voor jullie bijdrage.

Erik, Hanne, Lieve, Petra en Selma, bedankt voor jullie hulp en raad bij het moleculaire werk, maar meer nog voor jullie steun, de gezellige babbels en alle leuke momenten buiten het werk om.

Bacteriologie research. Ook al zorgden jullie vaak voor heel wat geurhinder ;-), vond het altijd heel gezellig met jullie in de buurt.

Wie ook niet mogen ontbreken zijn de mensen van de spoelkeuken (Ans, John), Wil, Peter en de lieve dames van het secretariaat (Angèle, Fia, José). Bedankt voor jullie hulp. Eveneens bedankt aan de mensen van het CPV.

Dan wil ik natuurlijk ook het "achterste" lab/kamer bedanken met Erik, Hilde Kees, Koen, Martijn, Patrick, Suzanne en Yvonne met wie het altijd heel gezellig was, ook buiten werktijden. Erik, heb nog altijd bewondering voor je omdat je er altijd in slaagde om onder "alle omstandigheden" kalm te blijven. Zeker met onder andere Koen en Suzanne, de monster(tje)s in de buurt, die (samen met de duivel) een tijd lang de afdeling terroriseerden. Ondanks al dat gepest denk ik dat er diep vanbinnen toch een lief persoon in jullie schuilt;-). Ik durf zelfs stiekem zeggen dat ik jullie kabaal en plagerijen toch wel mis maar "gelukkig" trakteren jullie mij daar nog geregeld op.

Tenslotte mijn kamergenootjes. Doorheen de jaren was er een wisselende bezetting maar het was er altijd even knus. Velen van jullie betekenen ondertussen meer dan gewone collega's voor mij en wil enkele dan ook even speciaal bedanken! Allereerst mijn Belgische maatjes, Inge en Sita, jullie zijn ondertussen vriendinnen geworden, ook buiten het werk om. Geniet altijd van onze gezellige etentjes en meer nog van onze gesprekken. Apprecieer de raad 
en steun (en de duwtjes in de rug) die jullie me hebben gegeven enorm! Merciekes!! Sita wil ik speciaal nog eens bedanken voor alle hulp bij de afronding van mijn proefschrift en alle morele steun. Ruud, in het begin toen ik op de afdeling kwam leek je mij zo een nors en eigenaardig manneke maar ondertussen weet ik wel dat je geen mens (daarentegen wel gsm's) kwaad doet. Ik heb veel steun gehad aan onze gesprekken tijdens moeilijke periodes. Bedankt!! Guy, voor iemand die zo graag en zoveel praat was het vast niet gemakkelijk om wat stiller te zijn tijdens het afgelopen jaar. Bedankt voor al die moeite en je luisterende oor!

Het "Limburg-groepje" van Leuven. Ik ben blij dat we nog regelmatig afspreken en iedereen zal wel content zijn dat de gesprekken binnenkort niet meer over doctoreren en de daarmee gepaarde stress zullen gaan. Merciekes dat ik nog altijd kan rekenen op jullie steun, begrip en vriendschap!!

Mijn vrienden in Hoeselt en omstreken. Bedankt voor de interesse naar wat ik allemaal in Maastricht uitspookte en het luisterend oor als ik het weer even niet meer zag zitten. Dankzij jullie kon ik mijn gedachten op andere dingen zetten en soms helemaal ontspannen. Doorheen de jaren beleefden we samen vele mooie momenten maar echter ook wel sombere en het betekent veel voor me dat er mensen zijn op wie ik altijd kan rekenen. Denk dat voor sommigen "one fine day" zeer bekend in de oren klinkt. Zou het dan dit "eindelijk" allemaal zijn?

De families Boelen, Mewissen en Koens familie wil ik graag bedanken voor hun oprechte interesse, medeleven en bezorgdheid. Bedankt dat ik altijd bij jullie terecht kan. Stefanie, er waren tijden dat we elkaar wel konden "villen", gelukkig is deze fase voorbij en ben je de afgelopen maanden een enorme steun voor me geweest, bedankt!!

Lieve Koen, het minste wat we kunnen zeggen is dat het afgelopen jaar "bewogen" was. Het was niet altijd even gemakkelijk maar je hielp me er telkens weer bovenop. Je betekent zoveel voor me en wil je bij deze dan ook enorm bedanken voor alle vertrouwen, geduld en zoveel liefde. Ben blij dat we elkaar gevonden hebben en kijk uit naar onze toekomst...

Tenslotte zou ik graag mijn ouders bedanken voor alle kansen die ze mij gegeven hebben. Lieve mama en papa, ik kan onmogelijk beschrijven hoezeer ik jullie onvoorwaardelijke liefde, steun en vertrouwen doorheen al die jaren waardeer. Jullie hebben altijd in me geloofd en stonden altijd voor me klaar...dit proefschrift is dan ook voor jullie. Bedankt voor alles!! 



\section{Curriculum vitae \& List of Publications}




\section{Curriculum vitae}

Ellen Boelen werd geboren te Genk op 26 juli 1980. In 1998 behaalde zij het diploma secundair onderwijs (Latijn-Wiskunde 6u) aan het Humaniora Onbevlekte Ontvangenis te Tongeren. In datzelfde jaar startte zij aan het Limburgs Universitair Centrum te Diepenbeek (nu Universiteit Hasselt) haar kandidatuurjaren Biologie. In 2000 zette zij haar studie verder aan de Katholieke Universiteit Leuven waar ze in 2002 de academische graad van licentiaat in de Biologie met onderscheiding behaalde. Het onderzoek voor haar afstudeerscriptie, "Lokalisatie van enkele neuropeptiden in de hersenen van Neobellieria bullata en in het zenuwstelsel van Drosophila melanogaster", werd uitgevoerd onder leiding van Prof. dr. Liliane Schoofs van de vakgroep Ontwikkelingsfysiologie en Moleculaire Biologie. In december 2002 trad ze in dienst als assistent in opleiding bij de capaciteitsgroepen Medische Microbiologie en Cellulaire Neurowetenschappen, onderdeel van the European Graduate School of Neuroscience (EURON), van het Academisch Ziekenhuis en de Universiteit te Maastricht. Tijdens deze periode was ze gedurende één jaar aangesteld als Marie-Curie fellow. De resultaten van haar promotieonderzoek zijn te lezen in dit proefschrift. Sedert 18 januari 2007 is zij werkzaam als onderzoeker binnen de capaciteitsgroep Medische Microbiologie waar zij vervolgonderzoek verricht naar de rol van infecties en inflammatie in neurodegeneratieve stoornissen. 


\section{List of Publications}

\section{Full articles}

Ellen Boelen, Harry WM Steinbusch, André JAM. van der Ven, Gert Grauls, Cathrien A Bruggeman, Frank RM Stassen. Chlamydia pneumoniae infection of brain cells: an in vitro study. Neurobiology of aging (2007) 28(4):524-532.

Ellen Boelen, Harry WM Steinbusch, Inge Pronk, Gert Grauls, Paul Rennert, Veronique Bailly, Cathrien A Bruggeman, Frank RM Stassen. Inflammatory responses following Chlamydia pneumoniae infection of glial cells. European Journal of Neuroscience (2007) 25 (3): 753-760.

Ellen Boelen, Harry WM Steinbusch, André JAM van der Ven, Gert Grauls, Cathrien A Bruggeman, Frank RM Stassen. Possible pathways involved in the control of intracellular Chlamydia pneumoniae infection by microglial cells. Submitted for publication.

Ellen Boelen, Harry WM Steinbusch, Gert Grauls G, André JAM van der Ven, Cathrien A Bruggeman, Frank RM Stassen. Impact of Chlamydia pneumoniae infection on astrocytic glutamate uptake - consequences for neurodegeneration. Submitted for publication.

Ellen Boelen, Frank RM Stassen, Marijke AM Lemmens, Hellen PJ Steinbusch, Cathrien A Bruggeman, Christoph Schmitz, Harry WM Steinbusch. Detection of amyloid beta aggregates in the brain of BALB/c mice after Chlamydia pneumoniae infection. Accepted for publication in Acta Neuropathologica.

\section{Abstracts}

Boelen E, Stassen FRM, van der Ven AJAM, Mulder M, Steinbusch HWM, Bruggeman CA - "Infections as a cofactor for vascular dementia". 2nd Dutch Endo-Neuro-Psycho Meeting, Doorwerth, The Netherlands, June 2003.

Boelen E, Stassen FRM, van der Ven AJAM, Grauls G, Markerink-v.Ittersum M, Bruggeman CA, Steinbusch HWM - "The brain and its susceptibility for Chlamydia pneumoniae infection". 3th Dutch Endo-Neuro-Psycho Meeting, Doorwerth, The Netherlands, June 2004. 
Boelen E, Stassen FRM, van der Ven AJAM, Grauls G, Bruggeman CA, Steinbusch HWM - "The susceptibility of various brain cells for Chlamydia pneumoniae infection: an in vitro study". 4th Dutch Endo-Neuro-Psycho Meeting, Doorwerth, The Netherlands, June 2005.

Boelen E, Stassen FRM, van der Ven AJAM, Grauls G, Bruggeman CA, Steinbusch HWM - "The susceptibility of various brain cells for Chlamydia pneumoniae infection: an in vitro study". 9th EURON Ph.D. student Meeting, Université de Liège, Belgium, Sept 2005

Boelen E, Steinbusch HWM, Grauls G, Bruggeman CA, Stassen FRM "Inflammatory responses following Chlamydia pneumoniae infection of glial cells". 10th EURON Ph.D. student Meeting, Maastricht University, The Netherlands, Sept 2006.

Boelen E, Steinbusch HWM, Grauls G, Bruggeman CA, Stassen FRM "Inflammatory responses following Chlamydia pneumoniae infection of glial cells". Neuroscience 2006, Atlanta, USA, Oct 2006. 